RUNNING OUT OF AND INTO OIL: ANALYZING GLOBAL OIL DEPLETION AND TRANSITION THROUGH 2050

\title{
October 2003
}

David L. Greene

Corporate Fellow

Janet L. Hopson

Research Assistant

Jia Li

Senior Research Technician 


\title{
DOCUMENT AVAILABILITY
}

Reports produced after January 1, 1996, are generally available free via the U.S. Department of Energy (DOE) Information Bridge:

Web site: http://www.osti.gov/bridge

Reports produced before January 1, 1996, may be purchased by members of the public from the following source:

\author{
National Technical Information Service \\ 5285 Port Royal Road \\ Springfield, VA 22161 \\ Telephone: 703-605-6000 (1-800-553-6847) \\ TDD: 703-487-4639 \\ Fax: 703-605-6900 \\ E-mail: info@ ntis.fedworld.gov \\ Web site: http://www.ntis.gov/support/ordernowabout.htm
}

Reports are available to DOE employees, DOE contractors, Energy Technology Data Exchange (ETDE) representatives, and International Nuclear Information System (INIS) representatives from the following source:

Office of Scientific and Technical Information

P.O. Box 62

Oak Ridge, TN 37831

Telephone: 865-576-8401

Fax: 865-576-5728

E-mail: reports@adonis.osti.gov

Web site: http://www.osti.gov/contact.html

\begin{abstract}
This report was prepared as an account of work sponsored by an agency of the United States Government. Neither the United States government nor any agency thereof, nor any of their employees, makes any warranty, express or implied, or assumes any legal liability or responsibility for the accuracy, completeness, or usefulness of any information, apparatus, product, or process disclosed, or represents that its use would not infringe privately owned rights. Reference herein to any specific commercial product, process, or service by trade name, trademark, manufacturer, or otherwise, does not necessarily constitute or imply its endorsement, recommendation, or favoring by the United States Government or any agency thereof. The views and opinions of authors expressed herein do not necessarily state or reflect those of the United States Government or any agency thereof.
\end{abstract}





\title{
RUNNING OUT OF AND INTO OIL: ANALYZING GLOBAL OIL DEPLETION AND TRANSITION THROUGH 2050
}

\author{
David L. Greene \\ Oak Ridge National Laboratory \\ Janet L. Hopson \\ Jia Li \\ The University of Tennessee, Knoxville \\ National Transportation Research Center \\ 2360 Cherahala Boulevard \\ Knoxville, Tennessee 37932
}

October 2003

\author{
Prepared by the \\ OAK RIDGE NATIONAL LABORATORY \\ P.O. BOX 2008 \\ Oak Ridge, Tennessee 37830 \\ managed by \\ UT-Battelle, LLC \\ for the \\ U.S. DEPARTMENT OF ENERGY \\ under Contract No. DE-AC05-00OR22725
}





\section{TABLE OF CONTENTS}

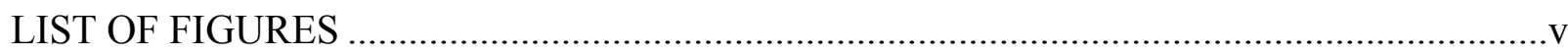

LIST OF TABLES ............................................................................................... vii

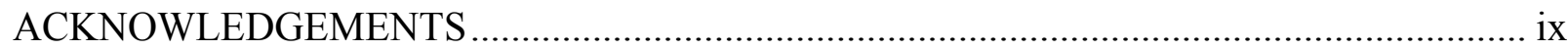

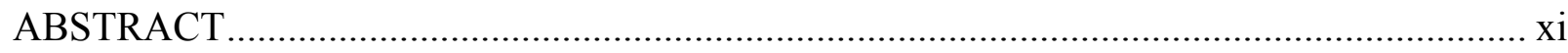

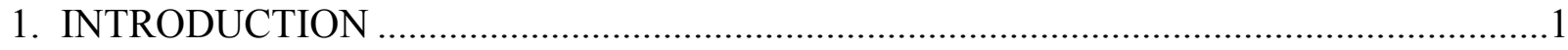

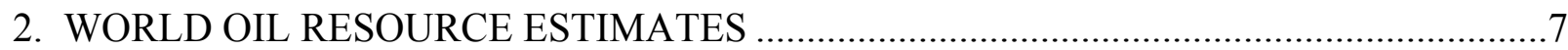

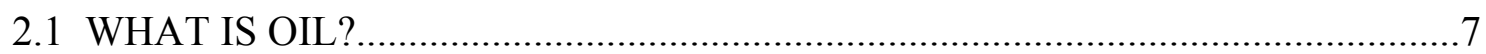

2.2 ARE OIL RESOURCES INCREASING? ......................................................

2.3 HOW MUCH UNCONVENTIONAL OIL IS THERE? .................................. 10

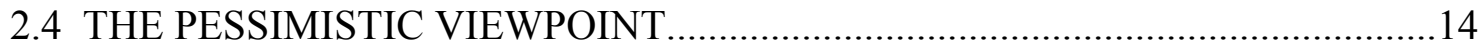

2.5 RESOURCE ESTIMATES USED IN THIS STUDY .................................... 15

3. MODELING OIL DEPLETION ........................................................................... 17

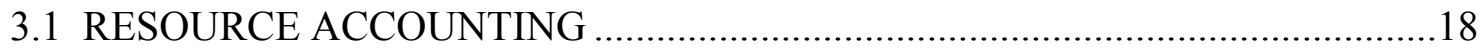

3.2 WORLD OIL MARKET MODEL: LONG-RUN DYNAMICS .........................20

4. SCENARIOS OF WORLD ENERGY SUPPLY AND DEMAND …...............................23

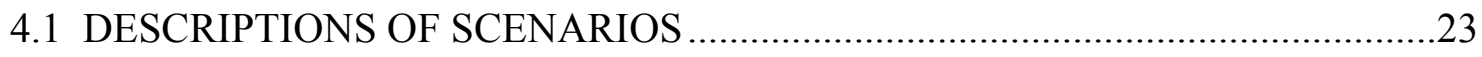

4.2 RISK ANALYSES AND KEY PARAMETERS ............................................29

5. RESULTS

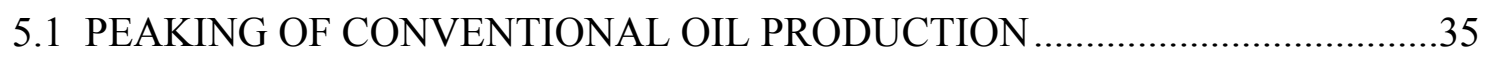

5.2 SENSITIVITIES OF PEAKING DATES TO KEY PARAMETERS ....................38

5.3 TRANSITIONS TO UNCONVENTIONAL OIL .........................................43

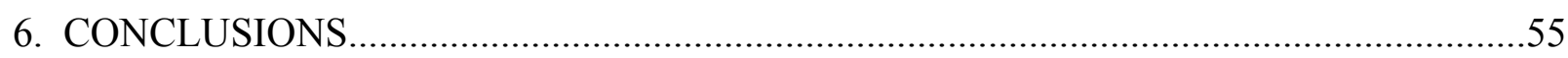

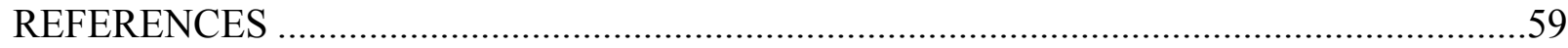

APPENDIX A. DESCRIPTION OF WESM MODEL.................................................... A-1

APPENDIX B. OIL RESOURCE ESTIMATES BASED ON CAMPBELL ..........................1

APPENDIX C. ALLOCATION OF USGS BASED UNCONVENTIONAL

RESOURCE ESTIMATES TO CATEGORIES V AND VI......................................... 



\section{LIST OF FIGURES}

Figure 1. Half a Century of World Oil Resources Estimates ............................................

Figure 2. 12 EIA World Conventional Oil Production Scenarios.........................................3

Figure 3. Incomplete Estimates of Regional Resources of Unconventional Oil.....................13

Figure 4. Flow Diagram of World Energy Scenarios Model ..............................................17

Figure 5. Structure of Resource Accounting Model......................................................... 18

Figure 6. Unconventional Oil Price-Depletion Curves ...............................................22

Figure 7. Champagne Model Reference Scenario, North American Transportation

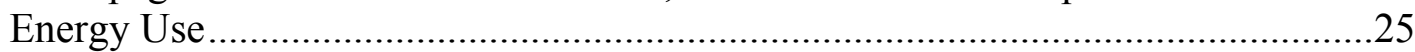

Figure 8. Champagne Model Go Your Own Way Scenario, North American Transportation Energy Use ............................................................................25

Figure 9a World Energy Production by Type, IIASA/WEC Scenario A1, IEO 2002 Reference Case ..............................................................................26

Figure 9b World Primary Energy Use by Region, IIASA/WEC A1 Scenario, IEO 2002 Reference Case .............................................................................26

Figure 9c Oil Consumption by Region, IIASA/WEC A1 Scenario, IEO 2002 Reference Case.

Figure 10a World Energy Production by Type, IIASA/WEC C1 Scenario, IEO 2020 Low Growth

Figure 10b World Primary Energy Use by Region, IIASA/WEC C1 Scenario, IEO 2002 Low Growth

Figure 10c Oil Consumption by Region, IIAASA/WEC C1 Scenario, IEO Low Growth, Champagne GYOW Scenario

Figure 11a Peak Year of ROW Conventional Oil Production: Reference/USGS .....................36

Figure 11b Peak Year of ROW Conventional Oil: Reference/Rogner ...................................36

Figure 11c Peak Year of ROW Conventional Oil: Reference/Campbell...................................36

Figure 12a Peak Year for World Conventional Oil: Reference/USGS ...................................37

Figure 12b Peak Year for World Conventional Oil: Reference/Rogner...................................37

Figure 12c Peak Year for World Conventional Oil: Reference/Campbell ................................37

Figure 13a Sensitivity Analysis for ROW Peak Year: Reference/USGS .................................38

Figure 13b Sensitivity Analysis for ROW Peak Year: Reference/Rogner ...............................39

Figure 14a Sensitivity Analysis for World Peak Year: Reference/USGS ..............................39

Figure 14b Sensitivity Analysis for World Peak Year: Reference/Rogner ..............................40

Figure 14c Sensitivity Analysis for World Peak Year: Reference/Campbell..........................40

Figure 15. Distribution of ROW Peak Year: Low-Growth/USGS ......................................42

Figure 16. Sensitivity Analysis for ROW Peak Year: Low-Growth/USGS ............................42

Figure 17. Distribution for ROW Peak Year: High-Growth/USGS ....................................43

Figure 18. Sensitivity Analysis for ROW Peak Year: High-Growth/USGS ..........................43

Figure 19. World Oil Production from Conventional and Unconventional Resources:

Reference/USGS

Figure 20. World Oil Production from Conventional and Unconventional Resources: Reference/USGS

Figure 21. World's Ultimate Oil Resource Depletion: Reference/USGS .............................46

Figure 22. U.S. Petroleum Production and Imports: Reference/USGS...............................46

Figure 23. World Oil Production from Conventional and Unconventional Resources: Reference/Rogner 
Figure 24. U.S. Petroleum Production and Imports: Reference/Rogner.

Figure 25. World Oil Production from Conventional and Unconventional Resources: Reference/Campbell

Figure 26. World Oil Production from Conventional and Unconventional Resources: Low Growth/USGS.

Figure 27. World Oil Production from Conventional and Unconventional Resources: High Growth/USGS ..

Figure 28. U.S. Petroleum Production and Imports: High-Growth/USGS .50

Figure 29. Middle East Share of World Conventional and Unconventional Oil Reserves, Resources and Production: Reference/USGS

Figure 30. Middle East Share of World Conventional and Unconventional Oil Reserves, Resources and Production: Reference/USGS (3\%/yr.).........................................52

Figure 31. World Oil Production from Heavy Oil and Oil Sands: Reference/USGS ...............53

Figure 32. World Oil Production from Oil Shale: Reference/USGS .................................53 


\section{LIST OF TABLES}

Table 1. Estimated World Oil Resources Occurrences in Gigatonnes of Oil Equivalent.........9

Table 2. Estimates of World Petroleum Resources for the Year 1996 from the USGS

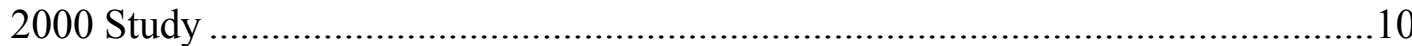

Table 3. Estimates of World Oil Sands and Oil Shale Resources from Three Sources...........12

Table 4. Estimates of World Conventional and Unconventional Oil Resources by

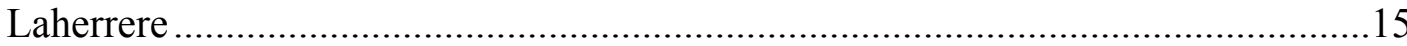

Table 5. Estimates of World Conventional and Unconventional Oil Resources by

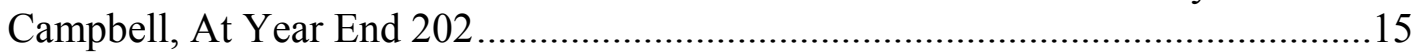

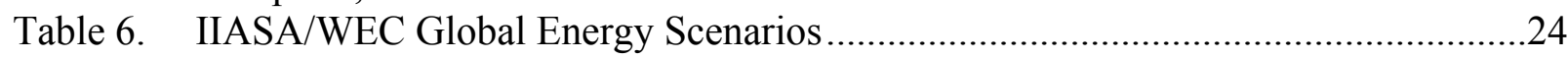

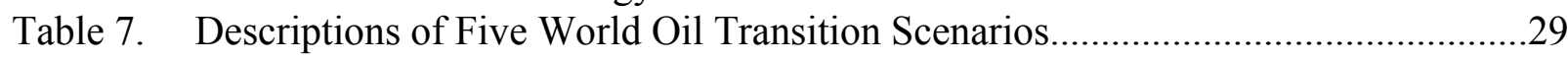

Table 8. Distribution Parameters for Depletion/Transition Risk Analysis ..............................31 



\section{ACKNOWLEDGEMENTS}

The authors are pleased to thank Thomas Ahlbrandt, Roger Bentley, Jean-Marie Bourdaire, Albert Cavallo, Jean Laherrere and three anonymous referees for their comments, criticisms and suggestions based on an earlier draft of this report. Their willingness to critique the report should in no way be interpreted as an endorsement of it and, of course, errors that remain are the sole responsibility of the authors. The authors also thank the U.S. Department of Energy and Natural Resources Canada for their support of this project. We note that the views expressed in this report are those of the authors alone and do not necessarily reflect the views of our sponsors. This report is dedicated to Michael David Greene. 



\section{ABSTRACT}

This report presents a risk analysis of world conventional oil resource production, depletion, expansion, and a possible transition to unconventional oil resources such as oil sands, heavy oil and shale oil over the period 2000 to 2050. Risk analysis uses Monte Carlo simulation methods to produce a probability distribution of outcomes rather than a single value. Probability distributions are produced for the year in which conventional oil production peaks for the world as a whole and the year of peak production from regions outside the Middle East. Recent estimates of world oil resources by the United States Geological Survey (USGS), the International Institute of Applied Systems Analysis (IIASA), the World Energy Council (WEC) and Dr. C. Campbell provide alternative views of the extent of ultimate world oil resources. A model of oil resource depletion and expansion for twelve world regions is combined with a market equilibrium model of conventional and unconventional oil supply and demand to create a World Energy Scenarios Model (WESM). The model does not make use of Hubbert curves but instead relies on target reserve-to-production ratios to determine when regional output will begin to decline. The authors believe that their analysis has a bias toward optimism about oil resource availability because it does not attempt to incorporate political or environmental constraints on production, nor does it explicitly include geologic constraints on production rates. Global energy scenarios created by IIASA and WEC provide the context for the risk analysis. Key variables such as the quantity of undiscovered oil and rates of technological progress are treated as probability distributions, rather than constants. Analyses based on the USGS and IIASA resource assessments indicate that conventional oil production outside the Middle East is likely to peak sometime between 2010 and 2030. The most important determinants of the date are the quantity of undiscovered oil, the rate at which unconventional oil production can be expanded, and the rate of growth of reserves and enhanced recovery. Analysis based on data produced by Campbell indicates that the peak of non-Middle East production will occur before 2010. For total world conventional oil production, the results indicate a peak somewhere between 2020 and 2050. Key determinants of the peak in world oil production are the rate at which the Middle East region expands its output and the minimum reserves-to-production ratios producers will tolerate. Once world conventional oil production peaks, first oil sands and heavy oil from Canada, Venezuela and Russia, and later some other source such as shale oil from the United States must expand if total world oil consumption is to continue to increase. Alternative sources of liquid hydrocarbon fuels, such as coal or natural gas are also possible resources but not considered in this analysis nor is the possibility of transition to a hydrogen economy. These limitations were adopted to simplify the transition analysis. Inspection of the paths of conventional oil production indicates that even if world oil production does not peak before 2020, output of conventional oil is likely to increase at a substantially slower rate after that date. The implication is that there will have to be increased production of unconventional oil after that date if world petroleum consumption is to grow. 



\section{INTRODUCTION}

Past warnings that the world will soon "run out of oil" have been compared with the fable of the shepherd boy who cried, "Wolf!" (Martin, 1999). To date, the warnings have proven to be unfounded. In the fable, the wolf finally did appear, but the townspeople, assuming yet another false alarm, failed to respond to the real danger. The sheep were devoured. The world's oil resources are unquestionably finite and world oil consumption continues to grow, yet there is little concern that the world will actually run out of oil. The modern debate has shifted from concern over "running out" to the "peaking" of oil production, the date beyond which oil production can no longer be increased (e.g., Bentley, 2002; Campbell and Laherrere, 1998).

Advances in technology have expanded and redefined resources in the past, raising the prospect that we may "run into" oil faster than we use it up. There is also the possibility that structural and technological changes on the demand side could cause the demand for oil to "run out" before the supply (Odell, 1999). The purpose of this analysis is to combine the best available knowledge about the extent of oil resources with scenarios of world energy use in a framework that allows quantification of uncertainties about the extent of undiscovered resources, rates of technological change and output expansion by key oil producers.

The ability to foresee the peaking of oil production would have great value, since it would allow the world's economies to prepare for what otherwise would be a disruptive and costly transition. Many past analyses of oil underestimated the size of the world's oil resources, the degree to which technology could expand the resource base and the impacts that markets would have on both demand and supply. On the other hand, Hubbert's (1962) famous prediction of the peak of U.S. oil output was strikingly accurate. The problem is difficult because while oil reserves are unquestionably finite, it is also true that oil resources are not a fixed quantity, but a variable that depends on the states of earth science, technology and economics (Adelman and Lynch, 1997). The possibility that technological change could greatly expand the base of exploitable hydrocarbon occurrences must be acknowledged (e.g., Odell, 1999), as must the possibility that systems of energy use will evolve that prefer other energy sources to oil.

Yet, to assume that whatever advances are needed will occur, and at the rates needed to assure continued plentiful supplies of low-cost oil is a matter of faith not science (Davies and Weston, 2000). Adelman and Lynch (1997) put it this way: "Some powerful force is at work to offset depletion...." (emphasis added). Market systems, human innovation and technological change comprise a powerful force indeed. Undoubtedly, markets will find solutions to problems of supply and demand, but will the solutions avoid costly economic dislocations and insure continued improvement in global economic welfare? Certainly, technology will advance, but will it advance fast enough to extend petroleum resources and facilitate a smooth transition to other energy sources?

The question of whether the availability of oil resources will someday soon prevent us from producing the quantities of oil necessary to power an increasingly mobile world economy seems to be neither a foregone conclusion nor an irrelevancy. If such a day is coming, it would undoubtedly be preferable to foresee it rather than to be taken by surprise. But is it possible to predict a peaking of world oil production? It would depend not only on how much oil there is in the world but future oil demand, rates of progress in technology, and the reactions of markets to 
future supply and demand. If precise accuracy is required, the answer is probably no, the peak cannot be predicted. But if uncertainty can be accepted, and if an exploration of the implications of the best available understanding of the question is useful, then the answer is yes. This report describes an attempt at such an analysis.

Probably the most important determinant of the usefulness of peaking analysis is whether the world's petroleum resources have been measured sufficiently accurately to support it. As knowledge of the earth's crust increases, the comprehensiveness and precision with which hydrocarbon occurrences can be characterized increases. Apparent evidence of this is the fact that estimates of ultimately recoverable resources of conventional oil (Figure 1) have remained in the vicinity of 2 trillion barrels over the past four decades (Grubb, 2001; Bentley et al., 2000; Wood et al., 2000).

Figure 1. Half a Century of World Oil Resource Estimates

\section{WORLD'S OIL (\& LIQUIDS) ULTIMATES}

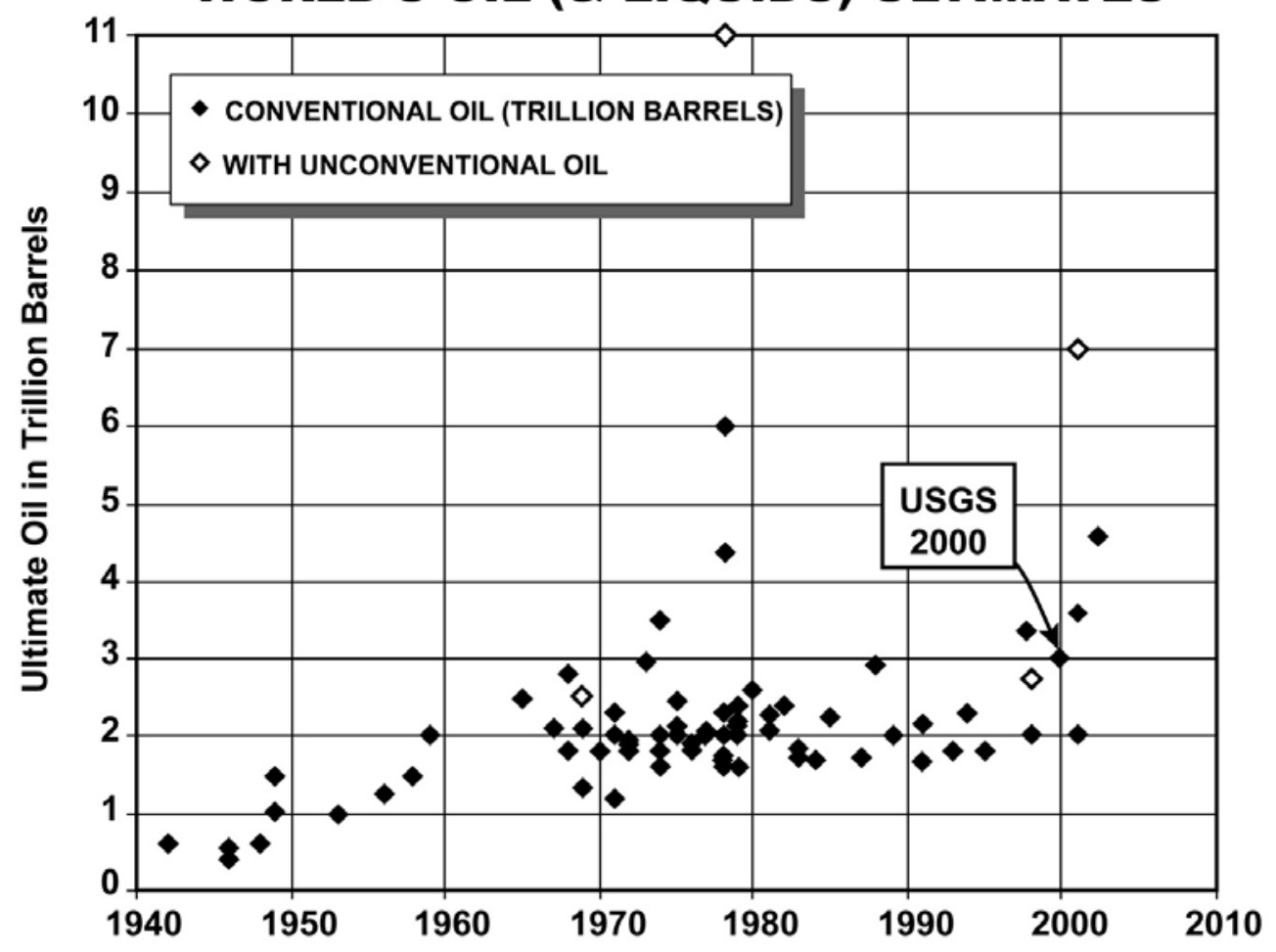

Source: Ahlbrandt, USGS, 2003.

Before a peak in oil production is reached, the world might begin a transition to an alternative source of energy, thereby permitting energy use to continue to grow. Such a transition would be especially critical for the world's transportation systems that rely almost entirely on petroleum fuels. The most likely, but not only alternatives to conventional oil are unconventional oil and other fossil hydrocarbon resources that can be converted to conventional liquid fuels. The world's resources of shale oil and coal, in particular, are vast and can be converted to suitable conventional hydrocarbon fuels at greater cost and with potentially greater damage to the environment. Other alternatives, such as hydrogen and biomass fuels need further technological development and could require massive, coordinated planning and policy intervention in order to displace conventional fuels. In this analysis, it is assumed that if a transition is necessary, it will 
be to unconventional sources of oil: oil and tar sands, heavy oil and shale oil. It is readily acknowledged that other transitions are possible and some might be preferable.

Several recent studies have considered the timing of the peaking of conventional oil production (e.g., Wood et al., 2000; Bentley 2002; Campbell and Laherrere, 1998; Cavallo, 2002; Duncan, 2003; Duncan and Youngquist, 1999; Edwards, 1997). With the exception of the simulations using the Energy Information Administration model (Wood et al., 2000), each study relies on a single scenario of world oil demand growth and a single estimate of total world oil resources. Wood constructed 12 peaking scenarios based on alternative rates of growth in world oil demand and the USGS's 5\%, 95\% and mean estimates of ultimate conventional oil resources. This produced a wide range of peaking dates between 2021 and 2112 (Figure 2). All of Wood's scenarios suggest catastrophically rapid transitions once conventional oil production peaks. Cavallo (2002) analyzed a single scenario of resources and demand, but varied the resource(proved + undiscovered)-to-production ratio at which production must begin to decrease between 10 and 15, thereby generating a range of dates for the peaking of non-OPEC production between 2015 and 2020. Cavallo used the USGS 2000 estimates of world oil resources.

Figure 2.

12 EIA World Conventional Oil Production Scenarios

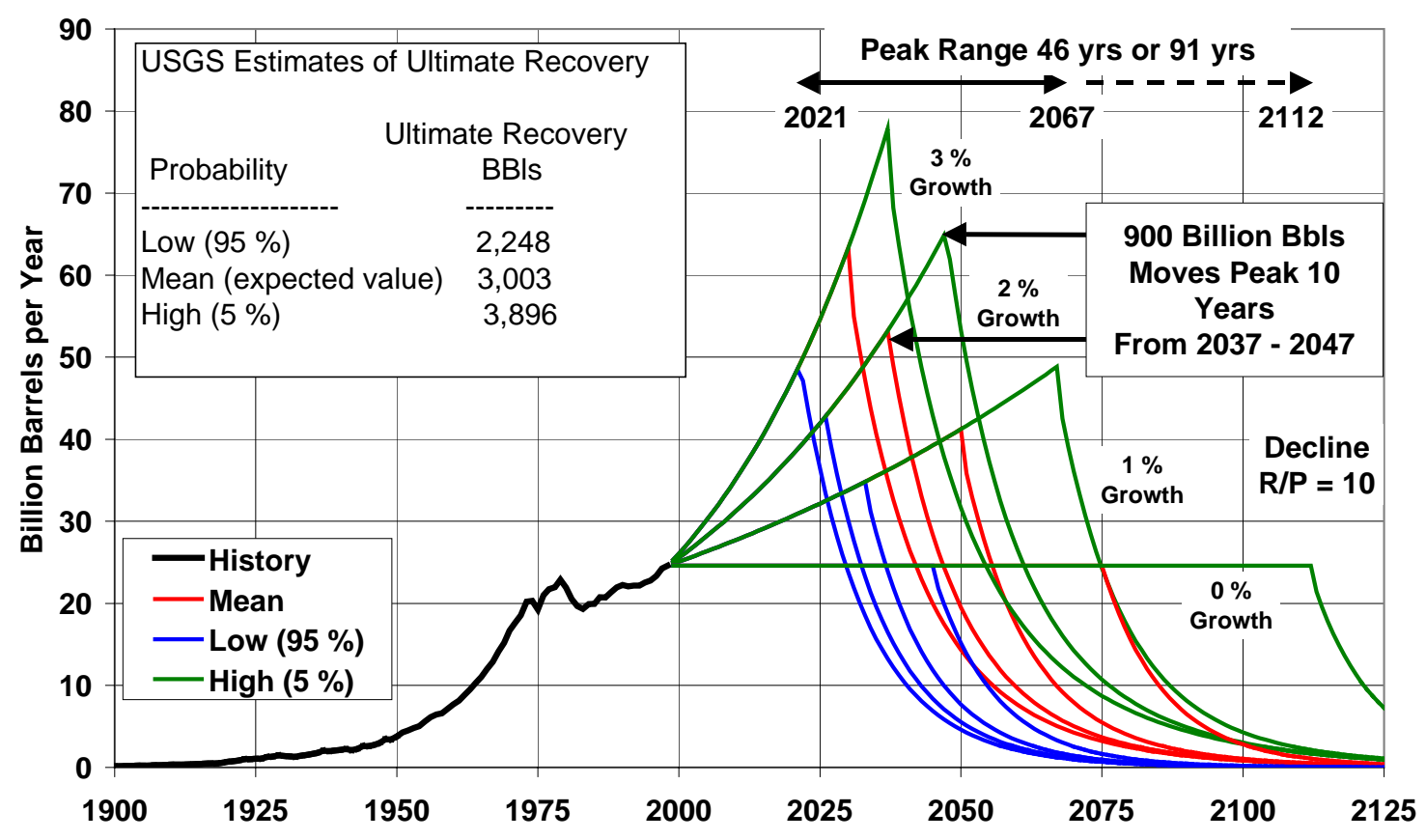

Note: U.S. volumes were added to the USGS foreign volumes to obtain world totals.

This study extends the parametric approach of Wood et al. (2000) by creating an integrated model of the depletion of conventional oil and the transition to unconventional oil resources in a systematic framework. This permits a risk analysis by assuming probability distributions for key parameters affecting: (1) the quantity of conventional oil resources available, (2) rates of technological progress, (3) oil production by Middle Eastern producers, and (4) other economic assumptions. The model can also be run using alternative scenarios of world oil demand. The model is described briefly in Section 3 and in greater detail in the appendix. 
Analysis of the possibility of a peaking of oil production should explicitly acknowledge the key uncertainties. First, as far as geological science has progressed, there is still incomplete knowledge of what lies beneath the surface of the earth. Some oil deposits remain to be discovered, and the true extent of known deposits is often unclear. Second, technological change will redefine the boundaries of producible resources and the costs of production. Advances in deep-water drilling have opened up new offshore resources and techniques such as horizontal drilling have increased recovery rates from known reserves (Alazard, 1996). Potential unconventional oil resources are vast, and are already beginning to be developed, particularly in Venezuela and Canada. Further technological advances could extend the range of usable resources to include even shale oil (Odell, 1999). Third, technological, economic, environmental and societal changes will alter the relative value of different energy sources and of energy efficiency, possibly leading the world's economies away from oil well before exhaustion of oil resources is a problem. Although one may try to predict how these three factors will determine future oil availability, substantial uncertainty about both timing and magnitude will remain.

The possibility of a disruptive and costly transition is not the only reason to be concerned about the transition from conventional oil. The threat of global climate change is cause for concern about a transition to unconventional oil resources. Such a transition seems likely because of the compatibility of unconventional oil with existing infrastructure. As Grubb (2001) and others have pointed out, the longer-term problem of climate change depends on the world's decision to burn or not to burn the world's vast fossil resources of coal and unconventional oil and gas and release the carbon to the atmosphere. ${ }^{1}$ There is not enough carbon in all the world's conventional oil and gas resources to raise atmospheric carbon concentrations above the threshold of $450 \mathrm{ppm}^{2}$ (Grubb, 2001, p. 838). To reach the higher levels that may cause drastic climate changes will require tapping into unconventional oil and gas resources, and coal.

It is possible that the world could go partway down the path of developing unconventional oil resources and later reverse direction. But such a strategy would strand huge investments in the more capital-intensive production and refining of unconventional oil. If the transition to unconventional oil is gradual, there might be time to introduce low-carbon alternatives and a reversal might not be too costly. But if the transition to unconventional oil is sudden and massive, the world's economies might quickly become locked into a high carbon future. Avoiding or even slowing the transition to unconventional fossil resources might improve the world's chances of successfully dealing with global climate change.

A global transition to unconventional oil might shift the balance of power in world oil markets. The U.S. National Energy Policy declared that the nation's dependence on petroleum in a carteldominated world oil market posed continued and growing economic and national security problems (NEPDG, 2001, pp. 1-11 to 1-13). Could a transition to unconventional oil help alleviate those problems by undermining OPEC's market power, or can OPEC maintain or even increase its market dominance despite such a transition? From the United States' perspective, this issue too is worth investigating.

This study attempts to shed light on a number of key questions.

${ }^{1}$ These resources might be used without affecting the climate if their greenhouse gas emissions were captured and sequestered.

${ }^{2}$ Of course, this will partly depend on which estimates of conventional oil resources are correct. 
- Is the peaking of conventional oil production imminent?

- What is the range of uncertainty?

- What are the key determining factors?

- Is a transition from conventional to unconventional oil likely to be gradual or rapid?

- Will a transition to unconventional oil undermine or strengthen OPEC's influence over world oil markets?

- Will a transition reduce or increase U.S. oil imports?

These issues are explored using a model that combines two alternative scenarios of world energy supply and demand with a detailed accounting of resource depletion and a market-based simulation of transition to unconventional oil resources. The World Energy Scenarios Model (WESM) is used to explore the sensitivity of the timing and rate of transition as a function of, (1) the size of world oil reserves and undiscovered resources, (2) rates of discovery and reserve expansion, and (3) rates of technological progress in the production of both conventional and unconventional oil resources. The model does not include political or environmental constraints on oil production, nor does it incorporate geological constraints on the rates at which oil can be produced. The authors believe that this imparts an optimistic bias to their analysis.

The issue is framed not solely as a matter of "running out" of conventional oil, but as one of the timing and rate of a transition from conventional to unconventional oil resources; a simultaneous "running out of" and "running into" oil. Of course, liquid hydrocarbon fuels can be produced from other resources besides unconventional oil, including coal, natural gas and biomass. But the focus on unconventional oil seems an appropriate starting point for two reasons. First, production of unconventional oil from Venezuela's heavy-oil fields and Canada's Athabascan oil sands is already underway on a significant scale. Second, of all the alternatives to oil, unconventional oil is most consistent with the massive, existing infrastructure for producing, refining, distributing and consuming petroleum. However, it can reasonably be argued that natural gas or even coal might prove to be more economical than shale oil as sources of liquid hydrocarbon fuels.

This study's results indicate that it is very likely that production of conventional oil from countries outside of the Middle East region will peak, or that the rate of increase in production will become highly constrained before 2025 . If the world's consumption of petroleum fuels is to continue to grow, development of unconventional oil resources (or some other source) will be required on a massive scale. While there are grounds for pessimism and optimism, the issue of conventional oil depletion cannot be lightly dismissed, and it is certainly not too soon for extensive, detailed analysis of transitions to alternative energy sources. 



\section{WORLD OIL RESOURCE ESTIMATES}

\subsection{WHAT IS OIL?}

In any assessment of world oil resources, the first question to be answered is, "What is oil?" (Laherrere, 2001). In this report, two kinds of oil are distinguished, conventional and unconventional. ${ }^{3}$ Conventional oil includes liquid hydrocarbons of light and medium gravity and viscosity, occurring in porous and permeable reservoirs. If such hydrocarbons require enhanced recovery techniques, Laherrere (2001) and Rogner (1997) consider them to be unconventional oil. In this report, oil available via enhanced recovery is considered conventional oil. Conventional oil resources are also defined here to include natural gas liquids (NGLs), since a large fraction of these liquids end up being consumed as petroleum products. ${ }^{4}$ Unconventional oil comprises deposits of greater density than water (e.g., heavy oil), viscosities in excess of $10,000 \mathrm{cP}$ (e.g., oil sands), or occurrences in tight formations (e.g., shale oil). As Rogner (1997) has pointed out, the definition of unconventional oil is somewhat flexible and depends in part on the state of oil recovery technology. Recently, some have argued that Canada's oil sands should be classified as conventional oil, while others argue that because of the cost and complexity of operations, water scarcity and other factors Canadian oil sands should remain unconventional (Economist, 2003). As Adelman (2003) notes, fifty years ago offshore crude oil was considered an unconventional resource. From this perspective, what is called here a transition to unconventional fossil resources might alternatively be viewed as a technologically, economically and culturally driven redefinition of conventional oil resources.

Rogner (1997) developed a useful framework for organizing and accounting for oil resource data by type of resource and region of the world. Rogner divided the world into 11 world regions, the same regions used in the International Institute for Applied Systems Analysis/World Energy Council (IIASA/WEC) study of global energy scenarios to 2100 (Nakićenović et al., 1998). Rogner's North American region has been subdivided into the United States and Canada for purposes of this study in order to distinguish between shale oil and other unconventional resources, as is explained in detail below.

Eight categories of resources are distinguished. Category I corresponds to proved recoverable reserves of conventional oil. Category II includes conventional oil occurrences that have not been discovered, but have a "reasonable probability of being discovered." These are comparable to the USGS $50^{\text {th }}$ percentile or mean undiscovered resource estimates. Category III represents more speculative occurrences of conventional oil, and according to Rogner, "...reflects the difference between Masters et al.'s 5\% and 50\% probability estimates of undiscovered oil and gas occurrences." (Rogner, 1997, p. 8). This same approach can be applied to the USGS 2000 estimates. Interpreted in this way, the most probable amount of Category III resources would be

${ }^{3}$ It is recognized that any hydrocarbon resource, including both coal and natural gas, can be converted to synthesis gas which, in turn, can be transformed into any desired liquid hydrocarbon. While this potential is not represented in the model presented below, its potential importance in allowing the world to continue to rely on liquid hydrocarbon fuels for a very long time must be acknowledged.

${ }^{4}$ Bentley et al. (2000) points out that NGL production is dependent on the production of natural gas and not oil. For this reason he excluded it from his "peaking" estimations. Combining NGL resources, as is done here, implicitly assumes that natural gas production will continue to conveniently provide NGLs to the petroleum market, as they are needed. 
close to zero. ${ }^{5}$ Category III is useful for quantifying optimism about future discoveries. Category IV represents the potential for enhanced recovery. Historically, only about 34 percent of in situ oil has been recovered. Rogner assumes that in the future this will increase to 40 percent, and notes that this assumption has already been incorporated in his estimates of Category I-III resources. Category IV represents further improvements in recovery rates beyond 40 percent. Rogner includes category IV with unconventional oil resources but here they are counted as conventional oil. The closest USGS category is reserve growth, but the definitions do not match exactly. Reserve growth is intended to combine the effects of technological improvements in recovery rates and the tendency for initial proved reserve estimates to understate the quantity of oil ultimately recoverable from a field. The USGS has acknowledged that its estimates of reserve expansion are based on U.S. experience and that application of U.S.based models to regions outside the United States is highly uncertain (Schmoker and Klett, 2000). Others argue that the tendency of initial reserve estimates to underestimate reserves, especially in the United States, is an artifact of the way proved reserves are reported formally, rather than a reflection of geologists' bias in estimating the size of a given resource (e.g., Bentley et al., 2000). In any case, although reserve expansion is mapped to Category IV for the assessments below, it is noted that the definition as applied to the USGS 2000 data differs from Rogner's Category IV definition.

Unconventional resources are represented in categories V-VIII. Category V comprises identified reserves of unconventional oil that can be produced today, or in the near future at current market prices. This includes, for example, most of the occurrences of oil sands in Canada and heavy oil in Venezuela. All other unconventional resources were estimated in toto, and then allocated by Rogner 20:35:45 percent among categories VI, VII and VIII. Also, all oil remaining after commercial production was added to category VIII. Given that oil shale accounts for the majority of the unconventional resource estimates, and that the vast majority of oil shale occurrences are very low grade $(<0.1$ ton of oil per ton of shale oil), only Category VI is included in the assessment of unconventional resources through 2050 (Table 1). This assumption is intended to exclude low-grade shale oil and all oil unrecoverable after enhanced recovery. Estimates of unconventional oil resources used with the USGS 2000 conventional oil resource estimates were derived from USGS, WEC and International Energy Agency (IEA) reports, and are described below in Section 2.3.

\subsection{ARE OIL RESOURCES INCREASING?}

The perception that estimates of world oil resources have uniformly increased over time is not consistent with estimates made since about 1960 (e.g., Grubb, 2001; Bentley, 2002; Bentley et al., 2000). As Figure 1 (Ahlbrandt, 2003) shows, estimates of ultimately recoverable conventional crude oil resources have been in the vicinity of 2 trillion barrels for the past 40 years. This lack of an increasing trend suggests a growing consensus, probably resulting from the accumulation of knowledge about the earth's geology.

The recent assessment of the USGS (2000) appears to be an exception, since its median estimate is 2.9 trillion barrels, about 40 percent higher than even its own estimate of six years earlier

${ }^{5}$ It will not be exactly zero because the USGS 2000 methodology allows for correlation among the resource estimates of different areas. 
(Masters et al., 1994). However, the majority of the apparent difference is one of definition. The USGS study includes, for the first time, an estimate of reserve growth that amounts to 0.7 trillion barrels. Excluding this newly defined category, the USGS 2000 estimate is 2.2 trillion barrels, relatively consistent with other estimates developed over the past 40 years. Including reserve growth is an important new feature of the USGS 2000 study, since it provides an explicit estimate of the future effects of potential technological advances, as well as knowledge gained about the true extent of fields as they are developed. This initial world estimate is acknowledged to be highly uncertain.

Table 1. Estimated World Oil Resource Occurrences, in Gigatonnes of Oil Equivalent (Gtoe)

(1 Gtoe $=7.33$ Billion bbls of oil = 20.1 Million bbls/day)

\begin{tabular}{lrrrrrrrrr}
\hline & \multicolumn{3}{c}{ Conventional Oil } & \multicolumn{1}{c}{ Unconventional Oil } & Total \\
\cline { 2 - 8 } Region & \multicolumn{1}{c}{ I } & \multicolumn{1}{c}{ II } & \multicolumn{1}{c}{ III } & \multicolumn{1}{c}{ IV } & \multicolumn{1}{c}{ V } & \multicolumn{1}{c}{ VI } & \multicolumn{1}{c}{ VII } & \multicolumn{1}{c}{ VIII } & I-VI \\
\hline NAM & 8.5 & 8.6 & 6.7 & 15.9 & 7.6 & 98.8 & 172.8 & 287.4 & 606 \\
LAM & 17.4 & 8.9 & 15.5 & 18.9 & 2.6 & 91.5 & 160.1 & 270.8 & 586 \\
WEU & 5.6 & 2.1 & 3.6 & 5.1 & 1.3 & 7.6 & 13.3 & 34.6 & 73 \\
EEU & 0.3 & 0.2 & 0.6 & 0.7 & 0.0 & 0.5 & 1.0 & 3.8 & 7 \\
FSU & 17.1 & 13.6 & 19.3 & 23.4 & 3.3 & 19.4 & 34.0 & 125.6 & 256 \\
MEA & 87.9 & 17.0 & 21.9 & 56.2 & 22.3 & 39.6 & 69.3 & 279.0 & 593 \\
AFR & 4.0 & 3.4 & 4.9 & 5.4 & 1.4 & 5.1 & 8.9 & 29.7 & 63 \\
CPA & 5.1 & 4.7 & 8.2 & 7.4 & 2.3 & 42.2 & 73.8 & 118.7 & 262 \\
PAO & 0.4 & 0.3 & 0.6 & 0.7 & 3.7 & 25.8 & 45.1 & 60.3 & 137 \\
PAS & 2.9 & 1.6 & 2.5 & 3.4 & 0.6 & 4.8 & 8.3 & 23.0 & 47 \\
SAS & 1.0 & 0.3 & 0.6 & 0.8 & 0.1 & 0.3 & 0.5 & 3.5 & 7 \\
& & & & & & & & & \\
WORLD & 150 & 61 & 84 & 138 & 45 & 336 & 587 & 1237 & 2638 \\
\hline
\end{tabular}

Source: Rogner, 1997, table 4. Regional acronyms are defined in Table A2, Appendix A.

Similarly, another recent reassessment reported that the world's ultimate resources of producible oil had increased dramatically to 2.9 trillion barrels from 1.7 trillion (Bower, 2002). On close examination, the increase turns out to due to be almost entirely due to differences in definition and explicit consideration of likely future advances in the technology of producing unconventional oil. The 2.9 trillion total includes NGLs, while the 1.7 trillion estimate does not, a difference of about 0.2 trillion barrels. The 2.9 trillion barrel estimate also includes 0.3 trillion barrels of estimated enhanced recovery not included in the 1.7 trillion estimate. Finally, unconventional oil in Venezuela and Canada amounting to 0.25 and 0.31 trillion barrels are also included because technological advances have now made these resources producible at current market prices. Subtracting these differences yields a comparable estimate of total world oil resources of 1.8 versus 1.7 trillion barrels. These differences suggest that it is not the understanding of the geological occurrences that is changing significantly, but rather the economic and technological interpretation of that geology.

The USGS also estimated world resources of NGL, many of which find their way into petroleum products. In general, NGLs are not counted among crude oil resources because they are coproducts of natural gas production. However, NGLs are generally counted in petroleum consumption and specifically are included in the petroleum use scenarios used in this study. 
Since oil consumption and production must balance, NGLs are added to conventional oil resources in this study.

In addition to median estimates, the USGS 2000 study provides mean (expected value) estimates, lower $\left(95^{\text {th }}\right.$ percentile) and upper $\left(5^{\text {th }}\right.$ percentile $)$ confidence intervals on estimates of undiscovered resources and reserve growth. The low estimate of total conventional oil resources is 2.3 trillion barrels, 2.5 trillion including NGLs. The upper estimate including NGLs is 4.4 trillion barrels. The mean estimate for crude oil is 3.0 trillion, for petroleum including NGLs is 3.3 trillion. All these estimates include cumulative production to 2000 of 0.54 trillion barrels (Table 2).

Table 2. Estimates of World Petroleum Resources for the Year 1996 from the USGS 2000 Study

\begin{tabular}{lcrrrrrrrrrrr}
\hline & \multicolumn{4}{c}{ Oil } & \multicolumn{4}{c}{ Natural Gas Liquids } & \multicolumn{3}{c}{ Total Petroleum } \\
\cline { 2 - 13 } & $95 \%$ & $50 \%$ & \multicolumn{1}{c}{$5 \%$} & Mean & $95 \%$ & $50 \%$ & $5 \%$ & Mean & $95 \%$ & $50 \%$ & $5 \%$ & Mean \\
\hline Undiscovered & 394 & 683 & 1202 & 725 & 101 & 196 & 387 & 214 & 495 & 879 & 1589 & 939 \\
Res. Growth & 255 & 675 & 1094 & 675 & 26 & 55 & 84 & 55 & 281 & 730 & 1178 & 730 \\
Proved Res. & 884 & 884 & 884 & 884 & 75 & 75 & 75 & 75 & 959 & 959 & 959 & 959 \\
Cum. Prod. & 710 & 710 & 710 & 710 & 7 & 7 & 7 & 7 & 737 & 737 & 737 & 717 \\
TOTAL & 2244 & 2953 & 3890 & 2994 & 210 & 334 & 553 & 351 & 2454 & 3287 & 4443 & 3345 \\
\hline
\end{tabular}

Source: USGS 2000, Table AR-1. USGS estimates combine U.S. NGLs with oil but separate the two for the rest of the world estimates. In Table 1, onshore U.S. NGLs have been removed from the USGS oil estimates and included with NGLs. Historical U.S. NGL production was calculated for 1949-2000 and also removed from U.S. oil estimates and added to NGLs. It was not possible to estimate U.S. offshore NGLs resources remaining under any category. These are included with oil.

\subsection{HOW MUCH UNCONVENTIONAL OIL IS THERE?}

The USGS 2000 study did not estimate the extent of unconventional oil resources. In this section estimates are derived from other USGS reports, as well as reports of the World Energy Council (WEC) and International Energy Agency (IEA). These are then compared to Rogner's estimates. The USGS/WEC/IEA estimates also prove to be useful for dividing regions into those containing predominantly shale oil and those containing oil sands, tar sands or heavy oil. This distinction is important for modeling purposes because of the large difference between the costs of producing the two types of resources.

\subsubsection{Heavy Oil and Bitumen (Tar or Oil Sands)}

Rogner's estimates of unconventional oil resources can be compared with estimates by the USGS (Dyni, 2000) and less comprehensive estimates from the WEC (2001) and IEA (2002). The WEC asserts that recoverable reserves of bitumen (oil and tar sands) and heavy oil are highly concentrated.

"Although natural bitumen and extra-heavy oil are worldwide in occurrence, a single extraordinary deposit in each category is dominant. The Alberta, Canada natural bitumen deposits comprise at least $85 \%$ of the world total bitumen in place, but are so concentrated as to be virtually the only such deposits that are economically recoverable for conversion to oil. The deposits amount to roughly 
1,700 billion barrels of bitumen in place. Similarly, the extra-heavy crude oil deposit of the Orinoco Oil Belt, a part of the Eastern Venezuela basin, represents nearly $90 \%$ of the known extra-heavy oil in place.” (WEC, 2001, Ch. 4)

This assertion is partly contradicted by an IEA (2002) report, which shows 1,350 billion barrels (197 Gtoe) of extra-heavy crude and/or bitumen in place in Russia, but reports no estimate of how much of this resource in place is ultimately recoverable. ${ }^{6}$ Rogner put the combined unconventional resources (categories V and VI) of the countries of the Former Soviet Union at 22.7 Gtoe. Natural Resources Canada (NRCan, 2002b) has published an estimate of FSU bitumen recoverable resources of 60 billion cubic meters (bcm) (60 Gtoe since $1 \mathrm{bcm}$ is approximately $1 \mathrm{Gtoe}$ ) out of $186 \mathrm{bcm}$ in-place. If $30 \%$ of the IEA's estimated resources inplace for Russia were recoverable, this would also amount to 60 Gtoe (suggesting that bitumen resources outside of Russia may be minor). These estimates make Rogner's seem low, but this may also be a question of allocation among categories VI, VII and VIII.

Both the IEA and WEC report ultimate recoverable resources of bitumen for Canada of 45.3 Gtoe. NRCan estimates 49 billion cubic meters of recoverable bitumen (equivalent to approximately 49 Gtoe), and the Energy Economist (Roberts, 2002, p. 7) published a slightly higher estimate of 54 billion cubic meters. For the U.S., the WEC reports 4.2 Gtoe of "estimated additional" resources of bitumen and extra-heavy oil. These resources are reported outside of the recoverable and proved reserves categories, reflecting considerable uncertainty about their economic utility. The IEA reports 5.8 Gtoe of extra-heavy oil and bitumen in-place in the United States but makes no estimate of how much is recoverable. If one accepts that 50 Gtoe of North American unconventional resources (categories V and VI) are bitumen, then the rest of Rogner's estimated 106.4 Gtoe (56 Gtoe) must be shale oil.

\subsubsection{Shale Oil}

The WEC (2001, Ch. 3) reports 3.34 trillion metric tonnes of oil shale in-place in the U.S., from which 60-80 billion metric tonnes of oil are deemed recoverable reserves. ${ }^{7}$ A roughly equal amount of "estimated additional" reserves of shale oil are reported by WEC. Thus, WEC's 6080 Gtoe of U.S. shale oil roughly matches Rogner's 56 Gtoe. In fact, taking the midpoint (70 Gtoe) and multiplying by the $89 \%$ of U.S. oil shale located in the Green River deposits of northwestern Colorado, northeastern Utah and southwestern Wyoming, returns exactly 56 Gtoe. So it may be that Rogner has assigned the $11 \%$ found in Devonian black shales in the eastern United States to category VII. Thus, it is probably reasonable to interpret Rogner's category V and VI unconventional resource estimates for North America as comprised of about half Canadian oil sands and half U.S. western oil shale.

World shale oil resources have been estimated by the USGS at 2.6 trillion barrels (376 Gtoe) in place (Dyni, 2000). The estimate is considered conservative because many oil shale deposits

${ }^{6}$ There are some differences in terminology between the IEA and WEC reports. The IEA use the term "resources in-place" to describe the amount of bitumen or heavy oil in the deposit, regardless of how much is recoverable. "Ultimate recoverable" takes into account the amount of the resource that can be extracted given current technology and economics. The WEC uses the term "proved in-place" to describe that amount that is recoverable, and "proved recoverable" as an equivalent to proved reserves.

${ }^{7}$ The in-place resource is reported by the WEC in tonnes of shale, while the recoverable and estimated additional resources are reported in tonnes of oil. 
have not been fully investigated and some countries do not report them at all. On the other hand, the estimate of 1.5 trillion barrels for the Green River formation in the United States is fairly well known. The quantity of in-place oil that can be recovered will depend on the nature of the deposit and the method of recovery. In terms of oil shale, an open pit mine could recover almost $90 \%$, and strip mining even more, while underground mining (in situ and modified in situ) would produce less than $60 \%$ (OTA, 1980, p. 123). While in principle strip or open pit mining could be used for much of the U.S. oil shale, there are many complications caused by thick overburden and the need to dispose of it. Estimates of recovery rates for several processing options applied to a representative deposit ranged from $29 \%$ for conventional in situ room-and-pillar mining leaving $40 \%$ of the shale oil in place as pillars, to $100 \%$ for full strip mining with above ground retorting. If only modified in situ methods are considered, the recovery estimates range from $29 \%$ to $68 \%$. A recovery rate of $50 \%$ (188 Gtoe) is used in the calculations described below and shown in Table 3.

Table 3. Estimates of World Oil Sands and Oil Shale Resources from Three Sources

\begin{tabular}{|c|c|c|c|c|c|}
\hline \multirow[b]{2}{*}{ Region } & \multicolumn{3}{|c|}{ IEA/WEC/USGS } & \multirow[b]{2}{*}{$\begin{array}{l}\text { Total } \\
\text { Unconv. } \\
\text { (Gtoe) }\end{array}$} & \multirow{2}{*}{$\begin{array}{c}\text { Rogner } \\
\text { V+VI } \\
\text { Unconv. } \\
\text { (Gtoe) }\end{array}$} \\
\hline & $\begin{array}{l}\text { Oil } \\
\text { Shale } \\
\text { (Gtoe) }\end{array}$ & $\begin{array}{l}\text { Heavy Oil \& } \\
\text { Oil Sands } \\
\text { (Gtoe) }\end{array}$ & $\begin{array}{c}\text { Share } \\
\text { Heavy Oil \& } \\
\text { Oil Sands } \\
(\%)\end{array}$ & & \\
\hline Canada & 1.1 & 45.3 & $97.7 \%$ & 46.4 & 45.3 \\
\hline USA & 154.8 & 4.2 & $2.7 \%$ & 159.0 & 61.1 \\
\hline LAM & 9.7 & 39.5 & $80.3 \%$ & 49.1 & 94.1 \\
\hline FSU & 6.5 & 39.5 & $85.9 \%$ & 46.0 & 22.7 \\
\hline EEU & 0.0 & 0.0 & $19.3 \%$ & 0.0 & 0.5 \\
\hline AFR & 7.3 & 0.6 & $7.7 \%$ & 7.9 & 6.5 \\
\hline MEA & 30.5 & 2.3 & $7.1 \%$ & 32.8 & 61.9 \\
\hline PAO & 37.0 & 0.0 & $0.0 \%$ & 37.0 & 29.5 \\
\hline PAS & 0.8 & 0.0 & $0.0 \%$ & 0.8 & 5.4 \\
\hline WEU & 6.9 & 0.0 & $0.0 \%$ & 6.9 & 8.9 \\
\hline CPA & 1.2 & 0.0 & $0.0 \%$ & 1.2 & 44.5 \\
\hline SAS & 0.1 & 0.0 & $0.0 \%$ & 0.1 & 0.4 \\
\hline World & 255.9 & 131.4 & $33.9 \%$ & 387.3 & 380.8 \\
\hline
\end{tabular}

Rogner's estimate of 106.4 Gtoe of category V and VI unconventional oil for North America has been divided between Canada and the USA by assuming that all Canadian oil sands are included and no Canadian oil shale. This leaves 61.1 Gtoe of category V and VI oil shale for the USA.

The WEC has published an incomplete set of estimates provided by their members that amounts to 217 billion metric tons of recoverable oil shale (WEC, 2001). Where the WEC provided a range of estimates for a country, the midpoint was used. Proved recoverable reserves and estimated additional reserves were added together to obtain total estimated reserves. The estimates thus derived from WEC are lower than those derived from the USGS for some regions and higher for others. Given that the WEC describes its data as a "sample" and the USGS characterizes its estimates as "conservative" the maximum of the two was used for each region to compile the estimates shown in Table 3. ${ }^{8}$ The differences are greatest for the Middle East and Asian Pacific Other regions, where the WEC-derived estimates are 4-5 times higher than those section A11.

${ }^{8}$ The division of the estimates shown in Table 3 into categories V and VI is explained in the appendix 
derived from the USGS study. Virtually all of the difference is attributable to estimated additional resources in Australia (PAO) and Jordan (MEA).

In terms of total unconventional oil resources, the estimates derived from IEA/WEC/USGS estimates compare well with Rogner's estimate of 381 Gtoe of category V and VI resources. A comparison at the regional level, however, reveals considerable disagreement reflecting the high level of uncertainty about these resources. Rogner assigns only two-thirds as much unconventional oil to North America as the composite IEA/WEC/USGS based estimate. We have attributed this primarily to less enthusiasm about U.S. oil shale potential, since Canadian oil sands resources are reasonably well known. Rogner puts double the amount of unconventional oil in Latin America as the composite estimate, but only half as much in the Former Soviet countries. Rogner also assigns twice as much to the Middle East region and a great deal more to the Centrally Planned economies of Asia (China).

The division of unconventional oil resources into oil shale and oil sands/heavy oil leads to a serendipitous dichotomy of regions that is useful for defining regional depletion cost curves. If one divides the North American region into Canada and the United States, it appears that every region can be described as either oil sands/heavy oil dominant, or oil shale dominant (Figure 3). Only FSU and LAM appear to have significant quantities of both resources, and these two regions are more than $80 \%$ oil sands. This result must be considered tentative because of the incompleteness of oil sands resource estimates and the uncertainty of both oil sands and oil shale resource estimates. Nonetheless, the dichotomy of "oil shale" and "oil sands" regions is useful for calibrating regional depletion cost curves because it implies that only two curves, one for each resource type, may be a reasonable simplification, given the enormous uncertainty about production costs in general.

Figure 3. Incomplete Estimates of Regional Resources of Unconventional Oil

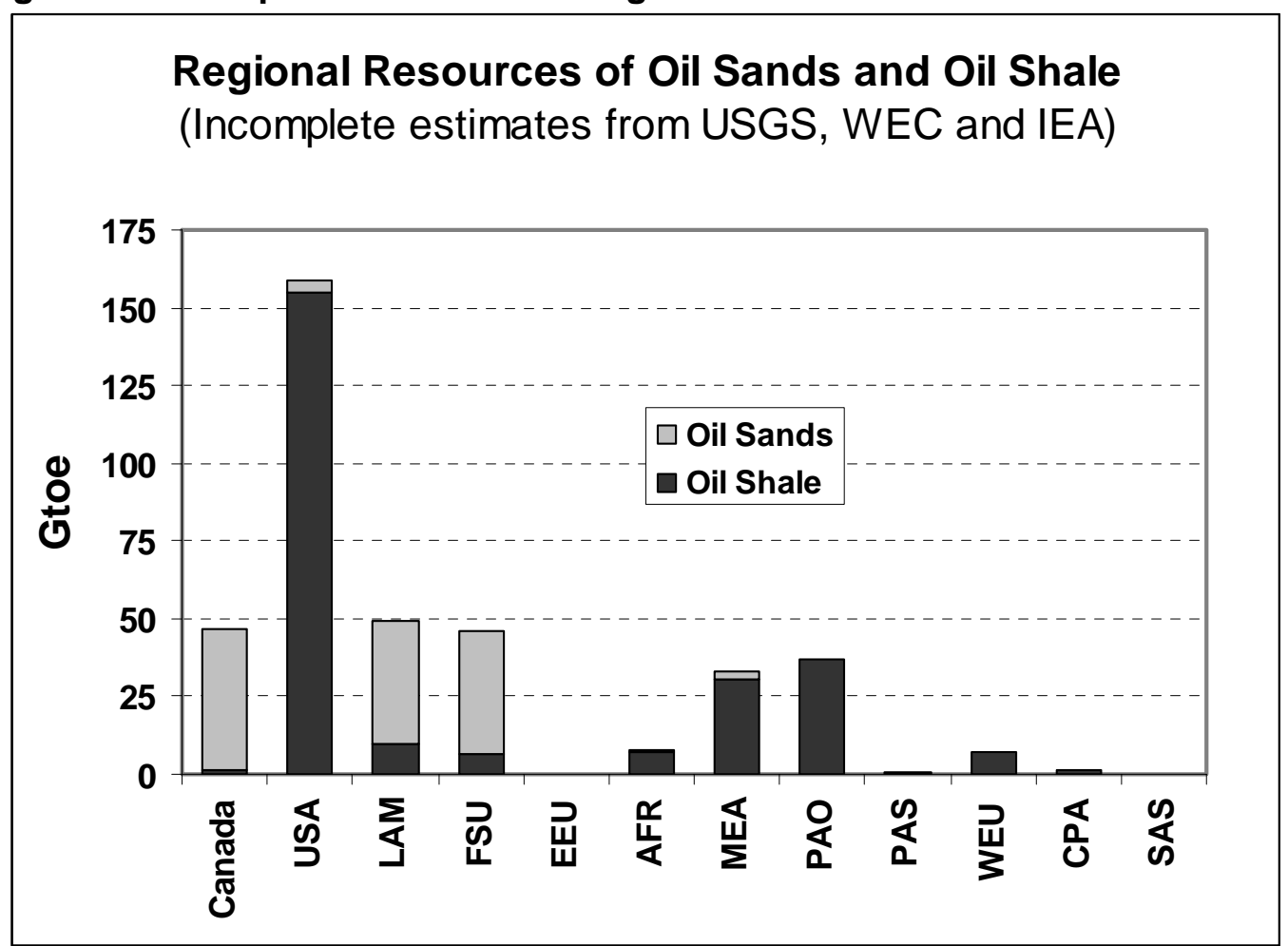


Because unconventional oil resources have been of little economic interest, much less effort has gone into establishing their nature and extent. The viewpoint of this analysis is that the extent of unconventional oil resources is highly uncertain, as are the costs of development for anything but Venezuelan extra-heavy oil and Canadian oil sands.

\subsection{THE PESSIMISTIC VIEWPOINT}

Some believe that the USGS (2000) and Rogner (1997) assessments substantially overestimate ultimately recoverable conventional oil resources and, furthermore, that unconventional resources are likely to be inadequate to fill the gap between demand and supply once conventional oil production peaks (Bentley, 2002; Laherrere, 2001; Bentley et al., 2000). What is often referred to as the "pessimistic" view attributes the overestimation of world oil resources to three key factors. These arguments are summarized below. Their validity is not addressed in this study (see e.g., Williams, 2003).

(1) Estimates of proved reserves are usually accepted at face value, but reserve estimates by OPEC members are inflated. Since reserves confer bargaining power in negotiating production quotas within OPEC, members have an incentive to inflate their proved reserve estimates to gain better bargaining positions. Campbell (1997) has estimated the overstatement of world proved reserves at about 360 billion barrels (about 35 percent).

(2) Historically, reserve growth is mainly a result of conservatism in the rules and procedures for booking field size rather than technological advances in recovery methods or downward bias in geologists' initial estimates. Initial proved reserve underestimates are generally made for institutional reporting reasons and usually do not correspond to the best estimates made by petroleum geologists. Estimates of resources that have been made correctly will have very modest reserve growth.

(3) USGS estimates of reserve growth were further biased upwards by assuming that the rest of the world's (ROW's) reserve estimates were comparable to U.S. reserve estimates and that U.S. reserve expansion could be applied to the ROW's estimates. Since the ROW lists as proven what the United States would consider proven plus probable reserves, applying U.S. reserve expansion rates to other countries' proven reserve estimates produces in inflated projections.

Of course there are counter arguments. While acknowledging that proved reserves in key OPEC countries may have been inflated, many believe that additional, undiscovered resources exist in these countries that will more than compensate for inflated proved reserves estimates. Also, the USGS (Attanasi and Root, 1993) has presented evidence of reserve growth outside of the United States that is approximately consistent with its U.S.-based reserve growth estimation methods. The authors of this report do not consider themselves qualified to resolve these disagreements. It is our view, however, that the USGS 2000 assessment is a model for other studies in terms of its extensive publicly available documentation and broadly-based peer review process.

The less optimistic oil resource assessments still put ultimately recoverable resources in the vicinity of 2 trillion barrels (Table 4). For example, Laherrere (2001) provides minimum, mean and maximum estimates for conventional oil of 1.7, 1.8 and 2.2 trillion barrels, respectively 
(Table 4). These compare with USGS 2000 estimates of 2.2, 2.9, 3.9 trillion barrels. Also provided by Laherrere are estimates of unconventional oil resources that are an alternative to Rogner's estimates and those shown in Table 3.

Table 4. Estimates of World Conventional and Unconventional Oil Resources by Laherrere

\begin{tabular}{lccc}
\hline \multicolumn{1}{c}{ Resource type } & Minimum & Mean & Maximum \\
\hline Conventional Oil & 1,700 & 1,800 & 2,200 \\
Conventional Gas Liquids & 200 & 250 & 400 \\
Non-conventional Liquids & 300 & 700 & 1,500 \\
Ultimate Liquids (Billion barrels) & 2,300 & 2,750 & 4,000 \\
\hline
\end{tabular}

Source: Laherrere, 2001, p. 62.

The estimates used in this study to represent the pessimistic view are from Campbell (2003). Campbell estimates 871 billion barrels of oil remaining in known fields and 133 in new fields (Table 5). Campbell's $896+871+133=1,900$ billion barrels of total conventional oil compares with Laherrere's mean estimate of 1,800 billion barrels. Only 133 billion barrels of this are as yet undiscovered resources. Campbell breaks out an additional 90 billion barrels of oil in deepwater and Polar Regions. He classifies these as "Non-Regular" oil, but in this analysis they are considered conventional oil. The definition of conventional oil used in this study also includes NGLs, which gives a total conventional oil estimate of 2.4 trillion barrels based on Campbell's data. For unconventional oil resources 300 billion barrels of heavy oil are reported. Shale oil is not included in Campbell's resource estimates.

\section{Table 5. Estimates of World Conventional and Unconventional Oil Resources by Campbell, At Year end 2002}

\begin{tabular}{lc}
\hline \multicolumn{1}{c}{ Resource Category } & Estimated Quantity (Billion Barrels) \\
\hline Conventional Oil & \\
Known Fields Produced & 896 \\
Known Fields Future Production & 871 \\
New Fields Future Production & 133 \\
Deepwater Future & 60 \\
Polar Future & 30 \\
Gas Liquids & 400 \\
Total Conventional & $\mathbf{2 , 3 9 0}$ \\
Heavy Oil (Unconventional) & $\mathbf{3 0 0}$ \\
\hline
\end{tabular}

Source: Campbell, 2003

\subsection{RESOURCE ESTIMATES USED IN THIS STUDY}

In the analyses carried out in this study, three sets of estimates are used.

- USGS 2000 conventional oil estimates plus the unconventional oil estimates synthesized from USGS/WEC/IEA as described above,

- Rogner's 1997 estimates and, 
- Estimates based on Campbell's (2003) year-end 2002 global assessment.

The USGS and Rogner estimates are similar, in part because Rogner made use of an earlier USGS study (Masters et al., 1994) in deriving his estimates of conventional oil resources. There are important differences, however, including the newly defined category of reserve growth and the alternative estimates of unconventional oil resources, described above. The USGS and Rogner estimates reflect similar premises: (1) that technological progress will significantly expand ultimate resources and, (2) that there is considerable uncertainty about how much oil remains to be found. Campbell is far less sanguine about the ability of technology to expand resources and his data reflect far less uncertainty about how much oil remains.

The USGS 2000 estimates are available by country, which allowed them to be rearranged into Rogner's regions, producing comparable regional estimates. Campbell's global total 2002 estimates were distributed to countries based on each country's share of his own year-end 1999 estimate, which was available by country (Campbell, 2000). The procedures and data are described in detail in the appendix.

The correspondence between Campbell's categories and Rogner's was done as follows. "Known Fields Future" was assigned to category I, proved reserves. Polar, deepwater and gas liquids reserves were shared between categories I and II, based on the division in Campbell's 1999 data between regular and yet-to-find. "New Fields Future" was assigned to category II, estimated additional reserves. Campbell's estimates do not provide information on categories III (speculative reserves) and IV (enhanced recovery). 


\section{MODELING OIL DEPLETION}

The WESM model was developed to assess the implications of alternative, long-term, world energy scenarios for the depletion of conventional oil and the likely transition to unconventional oil. It performs two main functions. The first is a detailed accounting of the use of conventional and unconventional oil resources by resource category. The second is an economic simulation of the transition from conventional to unconventional oil resources.

The model takes a pre-existing scenario of world energy production and use to 2050 as a starting point, performs an initial accounting for the availability of conventional oil by region and the likely need for unconventional oil world wide, calibrates world oil supply and demand curves to the scenario using regional depletion-cost functions and assumed price elasticities, then solves for equilibrium supplies and demands for conventional and unconventional oil by region. The resulting production estimates by region are again passed to the accounting model for final calculations of the depletion of conventional oil and the transition to unconventional resources (Figure 4). The details of this model including the equations used are presented in the appendix.

Figure 4. Flow Diagram of World Energy Scenarios Model

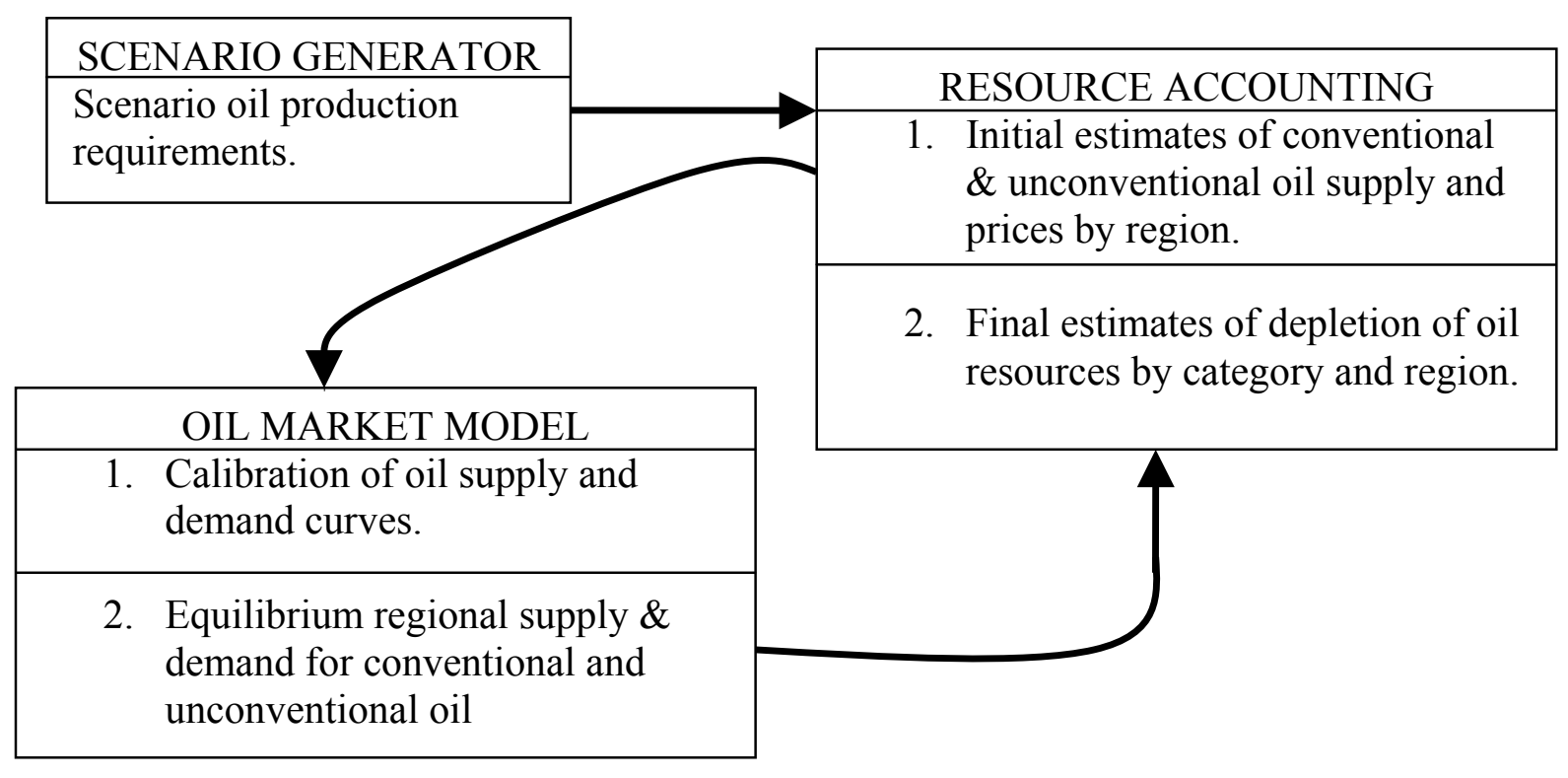

The WESM model was designed to use the world energy scenarios created by the IIASA and the WEC through 2050 (Nakićenović et al., 1998). A IIASA/WEC scenario can also be adjusted to match a U.S. Department of Energy International Energy Outlook 2002 projection to the year 2020 (U.S. DOE/EIA, 2002). Beyond that all variables are trended back towards the original IIASA/WEC scenario using splining methods. Every IIASA/WEC scenario for North America foresaw lower rates of growth in oil demand from 1995 to 2000 than were actually experienced. Therefore, for North America, WESM can also be calibrated to detailed transportation energy forecasts developed by the U.S. Department of Energy and NRCan using the Champagne Model (EEA, 1999; NRCan, 2002a). 
Simulation of the draw down of conventional oil and the transition to unconventional oil consists of two major components: (1) a set of resource depletion rules and (2) a long-run representation of world oil market behavior consistent with the scenario in question. The IIASA/WEC scenarios specify, by region, initial estimates of both oil consumption and oil production. WESM initially tries to satisfy a scenario's proposed regional oil production schedule using conventional oil. If a region's resources are inadequate to meet the scenario's call for production, the unsatisfied portion is set aside, to be met by conventional or unconventional oil from any region. The World Oil Market model determines the quantities of conventional and unconventional oil to be produced by each region. These market equilibrium estimates are sent to the resource accounting framework a second time to produce the final resource use and depletion estimates.

\subsection{RESOURCE ACCOUNTING}

Proved reserves are treated as the stock from which current production is drawn and to which additions are made from other resource categories (Figure 5). If a scenario's production requirement for a region can be met from the proved reserves of that region, the full amount of the requirement is withdrawn from proved reserves. A region is considered unable to meet a production requirement if the ratio of its proved reserves $(\mathrm{R})$ to the production requirement $(\mathrm{P})$ is below a user-specified target Reserves-to-Production $(\mathrm{R} / \mathrm{P})^{*}$ ratio. At that point, production is constrained to converge toward the target $(\mathrm{R} / \mathrm{P})^{*}$ ratio. The unproducible requirement is set aside as potential demand for unconventional oil.

\section{Figure 5. Structure of Resource Accounting Model}
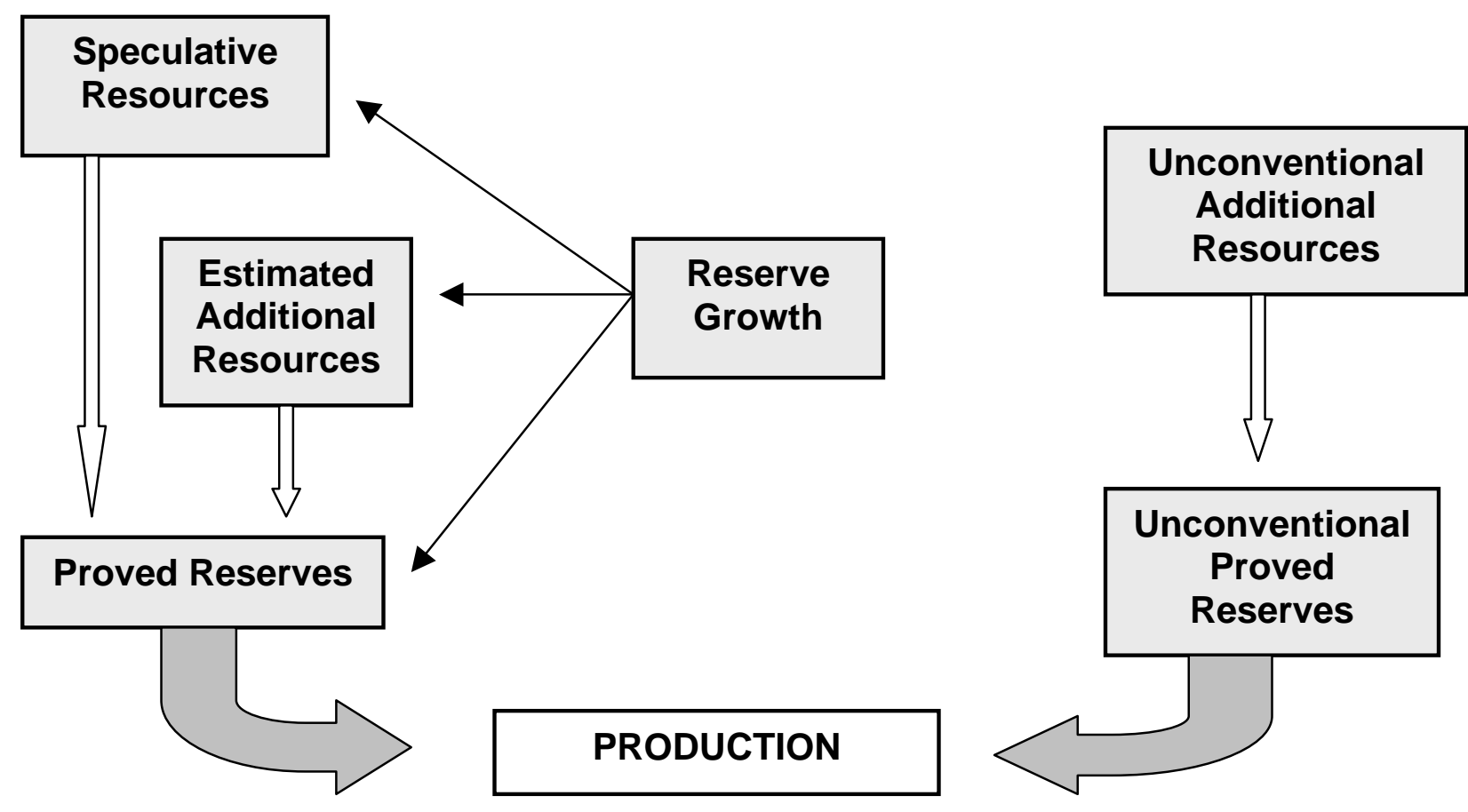

The "target R/P" approach is not likely to satisfy advocates of the Hubbert theory, who might argue that it will not be possible for regions to continue increasing production, or even hold it 
constant beyond the 50 percent depletion point (e.g., Bentley et al., 2000). On the other hand, economists might argue that the Hubbert theory is overly mechanistic and that if peaking ever occurs it will be determined more by economics and technology than geology (e.g., Odell, 1999). It is certainly true that an arbitrarily specified $(\mathrm{R} / \mathrm{P})^{*}$ ratio takes no account of geology and the increasing difficulty of finding and extracting oil from an increasingly depleted region. It might best be thought of as a rule-of-thumb specifying that producers will not invest in increasing output when the lifetime of the investment would be shorter than $(\mathrm{R} / \mathrm{P})^{*}$ years. Because the target $\mathrm{R} / \mathrm{P}$ ratio method ignores physical constraints it should be considered biased in favor of prolonging the time period during which production can increase.

The R/P ratio rule was used by the Energy Information Administration (Wood, et al., 2000) in its analysis of the potential peaking of world oil production. It is clear from Wood's peaking curves (see Figure 2) that if world producers really followed a strict R/P rule, sharp production peaks and catastrophically rapid transitions would result. Cavallo (2002) also used the R/P ratio to estimate the time at which world oil production might peak but he defined reserves differently, as the USGS estimates of proved plus undiscovered resources. He termed this the $\mathrm{R}_{\mathrm{P}+\mathrm{U}} / \mathrm{P}$ ratio, and concluded that production in a region would begin to decrease when the ratio was somewhere between 10 and 15 .

\subsubsection{Accounting for Conventional Oil Depletion}

Although WESM limits the quantity of oil a region can produce by the ratio of proved reserves to production, proved reserves in WESM are dynamic quantities. In WESM, proved reserves are continuously augmented by additions from speculative and estimated additional resources, as well as from reserve expansion (as illustrated in Figure 5). This representation views proved reserves as an inventory, "continuously replenished by investment in new and old fields" (Adelman, 1990, p. 9). The rates of additions from estimated additional, and speculative resources, as well as from reserve expansion are under the control of the model user, but the total quantities of conventional oil available from these sources are treated as a fixed stock. ${ }^{9}$. The size of that stock, however, depends on the resource assessment and technological change parameters chosen by the model user.

Withdrawals from proved reserves are primarily replenished by flows from estimated additional reserves, if adequate estimated additional reserves are available. The inflow from estimated additional reserves is set equal to the current year's production from proved reserves if the ratio of the quantity of estimated additional reserves to the required flow exceeds the target R/P ratio. Otherwise, the flow is set equal to the quantity of estimated additional reserves divided by the target $\mathrm{R} / \mathrm{P}$ ratio.

Speculative resources, if any are assumed to exist, are developed and added to proved reserves according to a user-specified bell-shaped curve. The user specifies the date at which half of the speculative resources will have been converted to proved resources and the fraction that has already been converted at the start of the forecast (2000). Like other conventional oil resources, speculative resources expand over time due to reserve growth. The conversion rates are scaled to account for the resource expansion.

${ }^{9}$ The stocks of proved reserves, estimated additional reserves, and speculative resources are not fixed, but are augmented by additions from the reserve expansion resource category. The sum of the four categories is fixed, however. 
All three types of conventional resources (proved, estimated additional and speculative) are augmented by reserve growth at a user-specified annual rate. This is intended to represent the combined effects of learning and technological advances on recovery rates. Reserve growth, however, does not appear out of thin air, but must be withdrawn from category IV resources, comprising "enhanced recovery" in Rogner's data and "reserves growth" in the USGS 2000 study. As long as there are remaining resources in category IV, reserve growth continues at the specified rate. This completes the accounting for conventional resources.

\subsubsection{The Transition to Unconventional Oil}

Just as for conventional oil, proved reserves of unconventional oil are the stock from which all unconventional oil is produced. Additions to proved reserves of unconventional oil, however, are drawn solely from category VI, remaining unconventional resources, using a function that attempts to maintain the target $\mathrm{R} / \mathrm{P}$ ratio for unconventional reserves. No reserve growth is assumed. A logistic function of the deviation of a region's actual $\mathrm{R} / \mathrm{P}$ ratio from the target ratio is used to calculate the fraction of unconventional resources converted to reserves. The logistic function makes the transfer to proved reserves responsive to demand. It is calibrated with userspecified parameters that can be chosen so that a $1 \%$ deviation from the target $\mathrm{R} / \mathrm{P}$ ratio causes approximately a $1 \%$ increase in the flow to unconventional proved reserves. Details can be found in the appendix.

A potential call on unconventional oil is generated when, in any given year, a region is unable to supply from its conventional oil reserves the oil production specified by a scenario. When this occurs, an oil production deficit is created for that region in that year. Conventional oil production deficits are summed over all regions to obtain a global conventional oil production deficit for the year. The global oil production deficit could be satisfied by either conventional oil from other regions or unconventional oil. Initially, the entire deficit is allocated to unconventional oil and shared to regions according to each region's share of unconventional recoverable reserves (remaining resources are not considered in allocating the current year deficit). The final division between conventional and unconventional oil, as well as each region's output, is determined in the oil market model, based on supply costs. If unconventional oil is expensive, the deficit will shift back towards less expensive conventional oil produced in regions with larger, cheaper conventional oil reserves. Whereas Middle East conventional production is exogenous, either following the initial global energy scenario or specified by the model user (this follows Cavallo's (2002) method), Middle East production of unconventional oil is endogenous.

If world resources of even unconventional oil are inadequate the price of oil will rise until supply equals demand. At present there is no "backstop" energy source beyond unconventional oil. As will be seen below, this becomes a serious constraint in model runs using the "pessimistic" resource estimates.

\subsection{WORLD OIL MARKET MODEL: LONG-RUN DYNAMICS}

The purpose of simulating world oil market dynamics is not to predict future oil prices or to change a scenario's patterns of supply and demand. Rather, it is to simulate the transition from 
conventional to unconventional oil with sensitivity to the assumed costs of producing the two categories of oil. Conventional oil production costs over the next 50 years are uncertain enough; the cost of producing unconventional oil decades in the future is still more uncertain.

\subsubsection{Simulating a Transition to Unconventional Oil}

In addition to producing an initial estimate of how much of each region's oil supply will come from conventional versus unconventional oil, the resource accounting model also calculates the state of depletion (\%) for each region's ultimate resources of conventional and unconventional oil. Logistic depletion/cost curves are used to predict the cost of producing conventional and unconventional oil in each region as a function of the fraction of each region's ultimate resources that have already been consumed. Each cost-quantity pair is assumed to be a point on a regional supply curve. In the World Oil Market model, regional short-run supply curves are calibrated based on these points and: (1) an assumed elasticity of supply, (2) an assumed rate at which supply adjusts to price changes, and (3) last year's production. Given the regional supply curves, it is possible to calculate the world oil market price that exactly satisfies the scenario's total world oil demand. This world oil price plus each region's scenario oil use is assumed to be a point on the regional demand curve. Short-run regional demand curves can then be calibrated given: (1) a user-supplied price elasticity, (2) and assumed adjustment rate, and (3) last year's oil consumption. The World Oil Market model then calculates a market equilibrium solution that determines which regions supply how much conventional and unconventional oil at each year's world oil price.

Logistic depletion/cost curves ${ }^{10}$ estimate the long-run marginal cost of discovering, producing and delivering a barrel of oil to the market as a function of the fraction of a region's ultimate resources that have already been produced (Figure 6). The denominator of this fraction is not merely proved reserves, but the sum of all categories of conventional resources, including what has already been produced. For conventional oil, all regions are assumed to have the same slope parameter while the heights of regional curves at a given percent depletion are allowed to vary (see appendix for details). For calculating the depletion of unconventional oil all category $\mathrm{V}$ and VI resources are counted. Two unconventional oil depletion cost curves are assumed: one for regions dominated by oil sands/heavy oil and another for oil shale dominated regions (Figure 5). These are calibrated to user-specified initial production costs and the world unconventional oil depletion status in 2000 (about 1\%). The heights of all three types of curves (conventional oil, oil sands + heavy oil, shale oil) are allowed to decline over time at different user-specified rates, representing the effect of technological progress on the costs of exploration and development. Thus, it is possible for costs of production to rise, fall or remain constant as oil resources are depleted. The use of these curves is admittedly a severe simplification of the economics of longrun regional oil supply. It might be possible to improve on this formulation in future research.

The Middle East and North Africa (MEA) region, comprised chiefly of OPEC members, is not represented by a supply function. Instead, its supply of conventional oil is treated as exogenous. MEA oil supply is initially set by the scenario but can be changed by the model user. For the risk analysis simulations, the user may supply a probability distribution of annual rates of growth in MEA conventional oil supply.

${ }^{10}$ The use of these curves and their functional form follow Rogner (1997). 
Oil demands, as well as conventional and unconventional supplies, by region, are equilibrated at a single world market price in the oil market model. Because the supply functions have been calibrated to different regional production costs, the equilibrium world price will shift supply between unconventional and conventional oil resources and among regions. If the depletion cost of unconventional oil from a region is high in comparison with the cost of conventional oil from other regions, the Oil Market Model will shift supply from regions with high-cost unconventional oil to other regions with more ample conventional oil reserves. On the other hand if conventional oil becomes so depleted that it is expensive relative to unconventional oil, production of unconventional oil will be increased.

Figure 6.

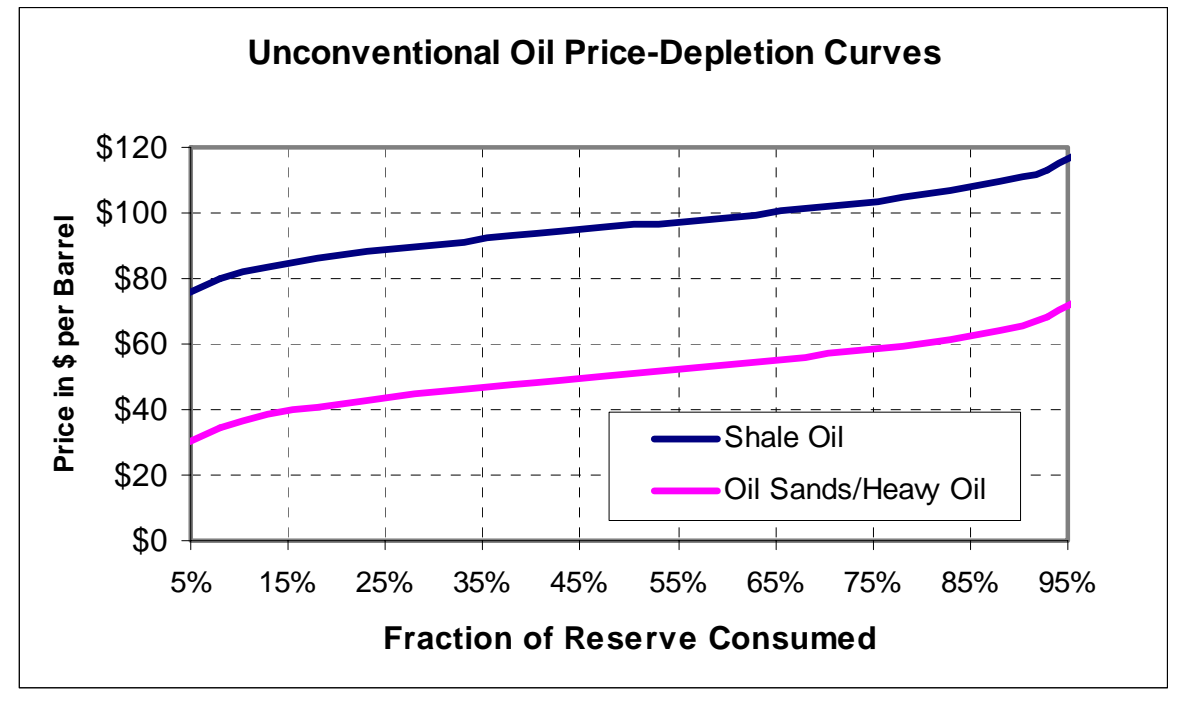




\section{SCENARIOS OF WORLD ENERGY SUPPLY AND DEMAND}

The purpose of the WESM model is to combine estimates of world oil resources that reasonably bound our current understanding of their extent with alternative scenarios of world energy use, in order to explore the times and rates of possible transitions from conventional to unconventional oil resources. Sources of world conventional and unconventional oil resource estimates have been reviewed above. World energy use and supply scenarios were taken from the IIASA/WEC study, Global Energy Perspectives, (Nakićenović et al., 1998) and from forecasts of international energy use to 2020 by the U.S. Energy Information Administration (U.S. DOE/EIA, 2002).

\subsection{DESCRIPTIONS OF SCENARIOS}

Two IIASA/WEC scenarios are used here: (1) Case A1, a variant of the "high growth" scenario in which "technological change focuses on tapping the vast potential of conventional and unconventional oil and gas occurrences" (Nakićenović et al., 1998, p. 8), and (2) Case C1, a variant of the "ecologically driven" scenario in which unprecedented international cooperation to protect the environment results in large increases in energy efficiency and renewable energy use, but little adoption of nuclear energy. While these scenarios were developed all the way to 2100 , only the portions up to 2050 are used here.

In both scenarios, world population grows from 5.3 billion in 1990 to 10.1 billion by 2050 (Table 6). ${ }^{11}$ Gross world product (GWP) increases from \$20 trillion (1990 US\$) in 1990 to $\$ 100$ trillion in the high growth A scenario, and to $\$ 75$ trillion in the ecologically driven $\mathrm{C}$ scenario. Largely due to significant declines in the energy intensity of GWP, total world primary energy use increases from 9 Gtoe to 25 Gtoe in the A scenario and from 9 to 14 Gtoe in the C scenario. Much of this growth occurs in the world's developing regions. Both scenarios assume substantial decreases in the energy intensity of GWP: $-0.9 \% / \mathrm{yr}$. for A and $-1.4 \% / \mathrm{yr}$. for C. A variant of this scenario considered below reduces the annual rate of energy intensity decline in the A1 scenario by 0.3 percent versus the IIASA/WEC assumptions, to $-0.6 \% / \mathrm{yr}$. Oil use grows at a slightly slower rate than total energy in the $\mathrm{A}$ scenario, and in the $\mathrm{C}$ scenario oil use increases modestly, then falls back to its 1990 level by 2050. All but one of the five scenarios examined below are based on the IIASA/WEC A1 scenario.

Developed from a base of 1990, the IIASA/WEC scenarios are already somewhat out of sync with actual year 2000 energy consumption and production. This is particularly true of the $\mathrm{C} 1$ scenario, but even the A1 scenario anticipated much lower petroleum use than has actually transpired, especially in North America. To calibrate the scenarios to actual 2000 data, and in order to substitute a more "conventional" view of the evolution of world energy markets through 2020, the scenarios were adjusted to match U.S. Energy Information Administration Annual Energy Outlook 2002 forecasts to 2020. The A1 scenario most closely resembled the AEO 2002 Reference Case, and so was calibrated to that projection through 2020. The C1 scenario was calibrated to the AEO 2002 "Low Growth" projection. After 2020, a splining method (see

\footnotetext{
${ }^{11}$ Since the IIASA/WEC study was completed, the UN has revised its population projections downwards to 8.9 billion in 2050 as a medium estimate and 10.6 billion as a high estimate.
} 
appendix for details) was used to trend the projections back towards the appropriate IIASA/WEC scenario.

Table 6. IIASA/WEC Global Energy Scenarios

\begin{tabular}{|c|c|c|}
\hline & High Growth A & Ecologically Driven C \\
\hline \multicolumn{3}{|l|}{ Population (billions) } \\
\hline 1990 & 5.3 & 5.3 \\
\hline 2050 & 10.1 & 10.1 \\
\hline \multicolumn{3}{|l|}{ Gross World Product (trillion 1990 US\$) } \\
\hline 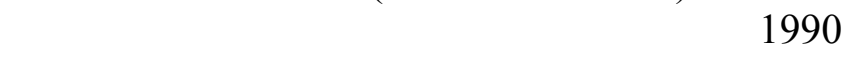 & 20 & 20 \\
\hline 2050 & 100 & 75 \\
\hline \multicolumn{3}{|l|}{ Primary energy intensity improvement (\%/year) } \\
\hline 1990 to 2050 & $-0.9 \%$ & $-1.4 \%$ \\
\hline \multicolumn{3}{|l|}{ Primary energy demand (Gtoe) } \\
\hline 1990 & 9 & 9 \\
\hline 2050 & 25 & 14 \\
\hline \multicolumn{3}{|l|}{ Oil, primary energy use (Gtoe) } \\
\hline 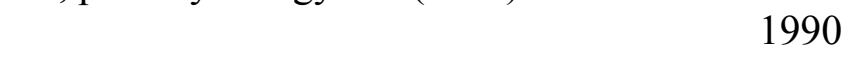 & 3 & 3 \\
\hline 2050 & 8 & 3 \\
\hline
\end{tabular}

Source: Nakićenović et al., 1998, tables 2.1 and 5.1.

In the IEO 2002 Reference Case, world energy use increases from 8.7 Gtoe (350 quads, at 40.4 quads/Gtoe) in 1990, to 9.6 Gtoe in 1999 and 15.4 Gtoe by 2020 (U.S.DOE/EIA, 2002, table A1). In the developing economies energy use increases from 2000-2020 at an average annual rate of 3.7 percent, nearly three times the rate of growth in energy use of industrialized countries over the same period. World oil use increases in the Reference Case at an annual rate of 2.2 percent, about the same as overall energy use. About two thirds of the total world increase in oil use is accounted for by growth in developing country demand.

Even after calibration to the IEO 2002 projection through 2020, oil use in North America is quite low in 2050. According to the IIASA/WEC A1 scenario, North American oil use increases from 834 Mtoe in 1990 to $899(7.8 \%)$ in 2020 and then decreases to 879 Mtoe by 2050. In reality, U.S. petroleum use increased $16 \%$ from 1990 to 2000 . The IEO 2002 Reference projection anticipates a further $35 \%$ increase by 2020 , for an overall increase of $55 \%$ over 1990 . Projecting a decline over the next 30 years to $10 \%$ below the year 2000 level does not seem reasonable for a reference case. For this reason, North American oil use projections based on the Champagne model (NRCan, 2002a; EEA, 1999) have been substituted for the IIASA/WEC scenarios' North American oil use projections (Figure 7) (details are provided in the appendix).

In the Champagne Reference scenario (NRCan, 2002b), transportation energy use in North America increases from 0.78 Gtoe in 2000 to 1.74 Gtoe in 2050 , an average annual rate of $1.6 \%$ for the entire period (Figure 8). In the Reference Scenario, North American Transportation remains almost entirely dependent on petroleum. The Go Your Own Way (GYOW) scenario, which is used in conjunction with the IIASA/WEC C scenario, reflects substantial efficiency gains and a moderate amount of fuel switching (Figure 8). Total transportation energy use increases to only 1.09 Gtoe, and the average annual rate is $0.7 \% / y r$. (although energy use first 
increases, then decreases, then increases again). Biofuels and hydrogen make significant inroads by 2050 , accounting for $12 \%$ and $13 \%$ of total transportation energy use.

Figure 7.

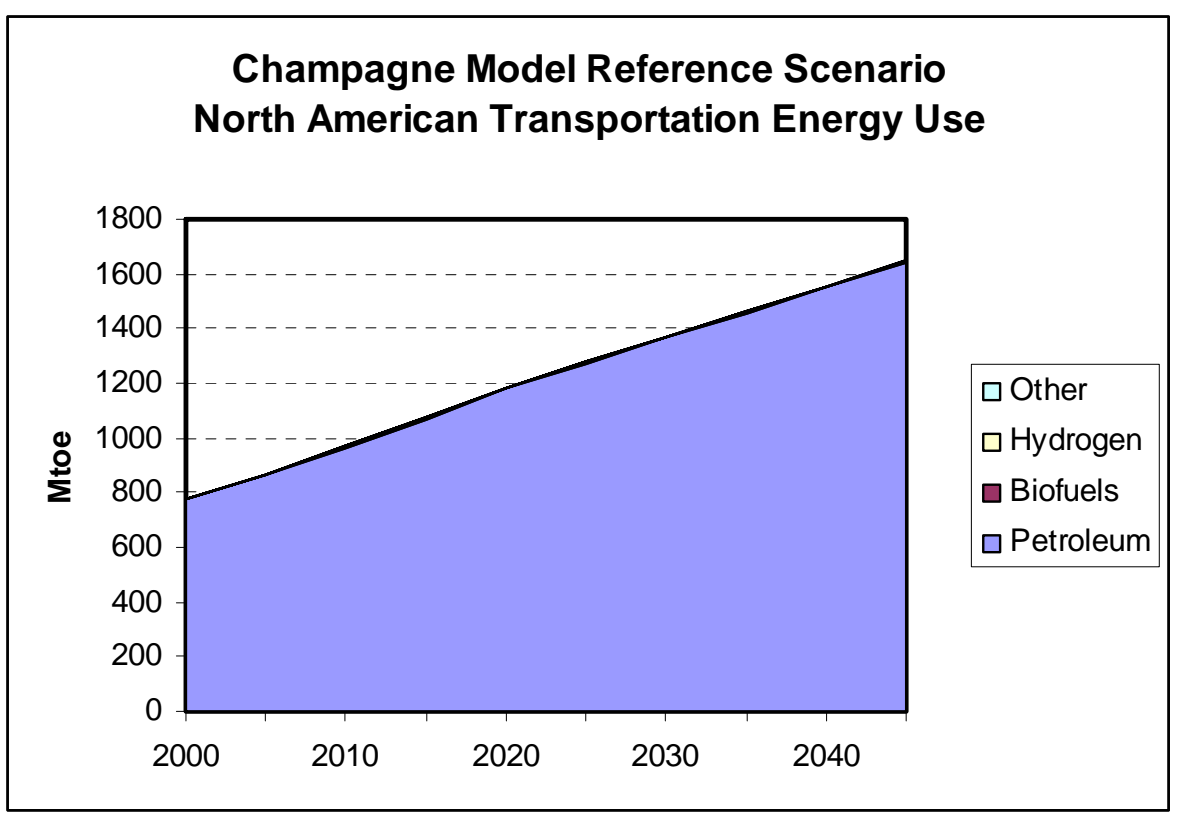

Figure 8.

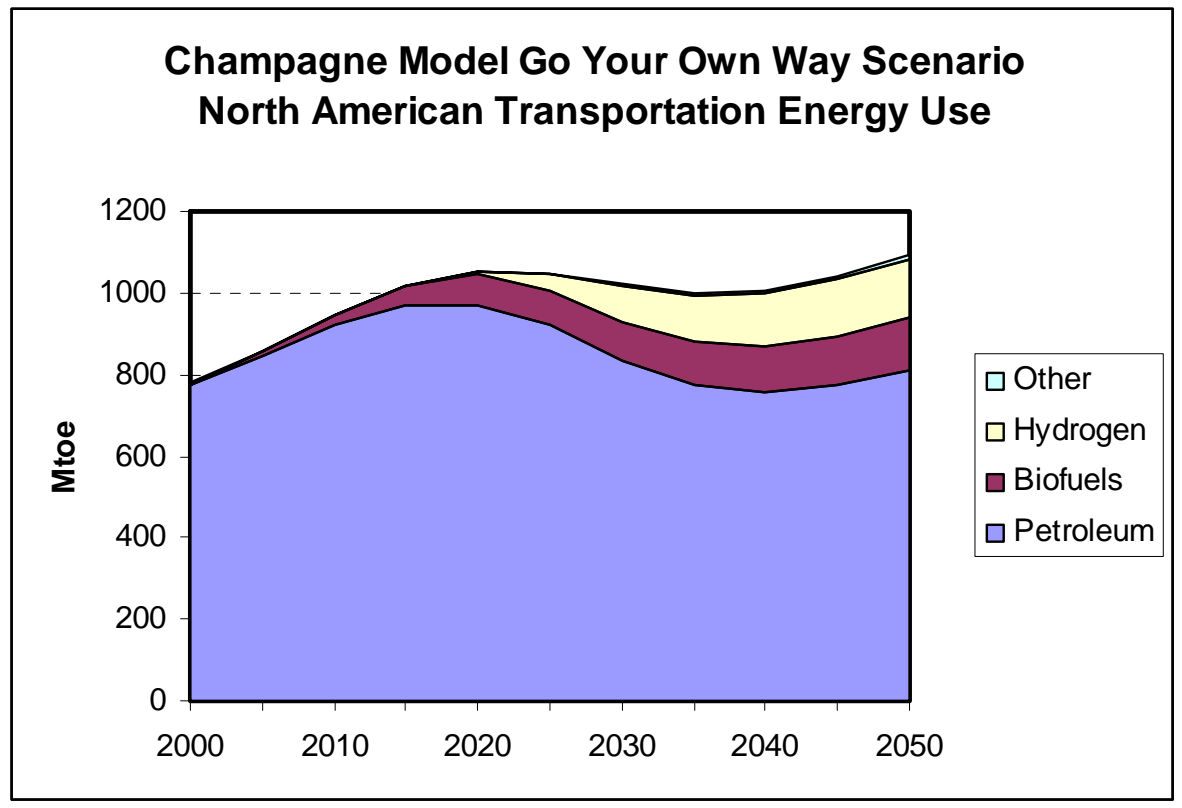

The patterns of energy production from 2000 to 2050 in the modified scenarios (IIASA/WEC scenarios adjusted to the IEO 2002 projections and, for North America adjusted to Champagne model projections) are shown in Figure 9a for the Reference Scenario (IIASA/WEC A1, IEO 2002 Reference Case, Champagne Reference Case). Total world energy production grows from 10.6 Gtoe in 2000 to 25.7 Gtoe by 2050 . World oil production increases from 3.95 Gtoe in 2000 to 9.48 Gtoe in 2050. Natural gas production peaks in 2030 at 5.6 Gtoe and remains relatively 
flat thereafter. Most of the difference is accounted for by rapid growth in nuclear energy production, which remains relatively constant at 0.7 Gtoe through 2020 and then expands rapidly to 2.6 Gtoe by 2050 .

Primary energy use by region is shown in Figure 9b. Total world energy use grows from 9.8 Gtoe in 2000 to 15.1 Gtoe by 2020 and to 25.2 Gtoe in 2050. Growth in primary energy use in the developed economies increases at an average annual rate of only $1 \%$ over the fifty year period. The majority of increase in energy use comes from the developing economies, which experience a $2.7 \%$ annual average growth rate. This same pattern is reflected in the growth of oil consumption across regions shown in Figure 9c. Increases in the OECD outside of the United States and Canada are modest $(1.1 \% / \mathrm{yr}$.), while in the developing world oil use increases at $2.6 \% / y r$. for an overall world growth rate of $1.9 \% / y r$. The effect of splining the IEO 2002 and IIASA/WEC projections can be seen in Figure 9c. The IEO growth rate is higher through 2020, there is a transition period from 2020 to 2030, and beyond 2030 the original IIASA/WEC path is followed.

Figures 9a, 9b \& 9c
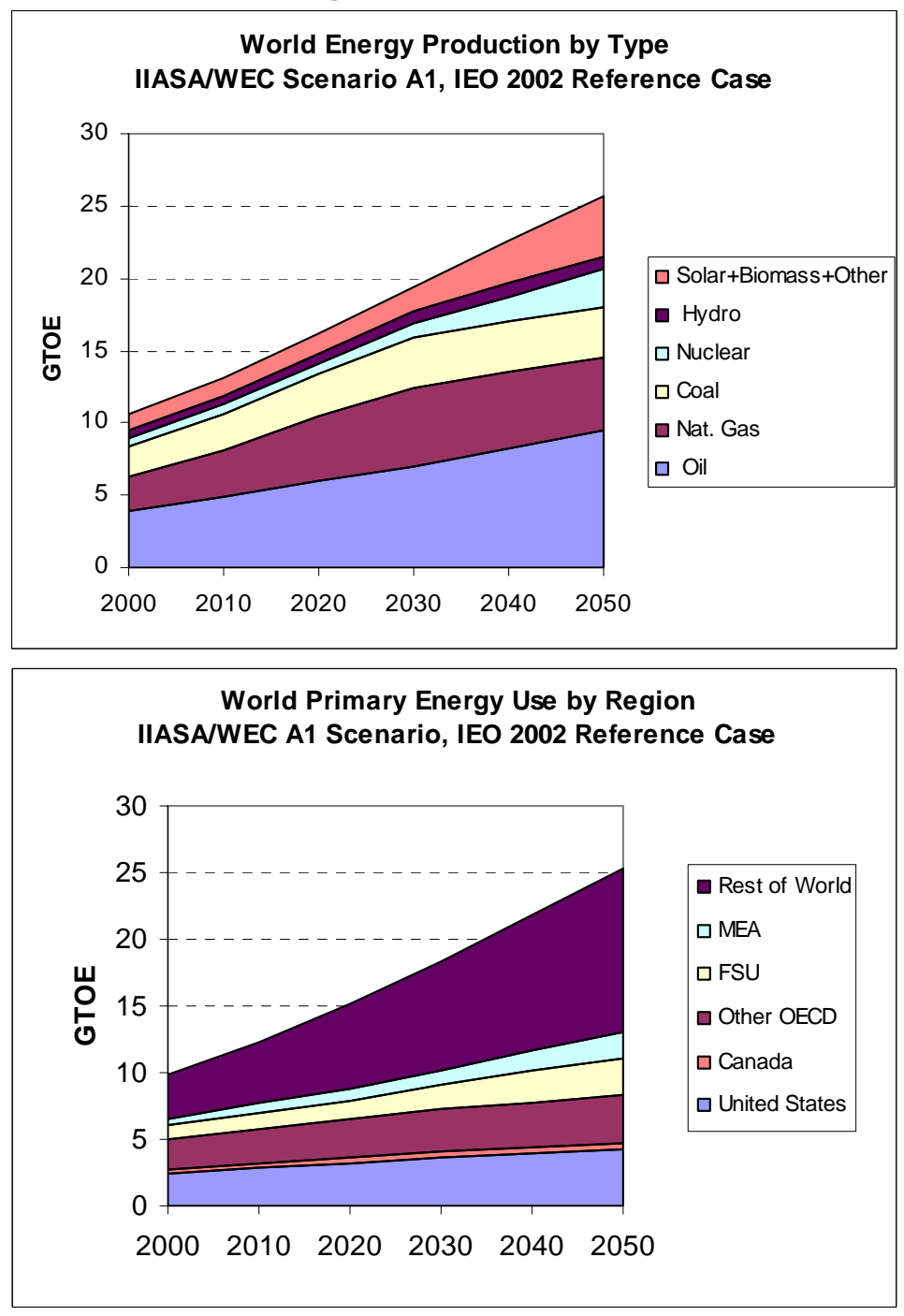


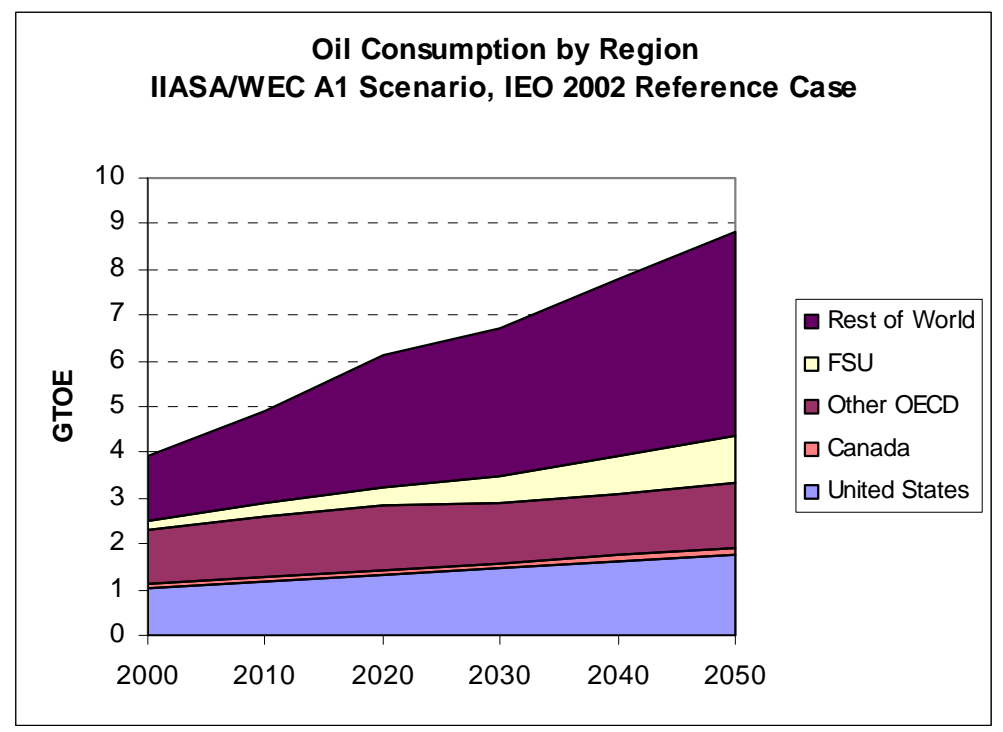

Both energy and oil use are much lower in the scenario based on IIASA/WEC's ecologically driven $\mathrm{C} 1$ scenario. Global energy production increases at an average annual rate of $0.8 \%$ over the fifty-year period, from 10.7 Gtoe in 2000 to 15.9 Gtoe in 2050 (Figure 10a). During the last 20 years, the average annual growth rate is only $0.14 \%$. Reflecting the ecological theme of this scenario, coal and oil use initially increase gradually, then begin a steady decline after 2020. World oil production in 2050 is only 0.3 Gtoe higher than in 2000 . Natural gas production increases through 2030, then holds constant as renewable energy expands rapidly.

For OECD countries, 2050 primary energy use is lower than 2000, reflecting aggressive efficiency improvements and conservation (Figure 10b). Energy use in developing countries and the Middle East expands, but at a slower rate than in the A1 scenario: 1.8\%/yr. Still, in 2050 countries outside of the OECD and Former Soviet Union account for 9.6 out of 15.7 Gtoe of world primary energy use. World oil use peaks in 2020 (a consequence of the IEO 2002 projection) and declines rapidly thereafter (Figure 10c). The most rapid decline takes place in the OECD countries outside of the United States and Canada. North American oil use is influenced by the Champagne model projection but is not identical to it because transportation is not the only oil consumer. Given the path of world primary oil use, it is a foregone conclusion that not only conventional but total world oil production will peak by 2020 in this scenario. There is still the possibility that conventional oil production, especially outside of the Middle East, might peak before 2020 and this is explored below. 
Figures 10a, 10b \& 10c
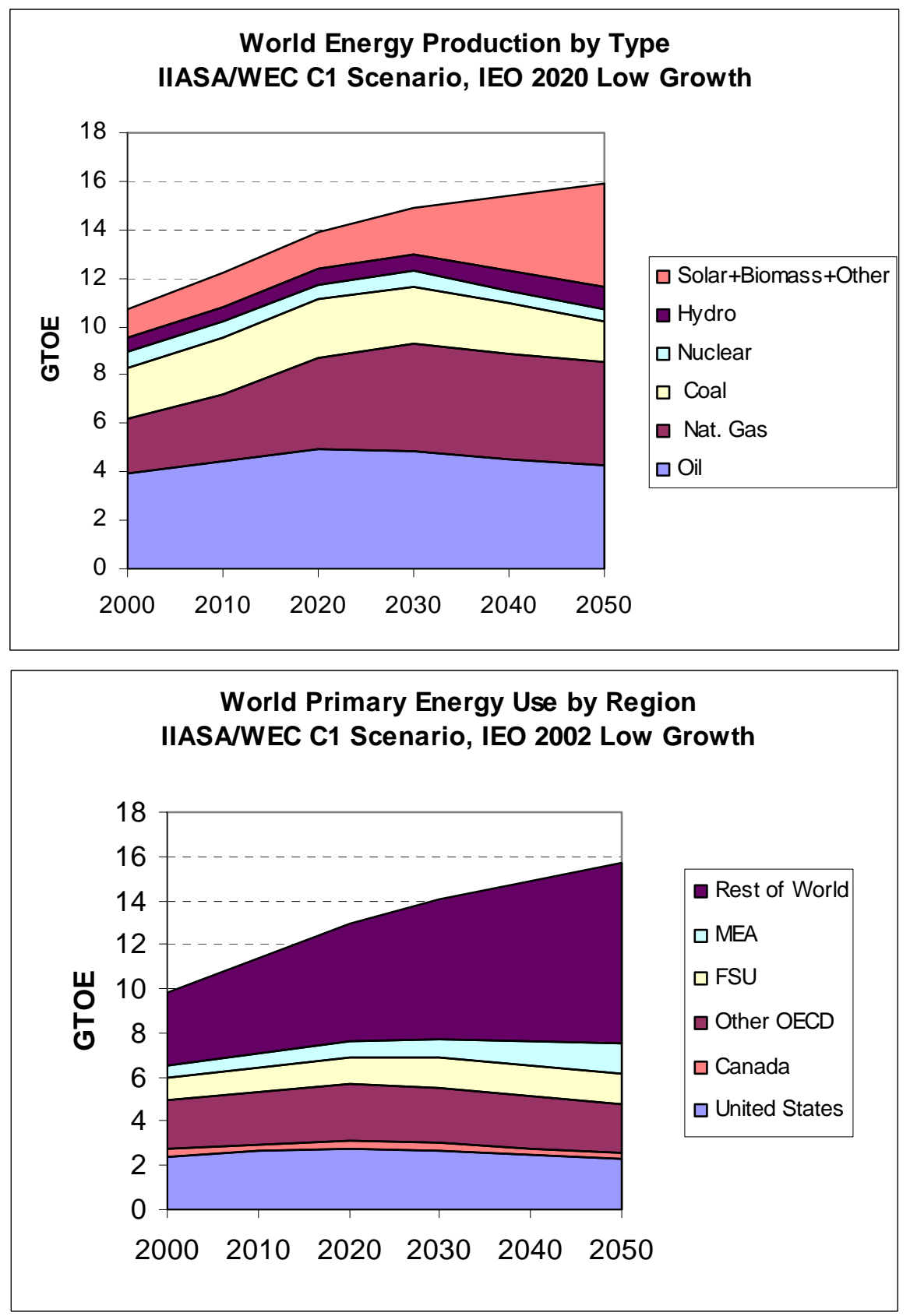


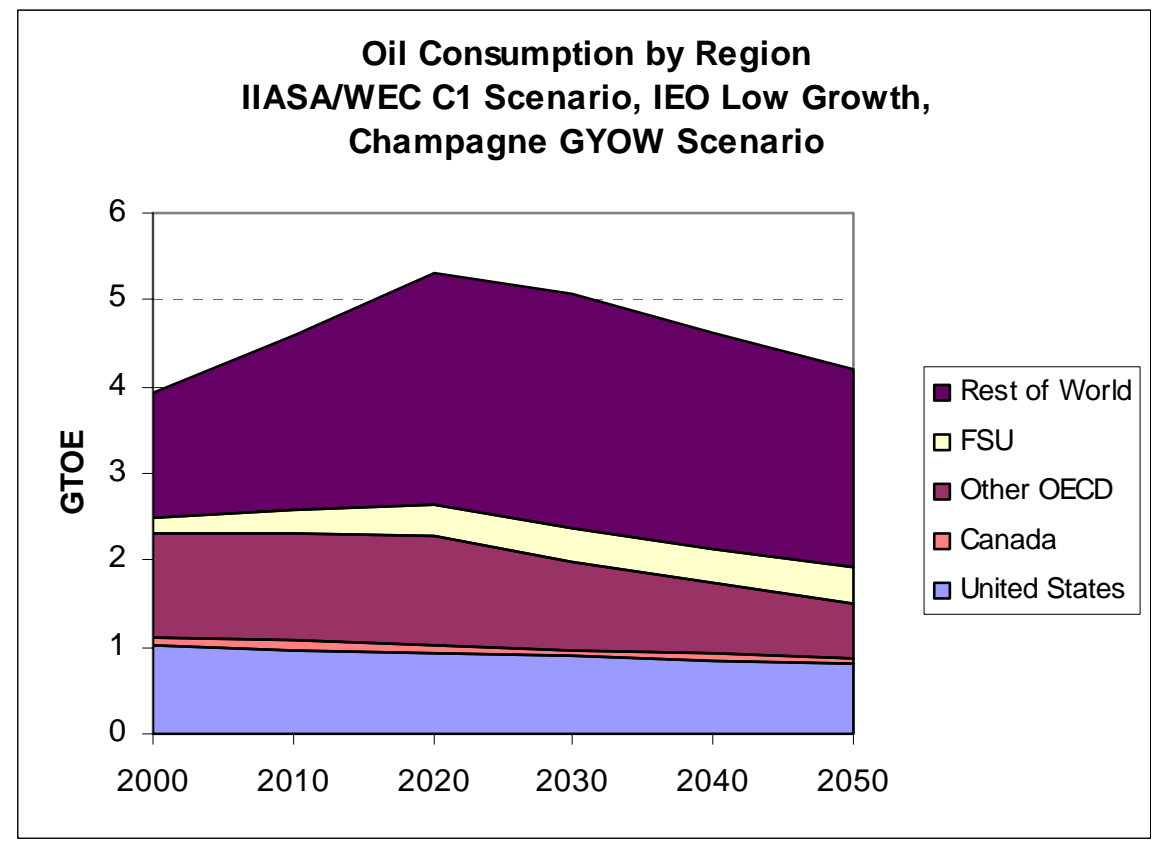

\subsection{RISK ANALYSES AND KEY PARAMETERS}

Risk analyses were conducted for six world energy and oil resource scenarios, as described in Table 7. The six scenarios test the three alternative sets of conventional and unconventional oil resources against a reference world energy scenario, then test somewhat higher and radically lower energy scenarios against the resource estimates based on the USGS 2000 assessment, and finally examine the implications of a pessimistic assessment of world oil resources in the low energy use scenario. The first three scenarios are based on the IIASA A1 scenario (A), the IEO 2002 Reference Case (R), and the Champagne Model Reference Case (R). They differ according to which oil resource estimates are used: those based on USGS 2000 (U), Rogner (R), or Campbell (C). Combining the letter symbols provides an acronym for each scenario (Table 7). The fourth scenario (AHRU) reflects higher growth in energy use: (1) the A1 scenario's annual rate of decrease in energy use per dollar of GDP is reduced to $0.6 \% / \mathrm{yr}$. from $0.9 \% / \mathrm{yr}$., and (2) the IEO High Economic Growth projection is substituted for the Reference projection. The fifth (CLGU) reflects low growth in energy use combined with the USGS resource estimates; the sixth (CLGC) substitutes oil resource estimates based on Campbell for those based on the USGS 2000 .

Table 7. Descriptions of Five World Oil Transition Scenarios

\begin{tabular}{|c|c|c|c|c|c|}
\hline $\begin{array}{l}\text { Scenario } \\
\text { Acronym }\end{array}$ & $\begin{array}{c}\text { IIASA/WEC } \\
\text { Global Energy } \\
\text { Scenario }\end{array}$ & $\begin{array}{c}\text { IEO } 2002 \\
\text { Projection to } \\
2020 \\
\end{array}$ & $\begin{array}{c}\text { Champagne Model } \\
\text { Projection }\end{array}$ & $\begin{array}{c}\text { Conventional Oil } \\
\text { Resource } \\
\text { Estimate Source }\end{array}$ & $\begin{array}{c}\text { Unconventional } \\
\text { Resource } \\
\text { Estimate }\end{array}$ \\
\hline ARRU (1) & A1 & Reference & Reference & USGS & USGS/WEC/IEA \\
\hline $\operatorname{ARRR}(2)$ & A1 & Reference & Reference & Rogner & Rogner \\
\hline ARRC (3) & A1 & Reference & Reference & Campbell & Campbell \\
\hline AHRU (4) & A1 & High Growth & Reference & USGS & USGS/WEC/IEA \\
\hline CLGU (5) & $\mathrm{C} 1$ & Low Growth & Go Your Own Way & USGS & USGS/WEC/IEA \\
\hline CLGC (6) & $\mathrm{C} 1$ & Low Growth & Go Your Own Way & Campbell & Campbell \\
\hline
\end{tabular}


Uncertainties about the quantity of oil remaining to be developed, future oil demand, rates of technological progress and other factors imply that there should also be uncertainty about the timing of the peaking of conventional oil production and the rate of transition to unconventional resources. Given a single set of values for all parameters, the WESM model will calculate paths of conventional and unconventional oil production and depletion for each of the twelve regions. Methods of risk analysis allow key parameter values, about which there is substantial uncertainty, to be specified as probability distributions rather than single point estimates. Risk analysis software can execute the WESM model hundreds to thousands of times, each time drawing a random sample of parameter values from the specified probability distributions. ${ }^{12}$ This simulation process produces a frequency distribution rather than single point estimates of selected output variables. In this study, distributions are calculated for the years in which world conventional oil production peaks, and the year in which oil production outside of the Middle East and Northern Africa peaks, as well as the volumes of oil produced at peak production.

The simulation procedure produces a database of outcomes and parameter assumptions that can be analyzed to determine which parameters have the greatest impact on the output variables. Stepwise regression is used to determine which parameters significantly influence the year in which oil production will peak, and to estimate the impacts of each significant determinant. The results of this analysis are summarized in the form of "tornado charts" that represent the impacts by bars, with the parameters ordered by the magnitude of their impacts.

The probability distributions used for fourteen key parameters are shown in Table 8. Although a wide range of probability distributions could have been used, in every case the parameters are assumed to follow the uniform distribution. In the absence of information about the form of the distributions of these parameters, the uniform distribution was chosen because it is the simplest. However, it gives greater weight to extreme values than most other distribution functions. The assumptions for each parameter are briefly reviewed below.

\subsubsection{Growth rate of Middle East Production}

Because Middle East conventional oil production is exogenous to WESM it can be varied but the impact of varying Middle East production must be interpreted with caution. In each scenario, supply from other regions as well as world demand are consistent with the path of Middle East production specified by the underlying world energy scenario. Changing Middle East production forces demand and supplies from other regions to adjust, but they will adjust from the scenario values to which they have been calibrated. As a result, changing Middle East production does not produce a new long-run equilibrium energy supply and demand scenario consistent with the new Middle East path; rather it produces an adjustment of demand and non-Middle East supply to an unexpected change in Middle East supply. Thus, large deviations from a scenario's assumed Middle East production levels are likely to produce inconsistent results.

In the $\mathrm{C} 1$ scenario adjusted to the IEO 2002 Low Economic Growth projection, Middle East oil production grows at an average annual rate of $1.5 \% / y$. from 2000 to 2050 . In the A1 scenario adjusted to the IEO 2002 Reference projection, Middle East production increases at an average annual rate of $2.4 \%$. Analyzing the most profitable strategies for OPEC over the next 20 years,

${ }^{12}$ The simulations were carried out using the @ Risk ${ }^{\mathrm{TM}}$ software. @ Risk offers two sampling options: Monte Carlo and Latin Square. The Latin Square method was used in all the simulations reported here. Also, the automatic convergence option was chosen. As a result, the number of samples will vary across scenarios. 
Gately (2002) concludes that OPEC is not likely to expand output at a faster rate than $2 \% / y$ r. Historically, production from the Persian Gulf region increased at an average annual rate of 11\% from 1960 to 1973, but since the first oil price shock Persian Gulf oil output has actually declined. The average annual rate of decline is $-0.5 \% / \mathrm{yr}$. but the path has been anything but smooth. Simulations based on the USGS 2000 data show that if MEA increases production at a rate much greater than $2 \%$ per year, its production will probably become supply constrained by 2050 (that is, a target R/P of 15 will become constraining). Thus, a uniform probability distribution over the range $1 \%$ to $2 \%$ per year is used when the USGS and Rogner resource estimates are used. Because ROW production peaks much earlier when Campbell's estimates are used, a wider range of $1 \%$ to $4 \%$ is used with his resource estimates. This also results in an early peaking of MEA oil production, a topic addressed by Bakhtiari (2003), e.g., using similar data.

Table 8. Distribution Parameters for Depletion/Transition Risk Analysis

\begin{tabular}{|c|c|c|c|}
\hline \multirow[t]{2}{*}{ Parameter } & \multicolumn{3}{|c|}{ Uniform Distribution Parameters } \\
\hline & USGS & Rogner & Campbell \\
\hline $\begin{array}{l}\text { Growth rate of Middle East production } \\
\text { A1 high growth scenarios } \\
\text { C1 low growth scenarios }\end{array}$ & $\begin{array}{l}(0.01,0.02) \\
(-0.01,0.01)\end{array}$ & $\begin{array}{c}(0.01,0.02) \\
-\end{array}$ & $\begin{array}{c}(0.01,0.04) \\
-\end{array}$ \\
\hline $\begin{array}{l}\text { Technological change affecting cost* } \\
\text { Conventional oil } \\
\text { Heavy oil \& bitumen } \\
\text { Shale oil }\end{array}$ & $\begin{array}{c}(-0.006,-0.002) \\
(-0.01,-0.004) \\
(-0.015,-0.005)\end{array}$ & $\begin{array}{c}(-0.006,-0.002) \\
(-0.01,-0.004) \\
(-0.015,-0.005)\end{array}$ & $\begin{array}{c}(-0.006,-0.002) \\
(-0.01,-0.004) \\
(-0.015,-0.005)\end{array}$ \\
\hline $\begin{array}{l}\text { Base prices } \\
\text { Conventional oil } \\
\text { Heavy oil \& bitumen } \\
\text { Shale oil }\end{array}$ & $\begin{array}{c}\$ 20 / \mathrm{bbl} \\
(\$ 15, \$ 25) \\
(\$ 40, \$ 90)\end{array}$ & $\begin{array}{c}\$ 20 / \mathrm{bbl} \\
(\$ 15, \$ 25) \\
(\$ 40, \$ 90)\end{array}$ & $\begin{array}{c}\$ 20 / \mathrm{bbl} \\
(\$ 15, \$ 25) \\
(\$ 40, \$ 90)\end{array}$ \\
\hline Recovery/reserve expansion & $(0.002,0.008)$ & $(0.005,0.015)$ & $(0.002,0.008)$ \\
\hline $\begin{array}{l}\text { Speculative resources parameters } \\
\text { Fraction available } \\
\text { Year of peak conversion }\end{array}$ & $\begin{array}{l}(0.05,0.95) \\
(2015,2025)\end{array}$ & $\begin{array}{c}(0.05,0.95) \\
(2015,2025)\end{array}$ & $\begin{array}{l}\text { N.A. } \\
\text { N.A. }\end{array}$ \\
\hline Target $\mathrm{R} / \mathrm{P}$ ratio & $(10,20)$ & $(10,20)$ & $(10,20)$ \\
\hline $\begin{array}{l}\text { Alpha (unconv. resource to unconv. } \\
\text { reserve conversion rate parameter) }\end{array}$ & $(-150,-50)$ & $(-150,-50)$ & $(-150,-50)$ \\
\hline $\begin{array}{l}\text { Supply and demand parameters } \\
\text { Short run demand elasticity } \\
\text { Short run supply elasticity } \\
\text { Adjustment rate }\end{array}$ & $\begin{array}{c}(-0.08,-0.04) \\
(0.04,0.08) \\
(0.85,0.95)\end{array}$ & $\begin{array}{c}(-0.08,-0.04) \\
(0.04,0.08) \\
(0.85,0.95)\end{array}$ & $\begin{array}{c}(-0.08,-0.04) \\
(0.04,0.08) \\
(0.85,0.95)\end{array}$ \\
\hline
\end{tabular}

* Technological change parameters are assumed to be correlated 0.5 .

\subsubsection{Technological Change Affecting Cost}

The WESM model allows the user to specify a technology-driven rate of reduction in the costs of oil production that may offset the depletion-driven tendency for increased costs. It is assumed that costs for shale oil production will decrease faster $(-0.5 \% / y$. to $-1.5 \% / y r$. $)$ than costs for oil 
sands production $(-0.4 \% / \mathrm{yr}$. to $-1.0 \% / \mathrm{yr}$.) and that costs of conventional oil production will decrease at the slowest rate $(-0.2 \% / y r$. to $-0.6 \% / y r$. $)$. Note that these are not net rates of decrease but represent the effect of technological change only. They may be partly or entirely offset by cost increases due to resource depletion. Generally speaking, with the exception of oil shale costs, these rates are not sufficient to offset increases in production costs through 2050 due to the effects of depletion.

\subsubsection{Base Year Production Costs of Conventional and Unconventional Oil}

In 2000, the long-run marginal costs per barrel of producing and delivering the three types of oil are assumed to be: conventional oil $\$ 20$, oil sands and heavy oil ( $\$ 15$ to $\$ 25)$, and shale oil ( $\$ 40$ to \$90). This implies that the long-run marginal costs of producing conventional oil (outside of the Middle East) and the median cost of producing oil sands and heavy oil are the same. The state of depletion of conventional oil is far greater, however.

\subsubsection{Reserve Growth Rates}

Reserves are assumed to expand due to reserve growth and enhanced recovery. When the USGS based resource estimates are used, reserves are assumed to grow at between $0.2 \%$ and $0.8 \%$ per year. Reserve growth of 0.5 percent per year is about twice the rate observed in the U.S. lower 48 from 1966-79 (Porter, 1995). When Rogner's data are used a range of 0.5\%/yr. to 1.5\%/yr. is used. A rate of 1 percent per year was considered relatively rapid by Davies and Weston (2000). The cumulative reserve growth, however, cannot exceed the total quantity available in resource category IV. Using the USGS based estimates, a rate of $0.5 \%$ is sufficient to transfer nearly all of oil in category IV to categories I, II and III by 2050. Because Rogner's estimates put significantly more oil in category IV, a higher rate is needed to include the possibility that all category IV oil might be available by 2050.

\subsubsection{Speculative Resource Availability}

Anywhere from 5\% to 95\% of speculative resources are made available when USGS or Rogner's estimates are used. Estimates based on Campbell's data do not include speculative resources. Speculative resources are converted to proved reserves at rates determined by a user-specified normal probability density function. The function is determined by specifying the fraction of speculative resources that have already been converted by the year 2000 and the year in which conversion will peak. Here the peak year has been specified as a uniform distribution over the years 2015 to 2025. In all cases it is assumed that 5\% of speculative resources have been converted to proved reserves by 2000. An alternative formulation worth considering in future analyses would assume that discovery of speculative resources has already peaked and that future discovery rates will decline exponentially.

\subsubsection{Target Reserves-to-Production (R/P) Ratio}

Target R/P ratios between 10 and 20 are allowed. If a region's $1995 \mathrm{R} / \mathrm{P}$ ratio was below the general target ratio, that lower value is used instead. For example, for the USGS based estimates, the United States' $1995 \mathrm{R} / \mathrm{P}$ ratio was 10.9 . 


\subsubsection{Conversion of Unconventional Resources to Reserves}

Unconventional resources are converted to unconventional reserves using a logistic function that depends on the $\mathrm{R} / \mathrm{P}$ ratio for unconventional reserves. As the unconventional $\mathrm{R} / \mathrm{P}$ ratio nears the target $\mathrm{R} / \mathrm{P}$ ratio, conversion accelerates. If the actual $\mathrm{R} / \mathrm{P}$ ratio is 25 and the desired ratio is 20 , an "alpha" value of -100 implies that a $1 \%$ change in the actual $\mathrm{R} / \mathrm{P}$ ratio will cause the rate of conversion to increase by about $1 \%$. Values of alpha range between -150 and -50 .

\subsubsection{Supply and Demand Parameters}

The short-run elasticity of oil demand in all regions is assumed to lie between -0.08 and -0.04 . The lagged adjustment parameter is assumed to lie between 0.85 and 0.95 , implying a range for the long-run elasticity of -1.6 and -0.3 , with a median value of -0.6 . Similarly, the short-run elasticity of supply is assumed to lie between 0.04 and 0.08 , with a lagged adjustment parameter also between 0.85 and 0.95 . 



\section{RESULTS}

Risk analysis simulations were carried out using the @Risk ${ }^{\circledR}$ software package (Pallisade Corp., 2002) for the six scenarios shown in Table 7 using the parameters displayed in Table 8 . The first three use the reference world energy scenarios and test the three alternative estimates of world conventional and unconventional oil resources. The next three scenarios test first higher growth and then lower growth in energy use against the USGS based estimates, followed by lower growth in combination with resource estimates based on Campbell.

\subsection{PEAKING OF CONVENTIONAL OIL PRODUCTION}

The distributions of the peak year of conventional oil production from "rest-of-world" (ROW) countries (outside the Middle East) are shown in Figures 11a, 11b and 11c. The simulation using resource estimates based on the USGS 2000 assessment indicates an expected peak year of about 2023 , with a roughly $10 \%$ probability that the date would be later than 2028 . The simulation results suggest only a 5\% probability that the peak year will occur before 2016, and essentially no chance of non-Middle East conventional oil production peaking before 2010 .

The simulations based on Rogner's estimates indicate a wider range of probable peaking dates for ROW conventional oil production, but a very similar expected peaking date: 2025 . These results suggest a nearly uniform probability for dates between 2013 and 2037 and, unlike the USGS-based estimates, a substantial probability of peaking after 2030 . There appear to be negligible probabilities for peaking dates before 2010 or after 2040.

In sharp contrast, the simulations based on Campbell's data indicate little chance of the peaking date occurring after 2010, and an expected peak production date of 2006. Given Campbell's resource estimates, for the quantities of oil required under the Reference case there is simply not enough conventional oil outside of the Middle East to sustain the growth of consumption for more than 10 years. Campbell (2003) estimates that ROW oil production has already peaked. The estimates presented here differ because Campbell does not include deep water and polar oil as conventional, as is done here. Also, this report's assumptions about the factors limiting oil production rates are more optimistic, as has been pointed out above.

Simulations using the USGS based resource estimates indicate that the peak year for world conventional oil production will be sometime after 2015, but is more likely to occur after 2040 than before (Figure 12a). Given the high relative frequency with which the year 2050 occurs, a post-2050 date must also be a possibility. The expected date is approximately 2040, but this estimate is undoubtedly biased downward by the truncation of the analysis at 2050 .

Substituting Rogner's resource estimates produces a greater certainty of the conventional oil peak occurring before 2050 but a similar expected peaking date: 2038 (Figure 12b). These simulations also indicate almost no chance of a world peak occurring before 2015.

On the other hand, the simulations using resource estimates based on Campbell point to 2015 as the expected date of peak world conventional oil production (Figure 12c). 
Figures 11a, 11b and 11c

Peak Year of ROW Conventional Oil

Production: Reference/USGS

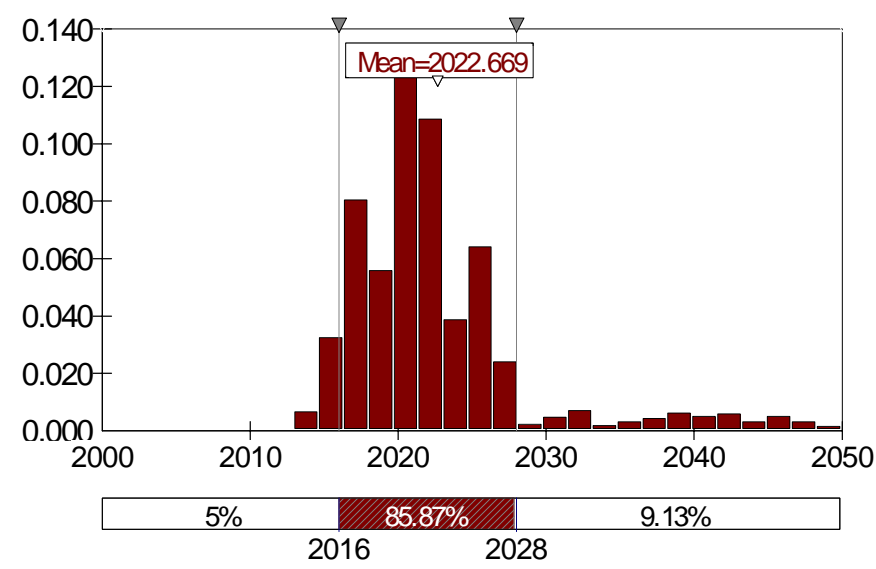

Peak Year of ROW Conventional Oil: Reference/Rogner

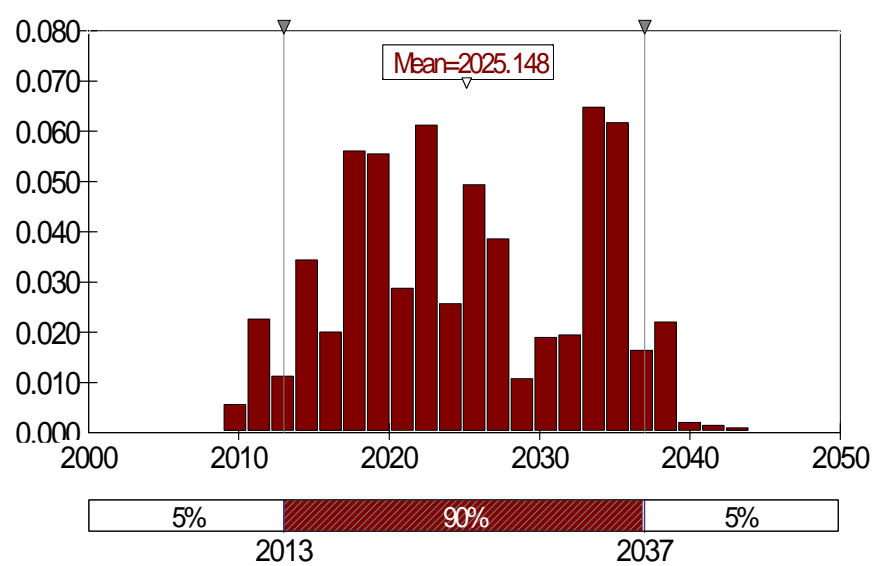

Peak Year of ROW Conventional Oil: Reference/Campbell

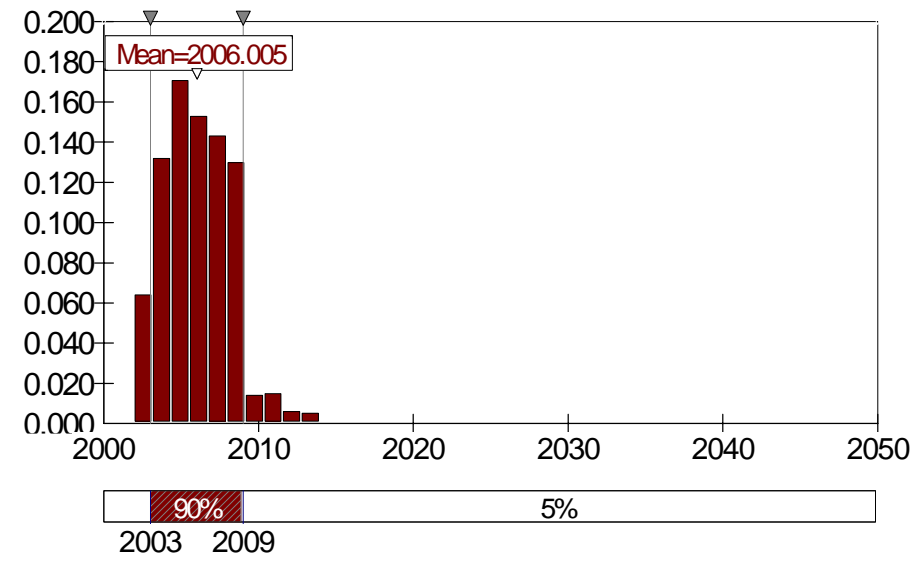


Figures 12a, 12b and 12c

Peak Year for World Conventional Oil:

Reference/USGS

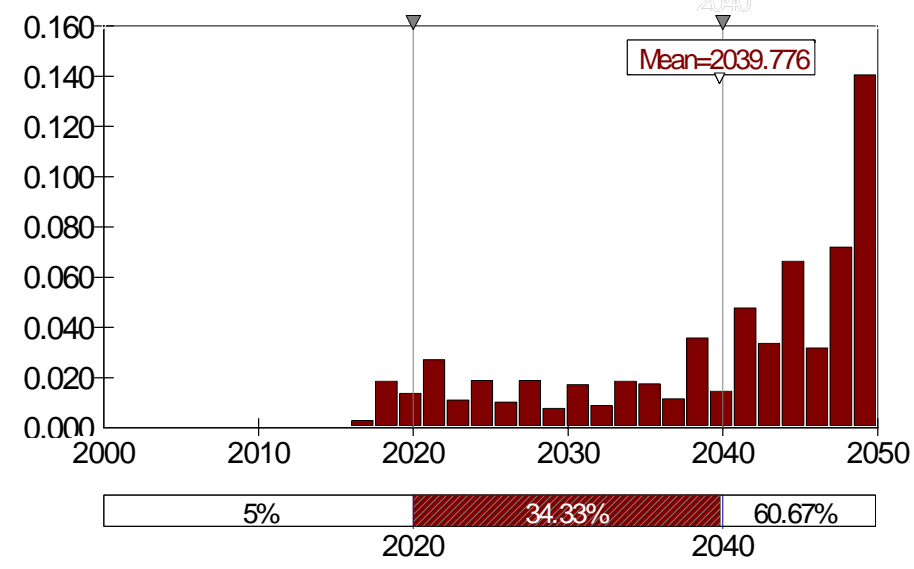

Peak Year for World Conventional Oil:

Reference/Rogner

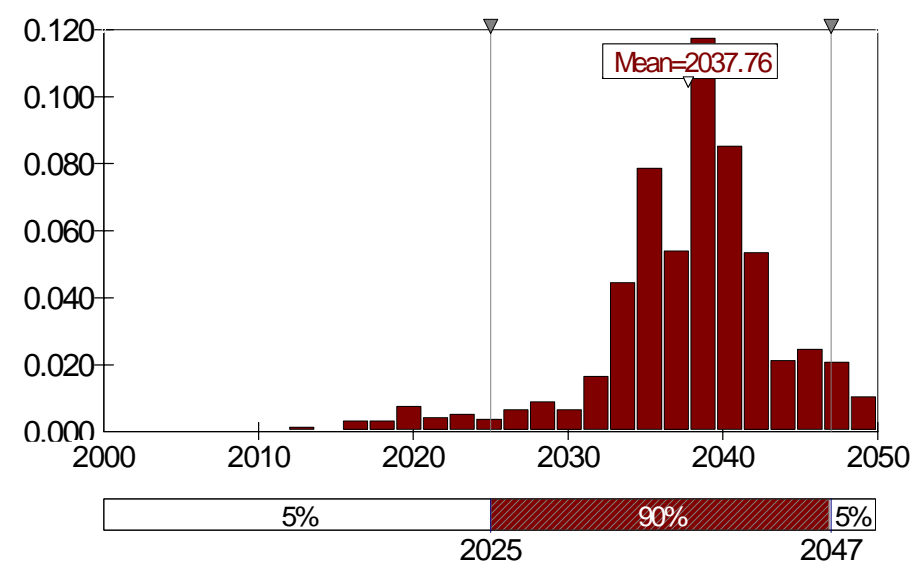

Peak Year for World Conventional Oil: Reference/Campbell

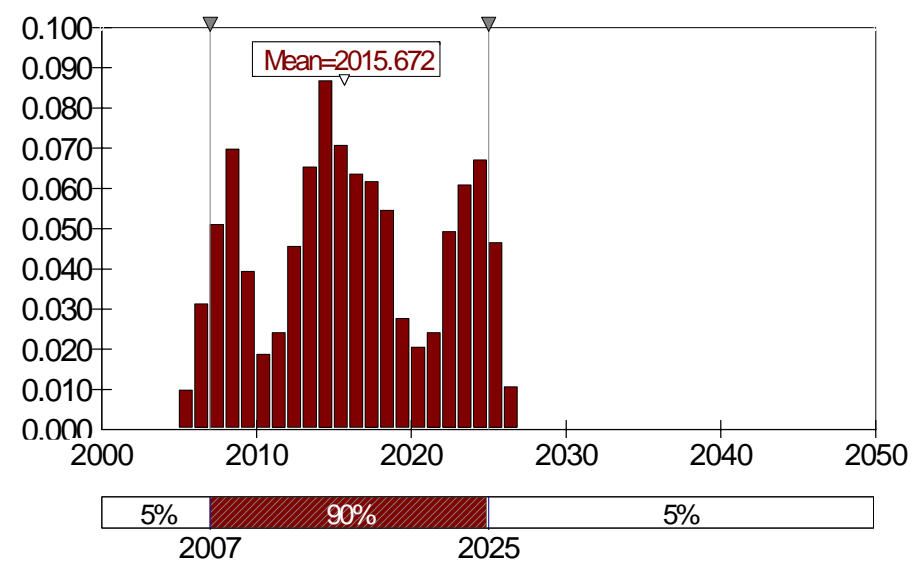




\subsection{SENSITIVITIES OF PEAKING DATES TO KEY PARAMETERS}

Each risk analysis simulation generates on the order of one thousand model runs, each with a different randomly chosen set of parameter values. The resulting database of results has been analyzed by means of stepwise regression to determine which parameters have the greatest influence on conventional oil peaking dates.

For analyses using either the USGS or Rogner based estimates, the fraction of speculative conventional oil resources assumed to exist is the most important determinant of the peaking date for ROW oil production (Figures 13a and 13b). This result quantifies the obvious fact that, all else equal, the more oil there is the later the date of peaking will be. For Rogner's data, the next most important factor is the rate of reserve expansion (growth): again a key determinant of how much oil there will be to develop. For the analysis of USGS based estimates, two technical (alpha) parameters that control how quickly unconventional oil resources can be converted to unconventional reserves are also important. "Alpha pass 1" controls the rate of conversion on the first pass through the Resource Accounting model, "alpha pass 2" controls on the second and final pass. The two effects are opposite in sign and nearly equal in magnitude, suggesting that the net effect of these parameters may be to increase the variance of the peak year distribution but have little impact on the central tendency. The date at which the conversion of speculative resources to proved reserves peaks is also significant, indicating that the timing of development of speculative resources also matters, but not as much as the quantity.

Figure 13a. Sensitivity Analysis for ROW Peak Year: Reference/USGS

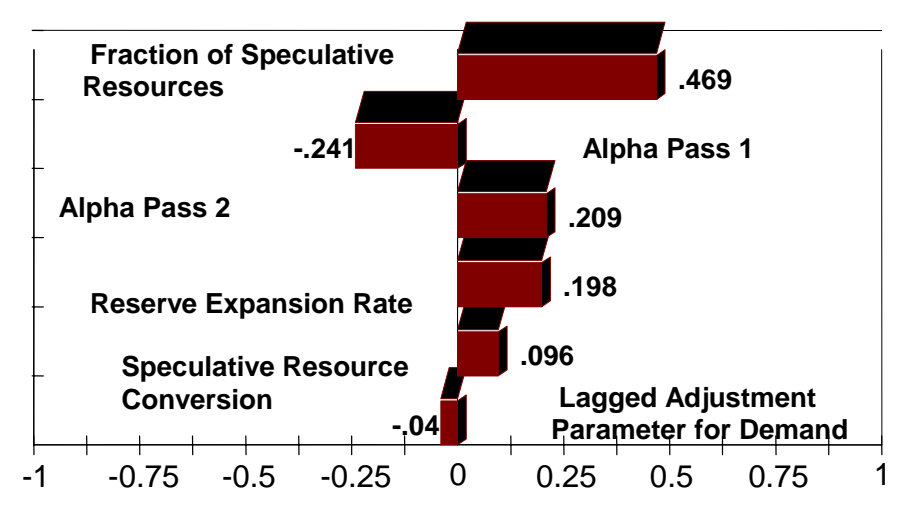

Std b Coefficients 


\section{Figure 13b. Sensitivity Analysis for ROW Peak Year: Reference/Rogner}

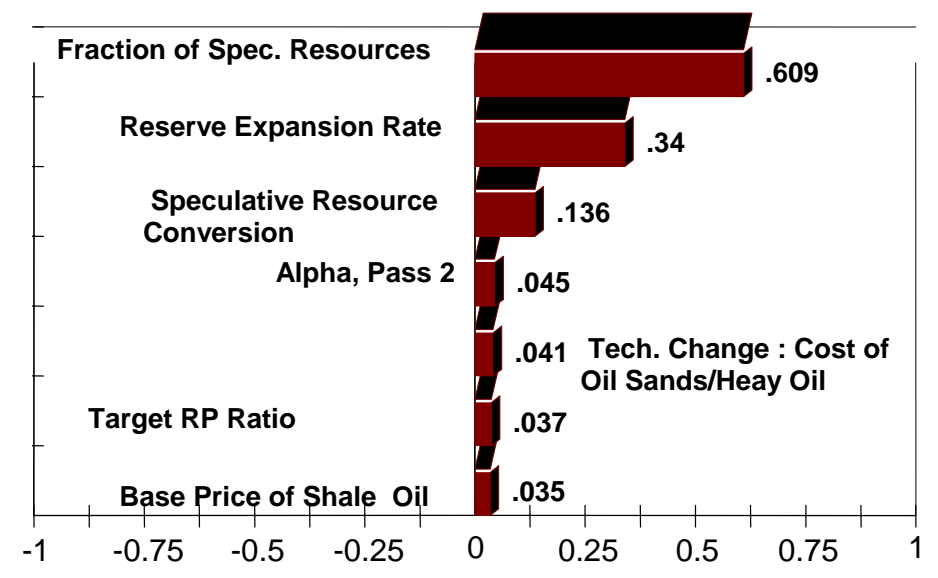

Std b Coefficients

Several other parameters (target R/P ratio, the lagged adjustment rate for world oil demand, and factors affecting the price of conventional and unconventional oil) are also significant but have relatively small impacts.

The peak year for world conventional oil production exhibits quite a different pattern of sensitivity to parameter values. The most important factor overall is the rate of increase in production from the Middle East and Northern Africa (Figures 14a and 14b). This parameter also has the obvious effect: the faster the Middle East increases production, the later world oil production peaks.

\section{Figure 14a}

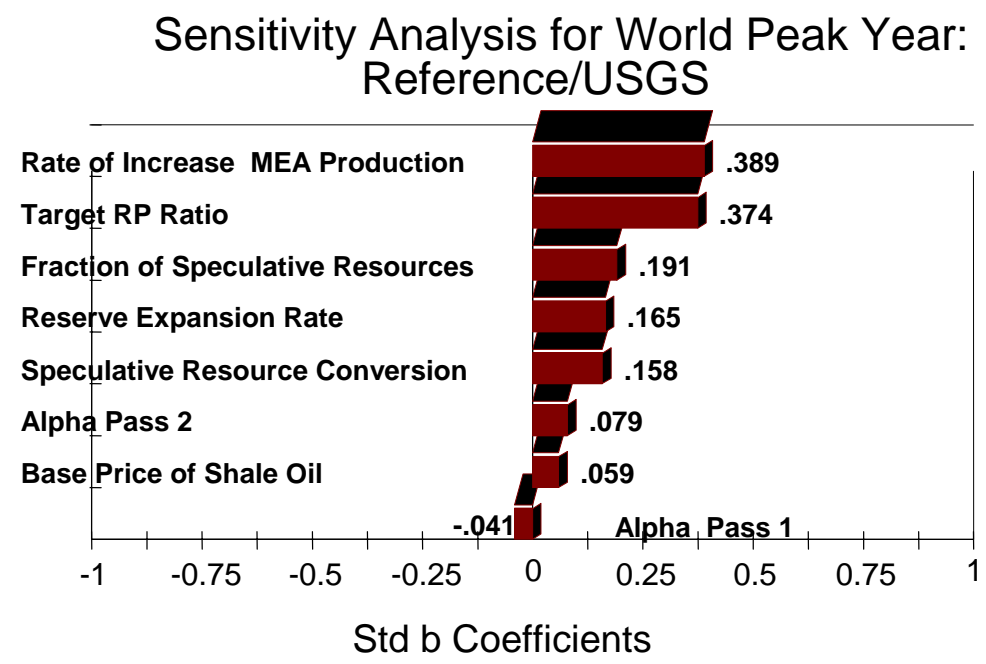


Figure 14b. Sensitivity Analysis for World

Peak Year: Reference/Rogner

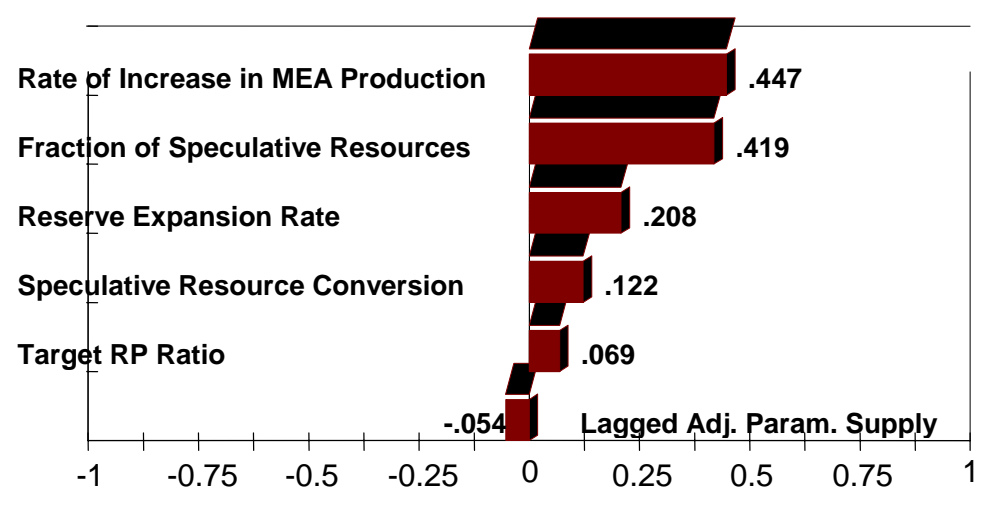

Std b Coefficients

For the risk analysis using USGS based estimates, the target $\mathrm{R} / \mathrm{P}$ ratio for non-Middle Eastern producers is the second most important factor. This factor's effect is less direct. The higher the target R/P ratio, the sooner ROW oil production peaks but the flatter the peak is. Since the world peak is largely determined by Middle East output, a long flat ROW production curve postpones the overall world peak. Next in importance are the key determinants of the quantity of conventional oil remaining to be developed: the fraction of speculative resources that will be found and the reserve growth/enhanced recovery rate.

The peaking of ROW and world oil production is less sensitive to any parameter assumptions when resource data based on Campbell's assessment are used. The world peaking date, for example, depends strongly on only one factor: the rate of increase in Middle East production (Figure 14c).

Figure 14c

Sensitivity Analysis for World Peak Year: Reference/Campbell

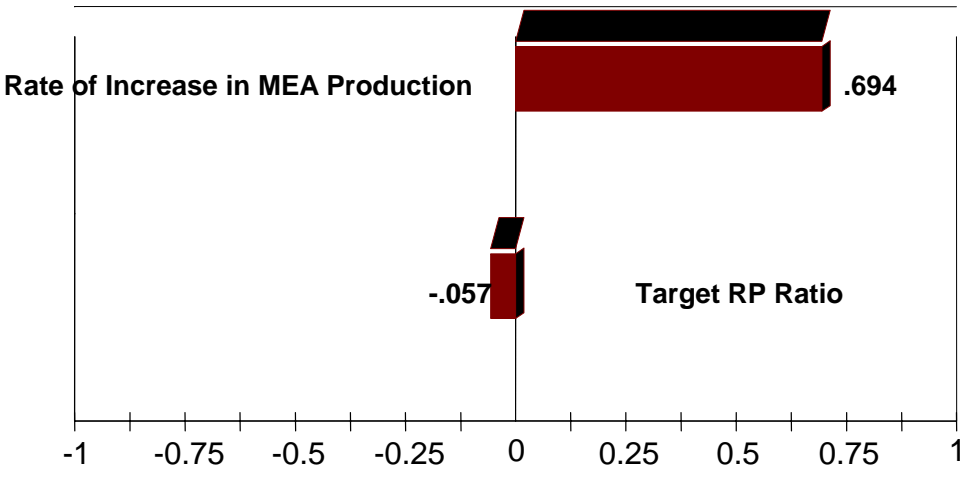

Std b Coefficients 
It is important to bear in mind that these estimates incorporate no political or environmental constraints on oil resource use. For example, there are no restrictions on drilling in the United States Arctic National Wildlife Refuge. Also, no attempt has been made to reflect geologic constraints on the rates of production, such as would be predicted by a Hubbertian analysis. In this sense, the peaking date analysis just described is optimistic.

The above results should not necessarily be interpreted to imply that geology is more important than economics in determining whether and when conventional oil production will peak, despite the fact that economic parameters are often not significant or have relatively small impacts. In the WESM model the overall levels of supply and demand are primarily determined by the scenario chosen. The function of the Oil Market Model in WESM is to simulate the transition to unconventional oil resources and to react to changes in Middle East output not to determine a new, world supply-demand equilibrium sensitive to the state of oil depletion. Thus, the effects of market forces are not fully reflected in this analysis. Building a model with fully endogenous oil supply and demand and reflecting the impacts of oil prices on economic growth is an interesting topic for future research.

\subsubsection{Low Growth Scenario}

In the Low-Growth scenario risk analysis the date of peak conventional oil production is sometimes constrained by depletion and sometimes by the peaking of world oil demand. The Low-Growth scenario requires a very different assumption about production from the Middle East and Northern Africa. The Reference and High-Growth scenarios assume that Middle East production will increase by from $1-2 \%$ per year and even up to $4 \%$ per year. In the face of decreasing demand, such exogenous rates of growth in oil production would drive world oil prices to absurdly low levels. For this reason, Middle East production is assumed to grow at between $-1 \%$ and $1 \%$ per year in the Low Growth Scenario. This implies that in the early years through 2020, ROW production will have to make up a greater share of world oil supplies.

Simulations using the USGS based estimates indicate virtual certainty of ROW peaking between 2010 and 2020 (Figure 15). Peaking generally does not occur after 2020 because 2020 is the peak year for world oil demand. The probability density spike at 2020 roughly indicates what fraction of the time the peaking is demand versus supply constrained. A very small probability of ROW production peaking after 2020 is possible, however, when the growth of Middle East production is negative.

The sensitivity analysis shows once again that how much oil exists is the most important factor (Figure 16). Increasing the target $\mathrm{R} / \mathrm{P}$ ratio causes production to peak sooner, as regions bump up against the ratio at an earlier date. Increasing Middle East production also leads to earlier peaking, an indirect effect that works via lower world oil prices. In the Oil Market Model, low oil prices driven by low demand growth and higher Middle East output cause ROW output to decrease from the initial scenario values. Under some circumstances, the decrease in output can cause an earlier peaking of conventional oil production. 
Figure 15

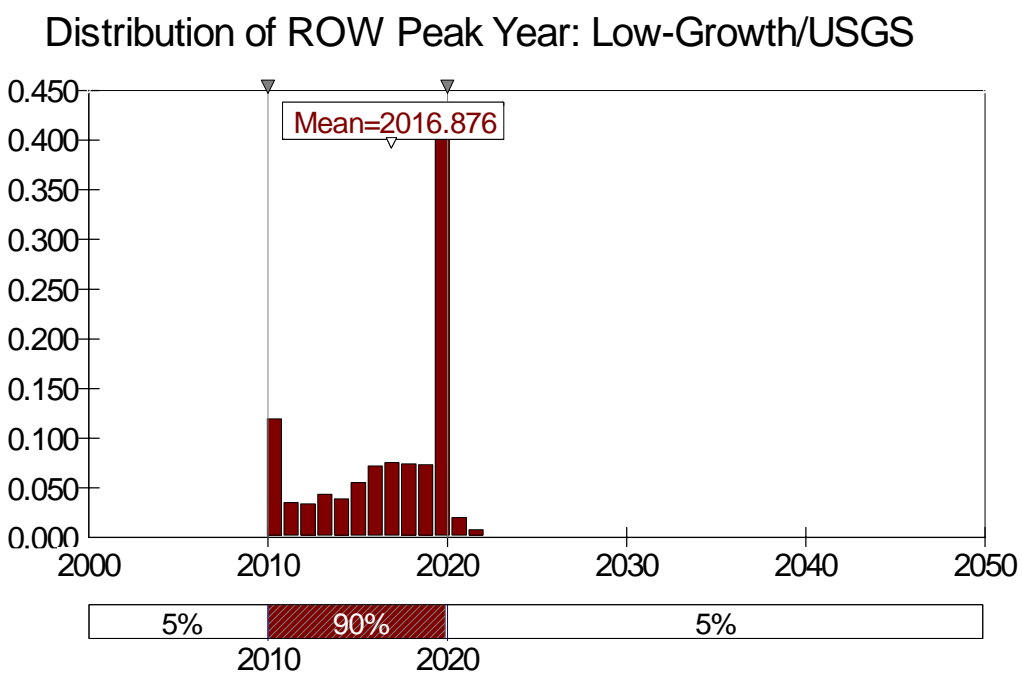

Figure 16

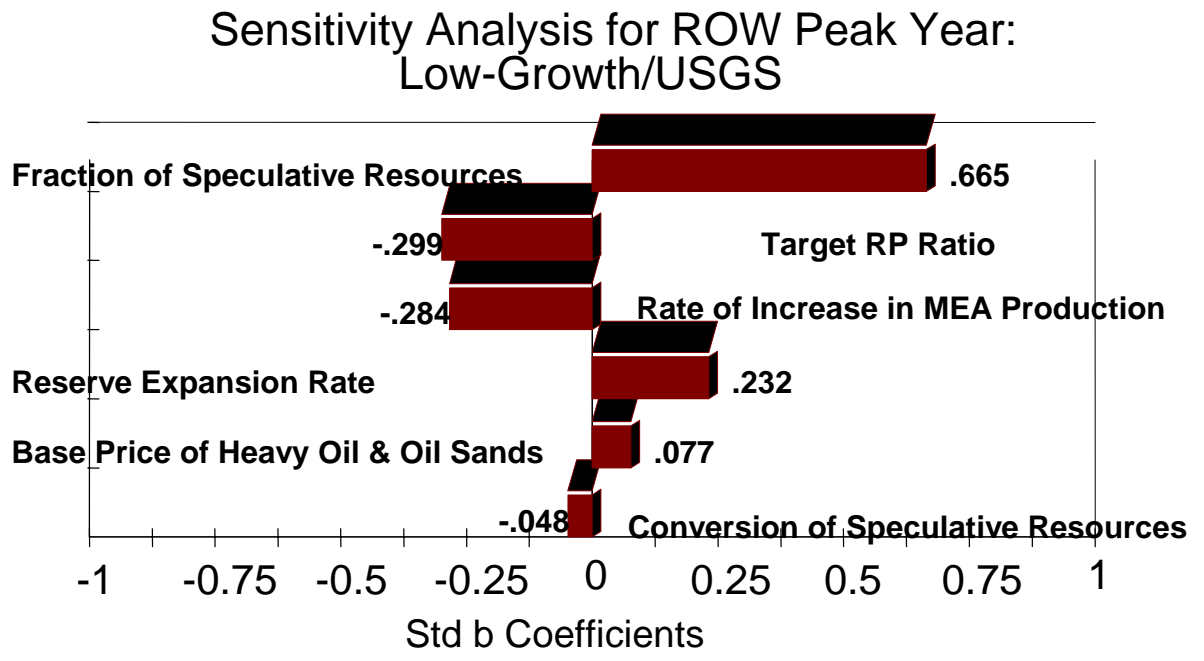

\subsubsection{High Growth Scenario}

Higher rates of growth in world oil use should bring the date of peak conventional oil production closer to the present. The High-Growth scenario is calibrated to the IEO 2002 High Economic Growth Projection and additionally assumes that energy intensities will decline at only $0.6 \% / y r$. instead of $0.9 \%$. This causes a greater concentration of probability around the year 2020 , but the mean is less than one year sooner than the Reference scenario, and there is still a 5\% probability that the peaking date will exceed 2036 (Figure 17).

The target $\mathrm{R} / \mathrm{P}$ ratio is a more important determinant of the date of peaking in the High-Growth scenario than in the Reference scenario (Figure 18). Other factors have a very similar influence. 
Figure 17

Distribution for ROW Peak Year:

High-Growth/USGS

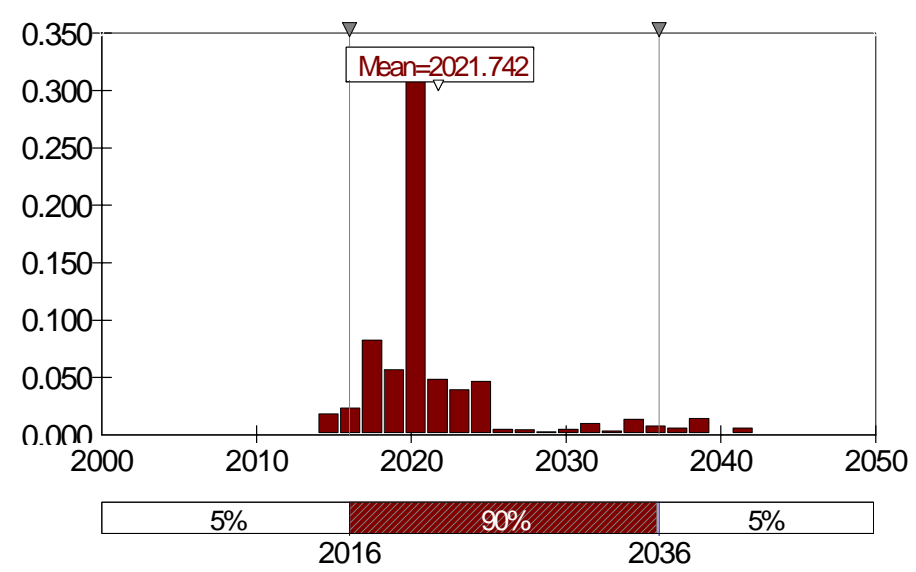

Figure 18

Sensitivity Analysis for ROW Peak Year:

High-Growth/USGS

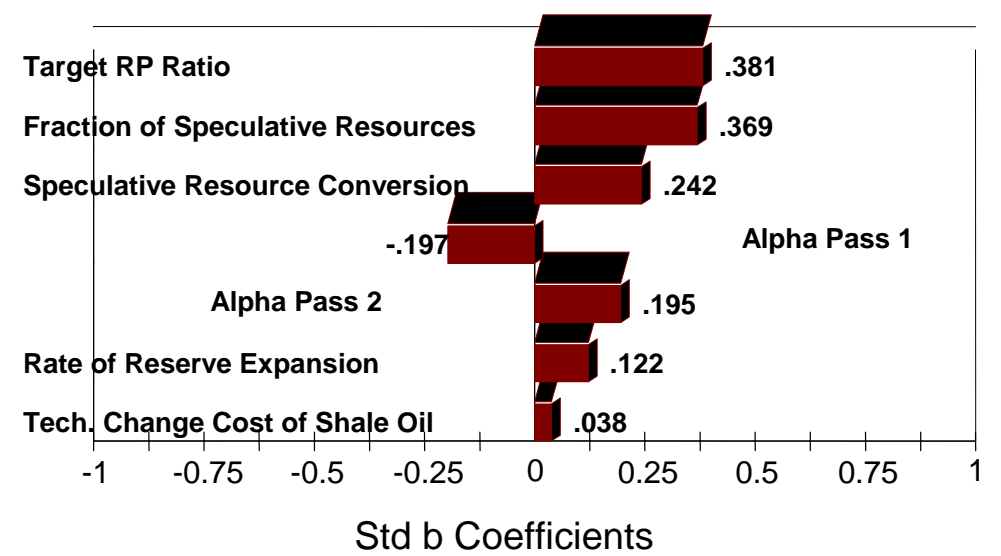

\subsection{TRANSITIONS TO UNCONVENTIONAL OIL}

The risk analysis distributions presented above provide a useful summary of key output variables but little insight about the paths oil production may take in the course of a transition to unconventional oil. By examining certain individual cases, one can get a better picture of how oil production and resource depletion are evolving over time. In this section, results are presented for the median values of parameters for five of the six scenarios. 


\subsubsection{The Reference Scenario at Median Parameter Values}

Using the Reference scenarios, USGS based resource estimates, and assuming the median values for all parameters, total world oil consumption, conventional plus unconventional, increases from 4.0 Gtoe in 2000 to 9.5 Gtoe in 2050. Conventional oil production outside the Middle East (ROW) peaks in 2020 at 3.6 Gtoe (Figure 19). The decline in ROW oil production after the peak is relatively slow, about $0.755 /$ yr. over the next 20 years. Duncan (2003) reports that of 24 nations whose oil production has already peaked, the average rate of decline in output has been only $-0.23 \% / \mathrm{yr}$. Of course, the rate of decline in ROW production will be affected by the rate of increase in Middle East production, which averages $+1.5 \% / \mathrm{yr}$. in the scenario illustrated by Figure 19. If Middle East output is assumed to remain constant, the post-peak rate of decline in ROW output falls to $-0.45 \% / y r$.

Figure 19

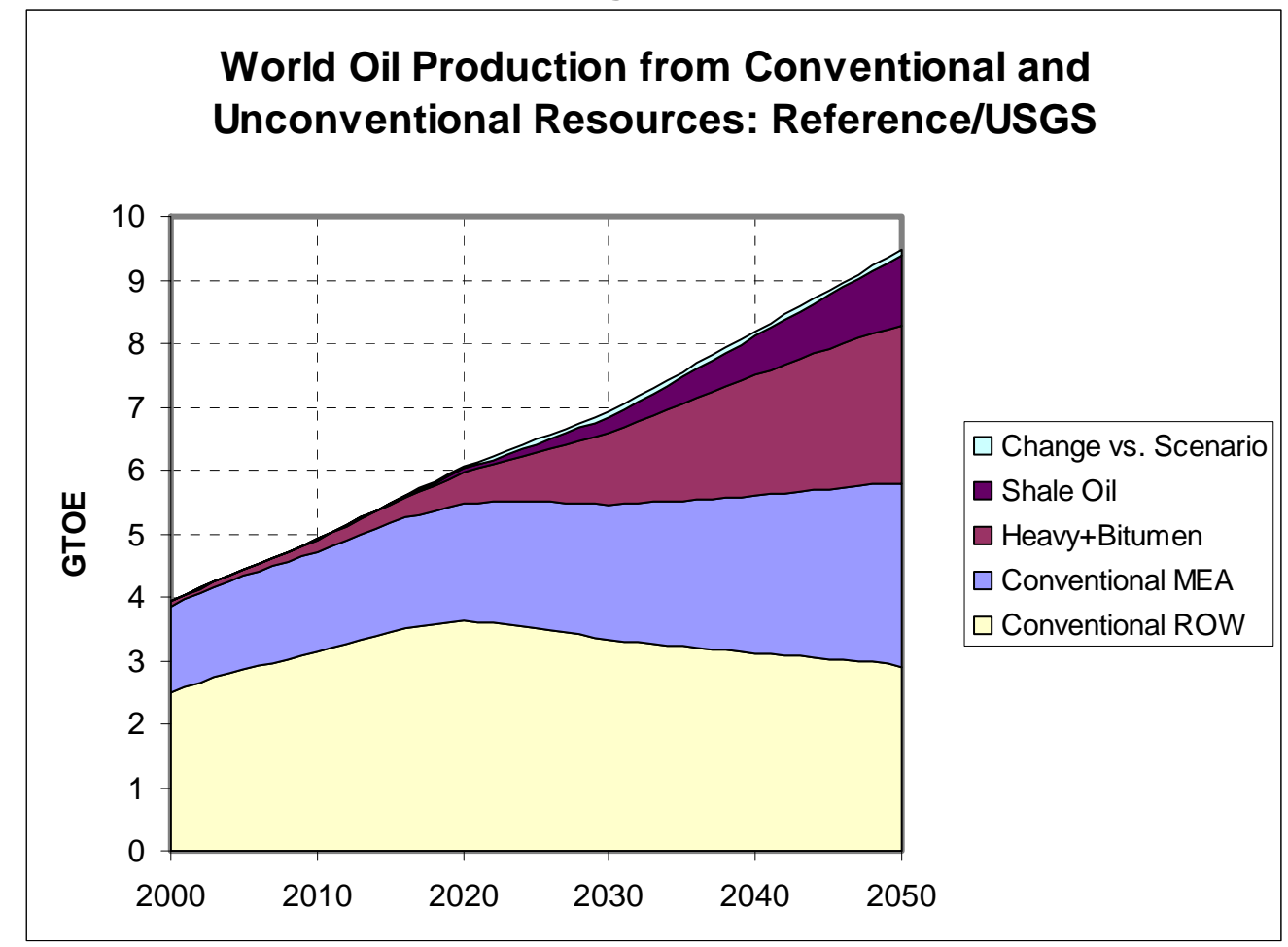

World conventional oil production initially peaks at about the same time, declines slightly and then recovers, finally peaking again in 2048. Since the path of Middle East production is assumed (increasing at 1.5\%/yr.) the path of world output is determined by the ROW path and the assumed rate of increase in Middle Eastern production. Middle Eastern producers could, if they so chose, increase production at a faster rate, thereby postponing the initial peak. Such a path, in which Middle East producers increase output at 2.5\%/yr. is shown in Figure 20. The increased Middle East production lowers the price of oil which advances the ROW peak year slightly to 2019. Producing this much conventional oil, however, the Middle East reaches the median target $\mathrm{R} / \mathrm{P}$ ratio of 15 in 2041 and then output then begins to decline sharply. The difference is made up by sharp increases in unconventional oil production. 
Figure 20

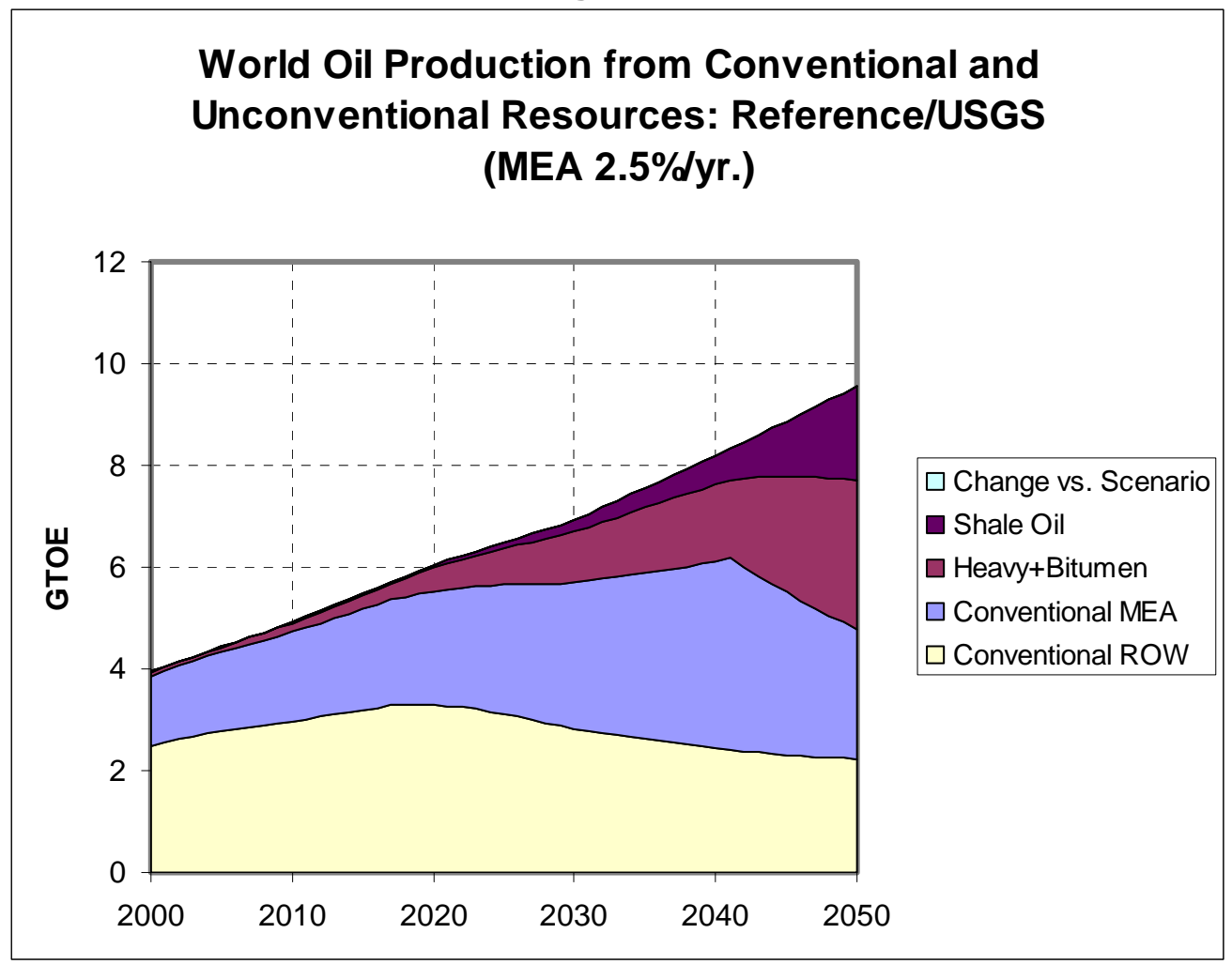

World proved reserves of conventional oil peak in 2022, just two years later than the peak of ROW production of conventional oil (Figure 21). By that time, the majority of other potential sources of conventional oil (estimated additional reserves, enhanced recovery/reserve expansion, and speculative resources) have been converted to proved reserves. Unconventional oil reserves only begin to increase after conventional oil production peaks, and by 2050 , the majority of unconventional resources have yet to be converted to reserves. The possibility that proved reserves of conventional oil might peak after ROW conventional oil production peaks raises interesting questions about whether markets would be able to anticipate turning points in oil supply, and if so, how?

In the Reference scenario with USGS based resource estimates, U.S. oil imports increase very slowly through 2020 (Figure 22). The WESM model estimates that U.S. conventional production can remain flat and even increase slightly until around 2020, as a result of increasing oil prices (to about $\$ 30 / \mathrm{bbl}$ ) and contributions to proved reserves from other sources. In 2021, however, the $\mathrm{R} / \mathrm{P}$ ratio hits the target value and subsequent production falls off sharply. Initially the gap is filled primarily by increased imports. Eventually U.S. shale oil production, which begins very gradually after 2010, increases rapidly after 2030 and begins cutting into U.S. oil imports after 2040. Of course, this is not intended to be a prediction of what will happen but rather a scenario that is contingent on the many assumptions underlying it. 
Figure 21

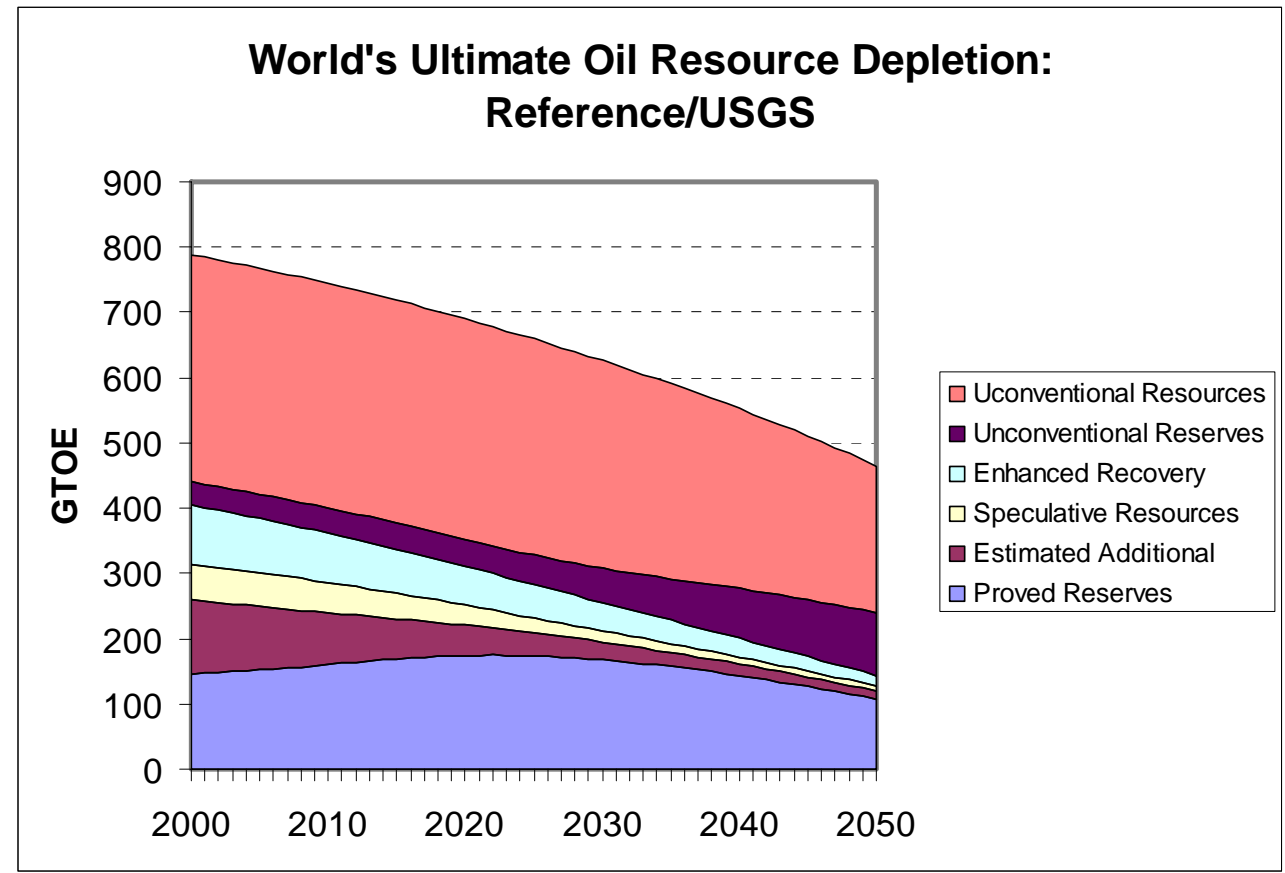

Figure 22

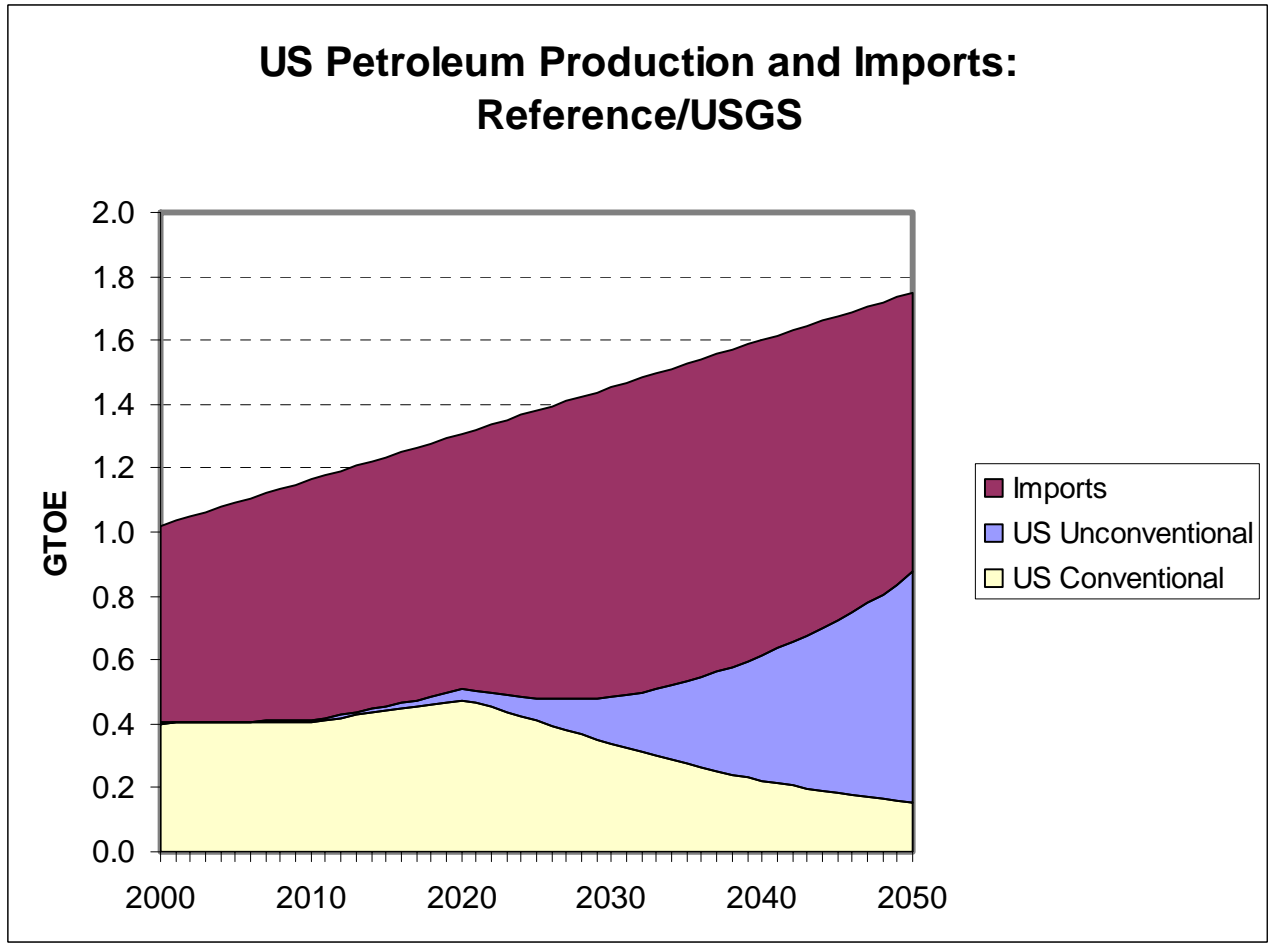

The pattern of U.S. production must be considered optimistic, given that it is well known that U.S. production already peaked in 1970. Three points are worth making in this regard. First, and most important, we are not predicting that this is what will happen but rather that it is a consequence of the data and assumptions that have been made in this analysis. The key relevant 
assumption is that production can increase until the target $\mathrm{R} / \mathrm{P}$ ratio has been reached. Hubbertian analysis would probably conclude that this is far too optimistic an assumption. Second, no resources are "out of bounds" in this analysis, whereas in reality resources may be barred from production for environmental or other reasons. Third, assumptions about the existence of speculative resources, rates of reserve expansion and technological progress affect the rate of oil production in this analysis, and may or may not be too optimistic. Still, this pattern for U.S. production through 2020 is consistent with our belief that the assumptions underlying this analysis are probably optimistic.

Substituting Rogner's resource estimates for the USGS based estimates makes little difference in the general pattern of depletion and transition. ${ }^{13}$ ROW conventional oil production peaks in 2021, world conventional production in 2043 (Figure 23). ROW production is a bit flatter when Rogner's estimates are used. For the U.S., Rogner's estimates show only about half as much category VI (unconventional resources) as we have assigned to that category for the USGS based estimates (Figure 24). Thus, there is less U.S. unconventional oil production and more imported oil in the out years when Rogner's data are used.

An entirely different picture appears when the resource estimates based on Campbell's data are used. Not only does ROW production peak much earlier in 2008 , but the peak in world production of conventional oil in 2019 is swiftly followed by a peak in total production of conventional and unconventional oil in 2020 (Figure 25). After that, things fall apart. WESM is not currently designed to handle a situation in which even unconventional resources fall far short of a scenario's projections. An enormous gap opens up between the scenario's planned production and what is feasible, a gap that must be filled by another energy source not included in WESM or accommodated by reduced consumption.

Figure 23

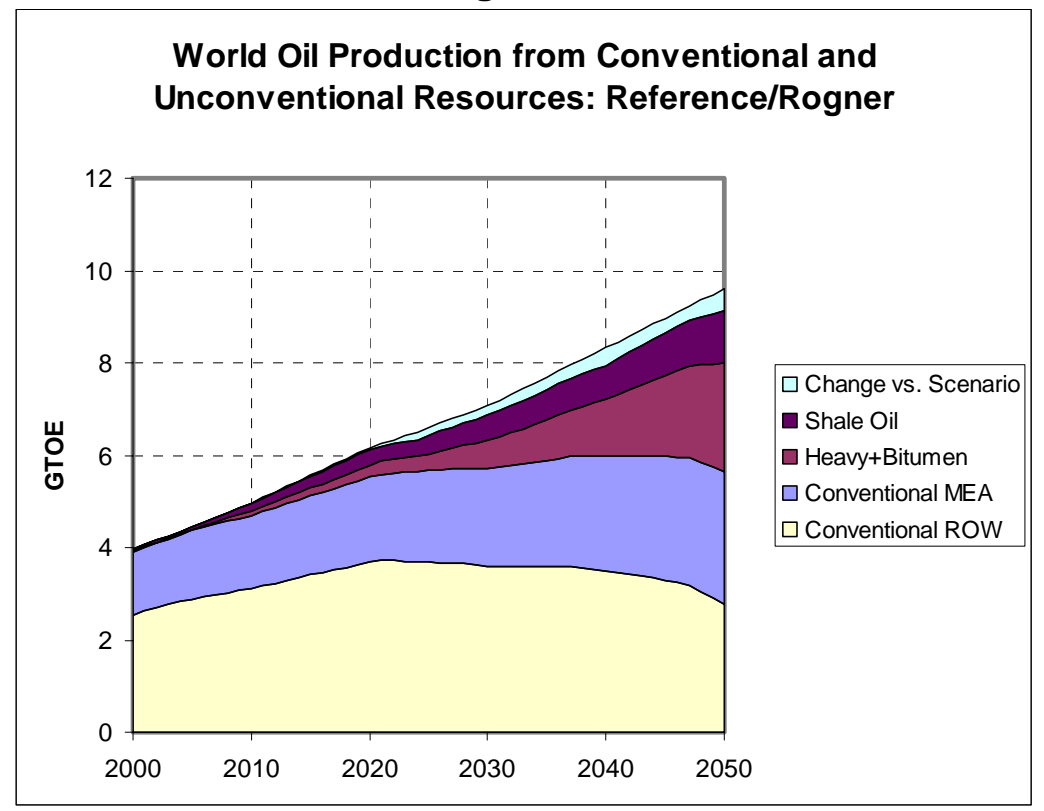

${ }^{13}$ Once again, the median values of the variable parameters are used. This includes a faster rate of reserve expansion/enhanced recovery: $1 \% / \mathrm{yr}$. versus $0.5 \% / \mathrm{yr}$. when USGS data are used. 
Figure 24

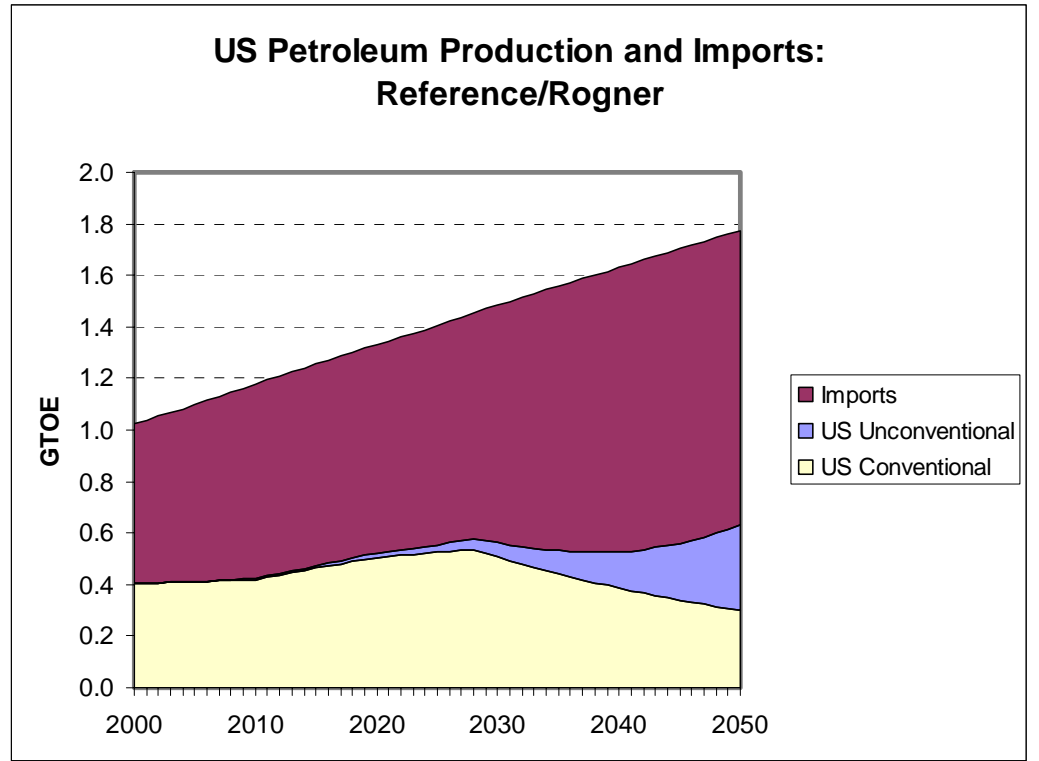

Figure 25

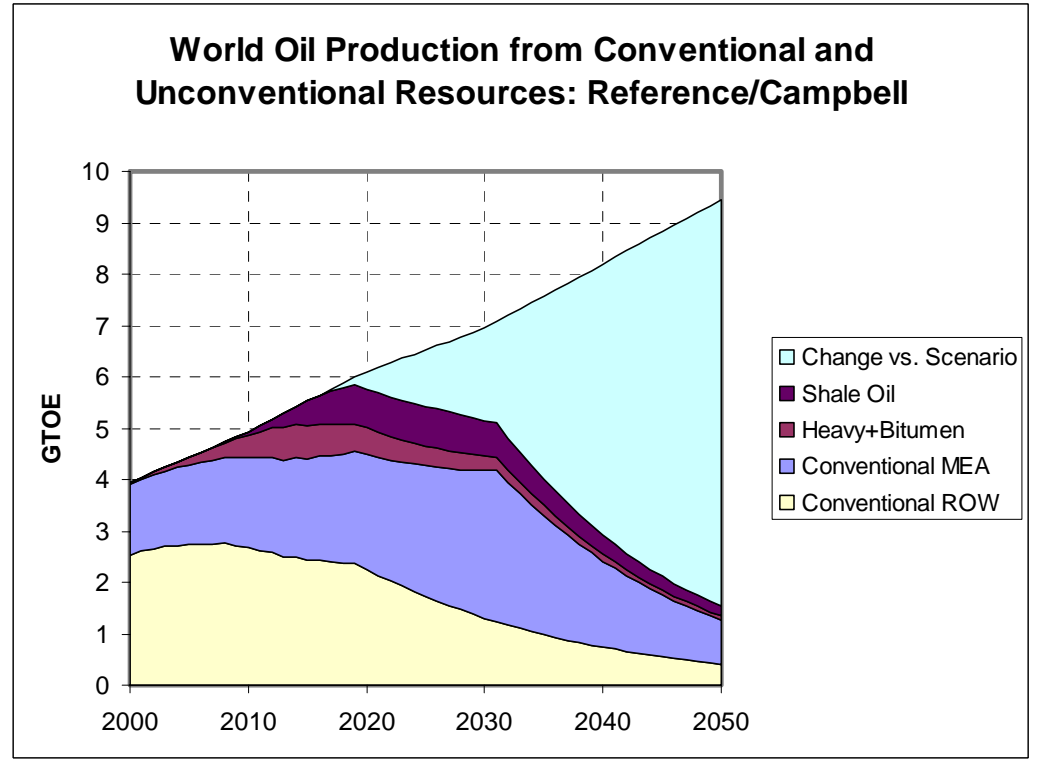

\subsubsection{Low and High Energy Growth Scenarios}

In the Low Growth scenario total oil consumption peaks at just under 5 Gtoe in 2020, flattens out and then declines to just over 4 Gtoe in 2050 (Figure 26), about half as much as in the Reference scenario. The pattern of growth and decline is demand driven. Middle East production is assumed to range between $-1 \%$ and $+1 \%$, implying a median of $0 \%$ growth. As noted above, if the Middle East expands production substantially in the face of declining demand, oil prices calculated by WESM will plummet. In the Low Growth scenario with median parameter values ROW conventional oil production peaks in 2015 at 3.1 Gtoe. The peak is a combination of the effects of depletion of conventional oil supplies outside of the Middle East and the economics of 
low oil prices as a result of slow growth in demand and a backstop supply of oil sands and heavy oil that cost little more than conventional oil. The result is a substantial increase in unconventional oil production after 2015, even though the Middle East region would be fully capable of supplying additional conventional oil if it had been assumed to do so.

Figure 26

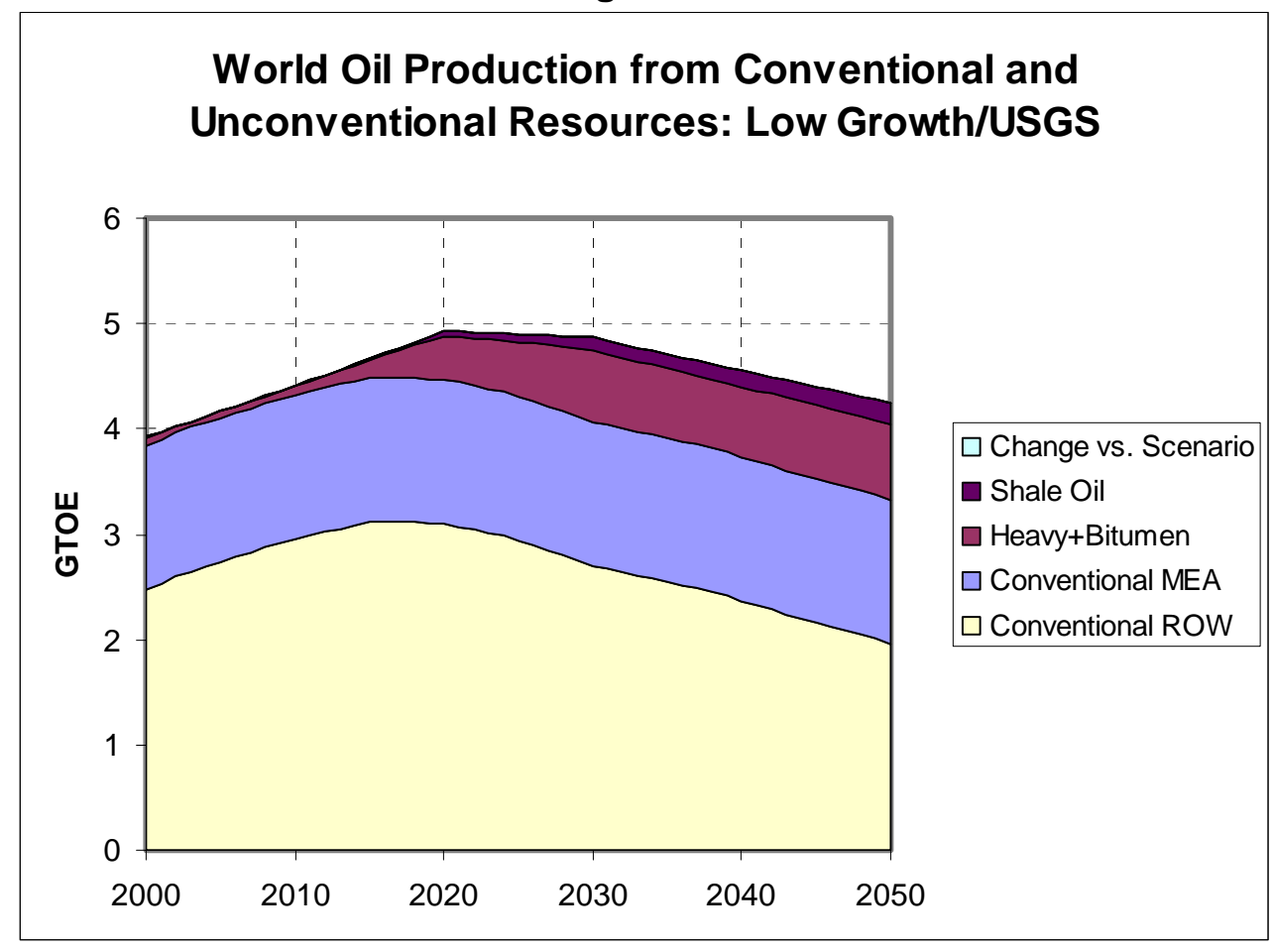

The High Growth path leads to 11.5 Gtoe of total oil consumption in 2050. Rest of World conventional oil production peaks in 2020 at 3.87 Gtoe, world conventional oil output peaks in 2041 at 5.95 Gtoe (Figure 27), largely driven by the assumed rate of growth in Middle East production of $1.5 \% / \mathrm{yr}$. In the High Growth case the rate of growth of ROW output begins to slow after 2010 resulting in an earlier increase in the market share of heavy oil and oil sands. By 2020 heavy oil and oil sands production exceeds 1 Gtoe $(20 \mathrm{mmbd})$. From 2010 to 2030, heavy oil and oil sands production grows at $7.9 \% / y r$., while overall unconventional oil production grows at an average annual rate of $8.8 \%$. The implied growth in U.S. shale oil production after 2020 is higher still: it increases from under 0.1 Gtoe in 2020 to 1.35 Gtoe $(27 \mathrm{mmbd})$ in 2050 at an average rate of $9.2 \% / y r$. As a consequence, there is a massive U.S. shale oil industry that nearly eliminates U.S. oil imports in 2050 (Figure 28).

Whether such a massive shale oil industry could be created in the United States is highly debatable. As we have pointed out previously, it might well be cheaper and more desirable to produce liquid hydrocarbon fuels from coal, natural gas or biomass, or to transition to a hydrogen-based transportation system, rather than make massive use of oil shale. However, WESM is restricted to use shale oil. Thus, these scenario results should not be taken literally and are not intended to be predictions. 
Figure 27

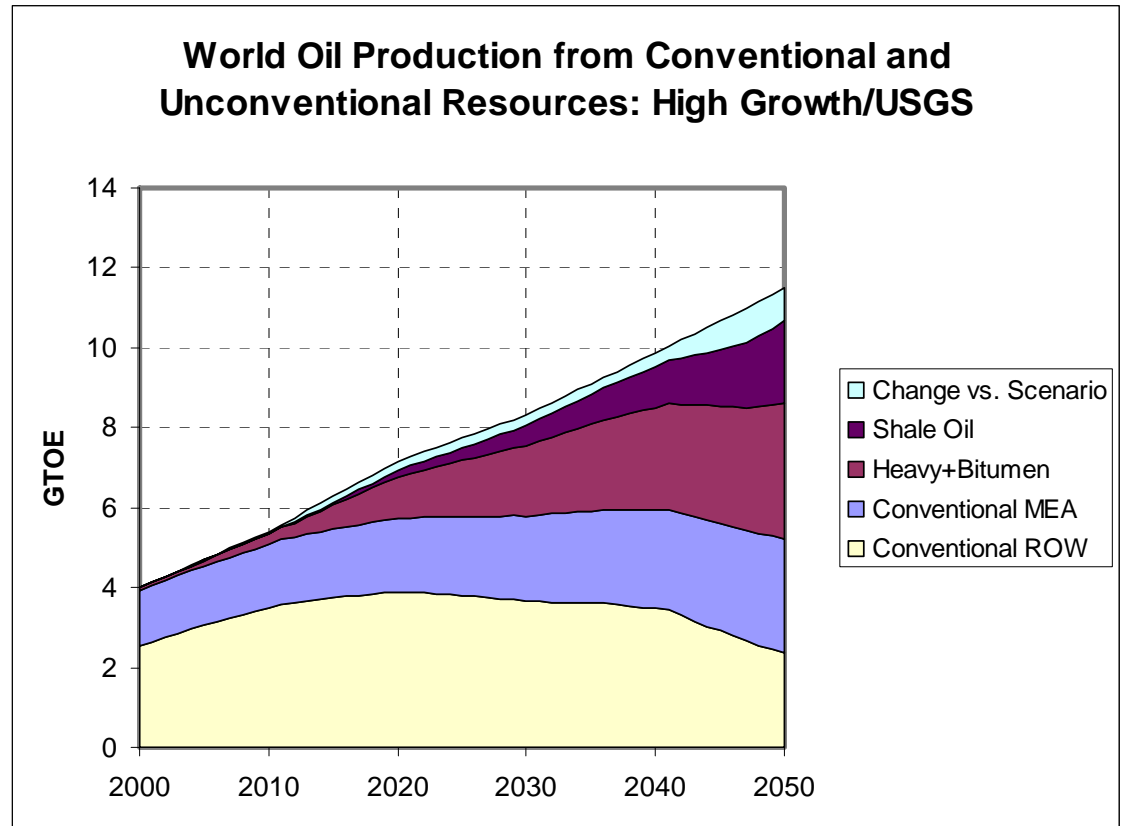

Figure 28

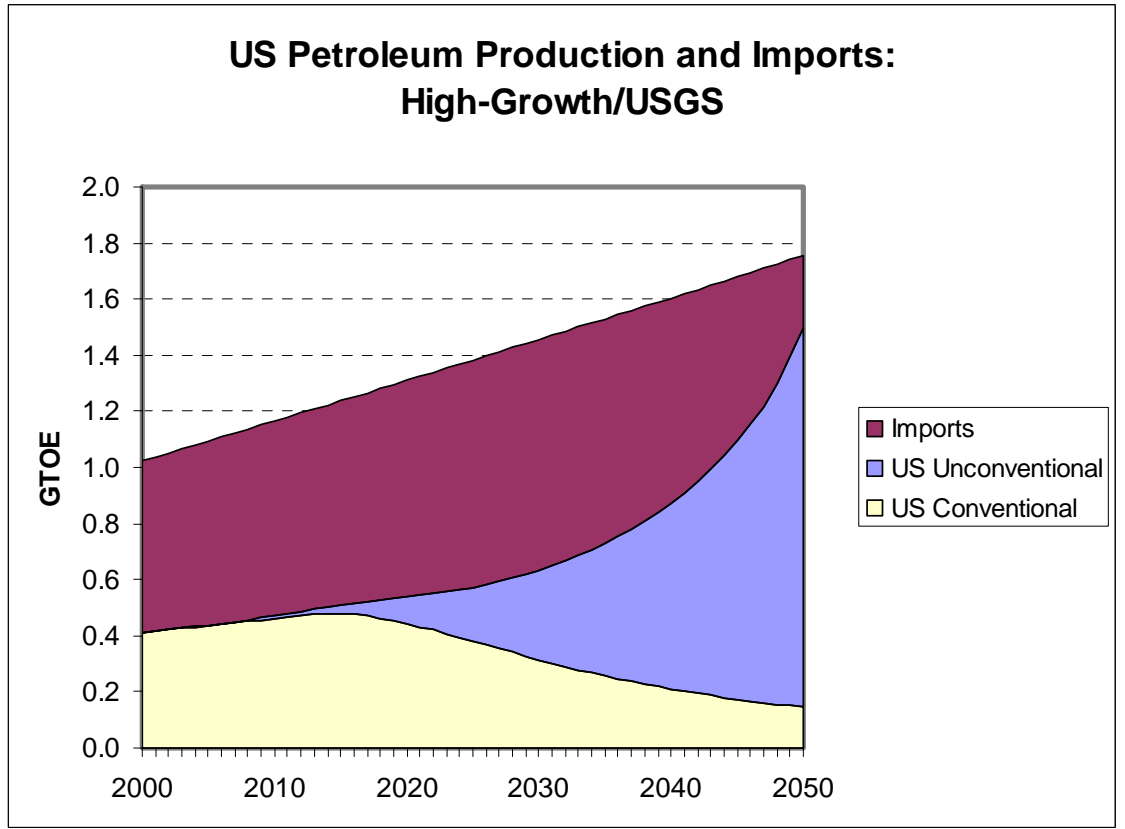

\subsubsection{Potential Implications for OPEC's Market Share}

In the WESM model, the Middle East and North Africa region can be considered a rough approximation of OPEC (Venezuela, Indonesia and Nigeria being the omitted members). Moreover, the composition of OPEC may well change over time as world oil market conditions change. Because Middle East production is an assumption, the WESM model has nothing to say about what OPEC will do. However, oil depletion and transition may have important implications for what OPEC could do. Market share is a key determinant of OPEC's market 
power, and WESM can track the Middle East market share as ROW conventional oil production peaks and unconventional oil supply comes on line. Different assumptions about OPEC's production path can be tested in the context of alternative scenarios.

Using the Reference Scenario and the USGS based resource estimates, if the Middle East region increases output at the modest rate of $1.5 \%$ per year it can maintain about a one third share of world oil production (conventional and unconventional) through 2050 (Figure 29). The region's share of conventional production would eventually rise to almost $50 \%$ by 2050 . The Middle East's share of proved conventional reserves also would remain constant at just under $60 \%$. As the supplier of a large fraction of the world's low-cost oil and owner of most of the low-cost reserves, the Middle East should be able to maintain a dominant position in world oil markets for the next 50 years. By expanding output at a faster rate, the Middle East could gain market share early on, but as a result might encounter its R/P limit before 2050. Figure 30 illustrates the Middle East's market position assuming a steady rate of increase in output of $3 \% / \mathrm{yr}$. The region's share of total production (conventional and unconventional) nears $60 \%$ after 2030, but then declines rapidly as the $\mathrm{R} / \mathrm{P}$ limit is reached. Of course, it is not necessary for OPEC to maintain a constant rate of expansion in production and an infinite number of production paths are available to choose from. Still, these results suggest that OPEC will be able to maintain a position of dominance in world oil markets for several decades, should it choose to do so, regardless of conventional oil depletion or a transition to unconventional resources.

Figure 29

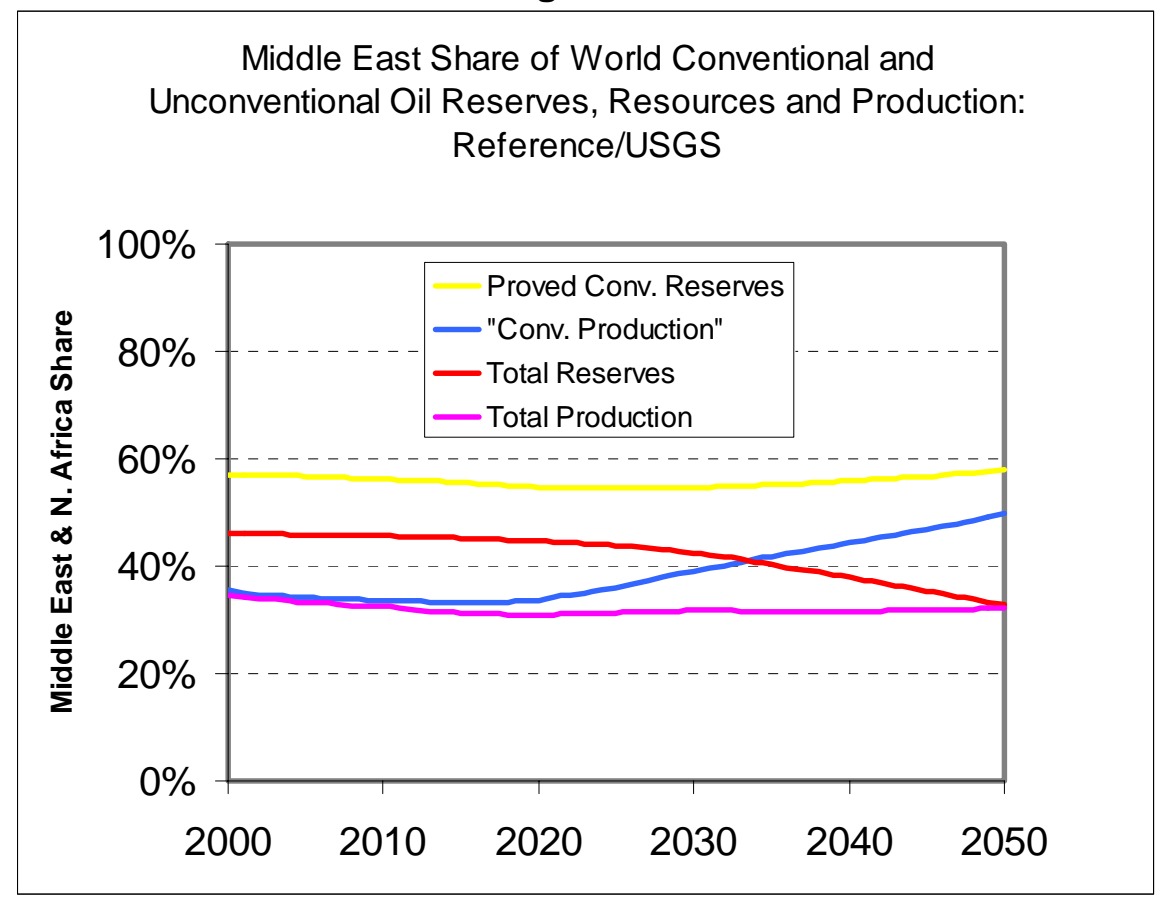


Figure 30

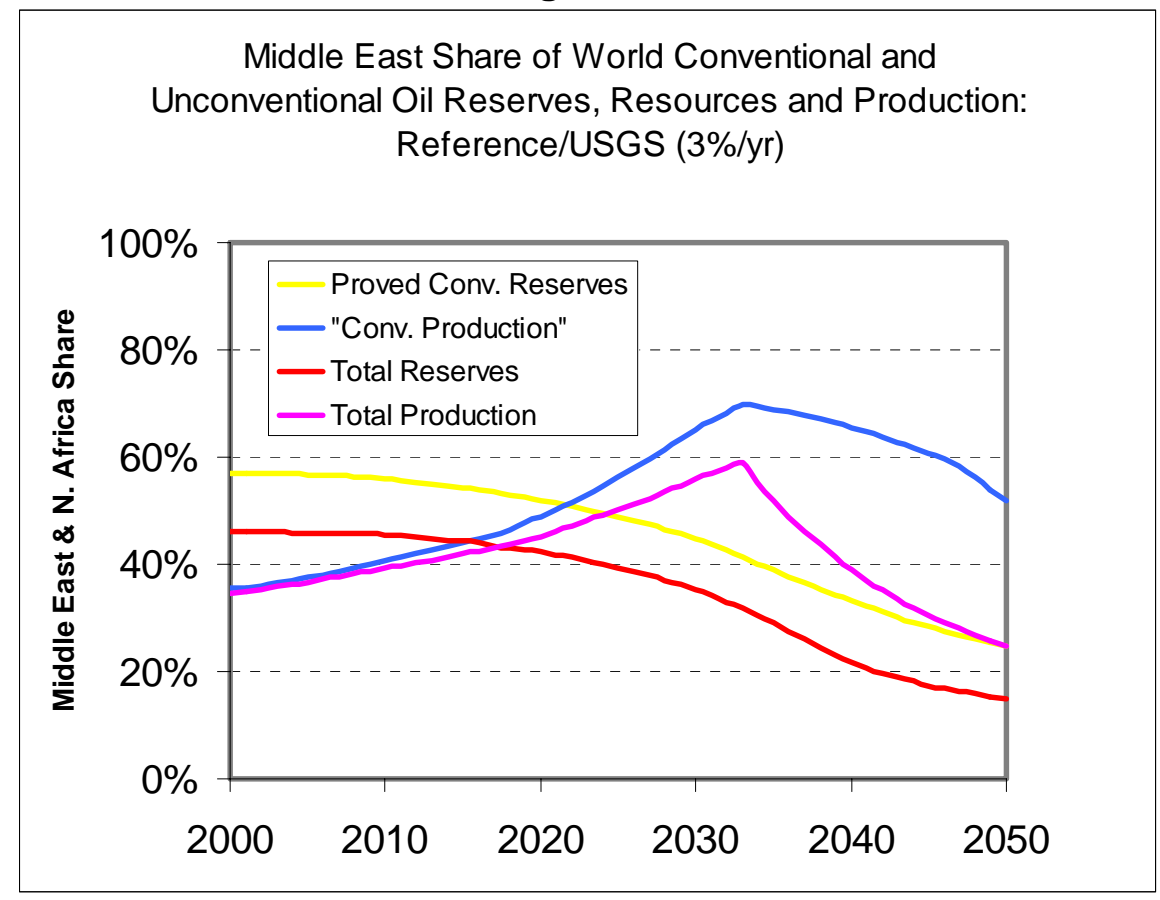

\subsubsection{Where Might the Unconventional Oil Come From?}

To fill the gap between total oil demand and conventional oil supply, WESM initially allocates production in proportion to the size of each region's unconventional reserves (rather than total resources). It then solves a market equilibrium based on the cost of production from each region, which depends on the type of unconventional oil (heavy oil and oil sands versus oil shale) and the state of depletion. Finally, unconventional resources are converted to reserves depending on the region's $\mathrm{R} / \mathrm{P}$ ratio and the size of its unconventional resource base. In general, unconventional oil production will come first from those regions with predominantly heavy oil or oil sands (because of the lower cost of production) and eventually from those regions with the largest resource bases. It is important to bear in mind that the state of knowledge about unconventional resources is not nearly as advanced as knowledge about conventional resources, so the results presented in this section should be considered very tentative.

Considering the Reference Scenario and using the USGS based resource estimates, oil sands from Canada are the initial major source of unconventional oil supply (Figure 31). Canadian oil sands production increases rapidly to about $0.7 \mathrm{Gtoe}(14 \mathrm{mmbd})$ after 2030 and then remains nearly flat through 2050. The specific pattern of Canadian supply should not be taken too literally since it partly depends on the initial allocation of oil sands resources between reserves and resources, an issue that is in a state of flux even today. It is also not clear whether such a rapid and massive increase in Canadian oil sands production is feasible or desirable. Considering 2030 production targets in the range of $5 \mathrm{mmbd}$, Canadian government and industry experts foresee major challenges in terms of water availability, on-site upgrading requirements for synthetic oil, energy consumption, environmental impacts and infrastructure needs (ARC, 2003). Additional resources come from Latin America (Venezuela) and the Former Soviet Union (Russia). 
Figure 31

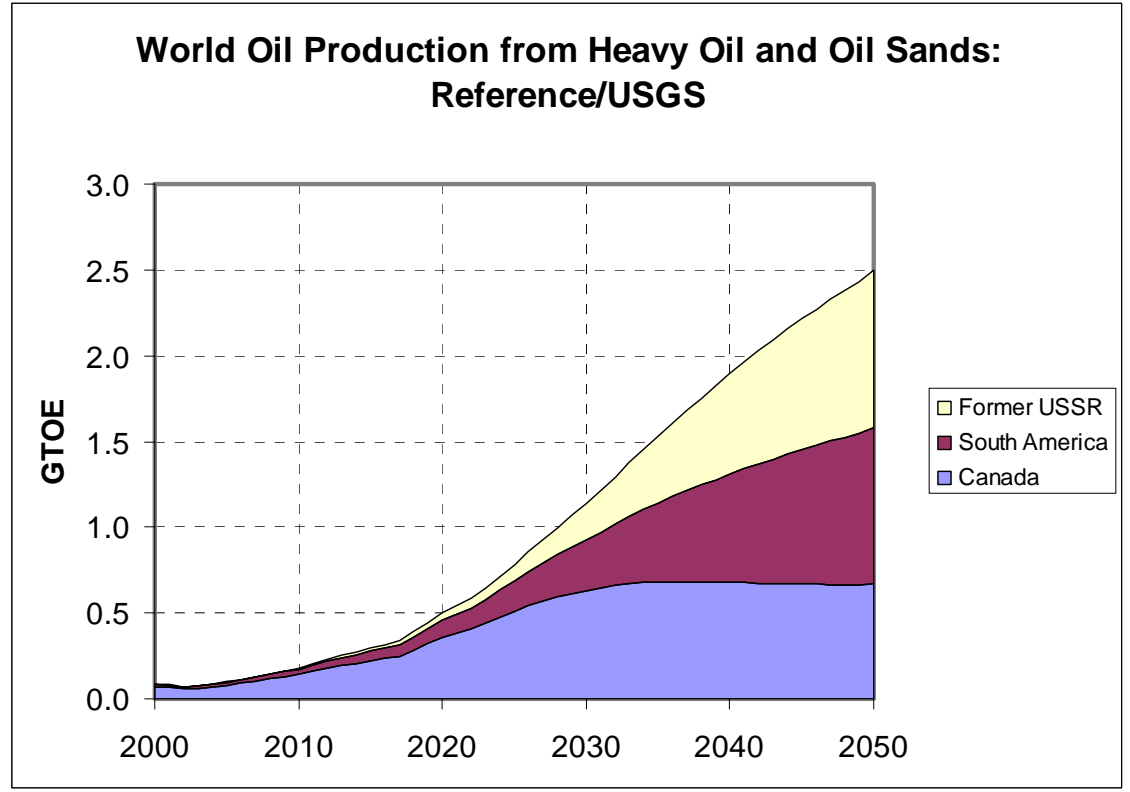

Oil shale production begins later, and is driven by continued growth in world oil demand, the peaking of conventional oil supply, limitations on the rate of increase in heavy oil and oil sands production (only three regions possess these resources) and decreasing costs of shale oil production as a result of technological progress. By 2050 more than 1 Gtoe $(20 \mathrm{mmbd})$ of shale oil is being produced, nearly all of it from the United States (Figure 32). In the High Growth scenario, 2 Gtoe of shale oil are required. Whether such a rapid expansion and massive production of shale oil would be feasible or acceptable to the United States is not considered here, and it is again noted that there may be better alternatives for producing liquid hydrocarbon fuels.

Figure 32

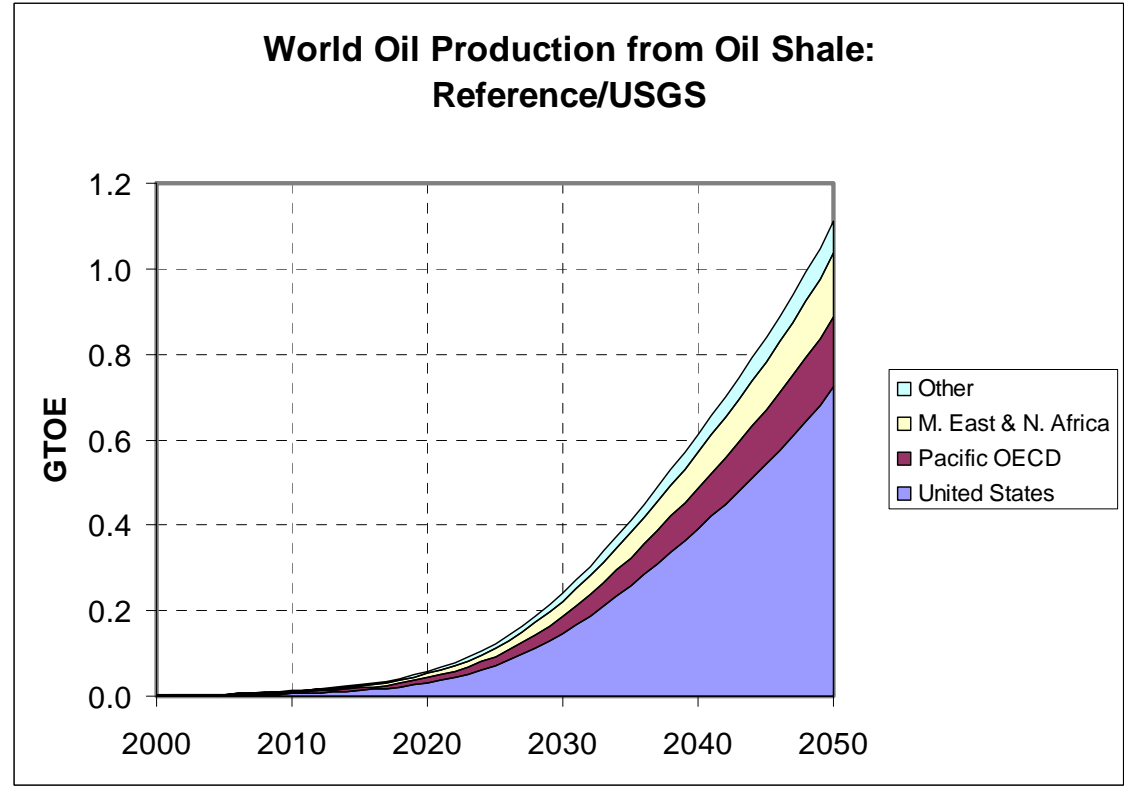





\section{CONCLUSIONS}

A model has been constructed to allow alternative estimates of world conventional and unconventional oil resources to be matched with alternative scenarios of world energy production and consumption in order to explore the implications for depletion of conventional oil and transition to unconventional sources. The primary functions of the model are to account for the depletion of oil by region and resource category and to simulate the transition to unconventional sources based on a representation of the market forces of supply and demand. The model is not a general equilibrium model of world energy supply and demand and its ability to estimate market responses is quite limited. Exogenously specified energy scenarios drive consumption and production of oil and the WESM model accounts for resource depletion and expansion and estimates when and how much unconventional oil is needed and from where it will be produced.

The results presented here strongly suggest that it is not too soon to begin analyzing potential transitions from conventional oil and considering whether more desirable alternatives may be achievable.

The risk analyses of world oil depletion presented in this report are dependent on a number of critical assumptions, nearly all of which are debatable. Furthermore, there are several areas in which improvements to data and methods are needed. Nonetheless, it is hoped that this analysis has made a contribution to a better understanding of the future of conventional and unconventional oil supply.

Is the Peaking of Conventional Oil Production Imminent?

If present energy use trends continue (as represented by the High Growth and Reference scenarios), unless the best available estimates of world conventional and unconventional resources as well as the representation of uncertainty in these estimates are very seriously in error, a major transition from conventional to unconventional oil will begin before 2030 . If the resource estimates based on Rogner (1997) or those based on the USGS 2000 survey are used, peaking of non-Middle Eastern conventional oil production is likely sometime between 2010 and 2030. If the lowest resource estimates are correct, the transition is already underway. The key determining factors of the date of peak production are how much conventional oil remains to be discovered and how quickly reserves can expand.

The peaking of conventional oil production is only a part of this equation. Under a wide range of assumptions the rate of growth in world conventional oil production will slow substantially after 2020 if it does not decline. In order for oil consumption to continue to increase at substantial rates, the Middle East region must rapidly expand production or production of oil from unconventional resources must be greatly expanded. The implication is that under almost any assumptions, it is not too soon to consider whether this transition is desirable and to evaluate the risks and opportunities it presents. 


\section{Will the Transition be Rapid or Slow?}

The transition to unconventional oil will be rapid if the growth of oil consumption continues at current rates or rates projected through 2020 by the Energy Information Administration or the IEA. Rates of growth in unconventional oil supply of 7-9\%/yr. appear necessary as the peak in non-Middle East oil production is approached. The transition could be greatly slowed and substantial development of shale oil resources avoided if the growth of world oil consumption could be curbed by 2020. If the pessimistic assessment of world unconventional resources proves to be correct, the transition to unconventional oil will be rapid but limited and short lived, and largely ineffective in preventing a supply-constrained downturn in oil consumption.

At first, unconventional oil supplies are likely to come from the oil sands resources of Canada, followed by increased development of Venezuelan and Russian unconventional resources. If growth in demand continues, U.S. shale oil (or some other source of liquid hydrocarbons) will begin to be developed at a rapid pace following the peaking of conventional oil production from regions outside of the Middle East. Development of oil shale could be delayed by a substantial increase in conventional oil production from the Middle East. Nearly all of the supply of shale oil is likely to come from the United States due to its massive shale oil resources. Alternatives to shale oil exist but have not been included in this study.

\section{Will a Transition to Unconventional Oil Weaken OPEC's Market Power?}

It appears that the market dominance of MEA oil producers is robust to a wide range of alternative demand and resource availability scenarios. This is evidenced by their ability to maintain market shares in the vicinity of 30 percent to 50 percent over the entire 50 -year period in all scenarios and variants. Moreover, the Middle East will remain the lowest cost supplier of oil. While the emergence of large-scale unconventional oil production could put a cap on longrun oil prices, with the majority of the world's proved conventional reserves Middle East producers will have the ability to temporarily raise or lower world oil prices throughout the period.

In the absence of dramatic efficiency improvements, U.S. oil imports are likely to increase until shale oil (or perhaps coal) becomes an important resource. This is not likely to happen until after 2025 , if then. If the WESM model's predictions of flat or increasing U.S. oil output for the next decade or more are overly optimistic (as they probably are) the near-term increase in U.S. imports will be greater still. This implies that the U.S. oil dependence problem is a long-run problem, and one that will probably require major changes in transportation technology, or energy sources for transportation, or both.

While the price estimates presented here are highly dependent on assumptions, there is at least a suggestion that neither increasing costs nor falling proved reserves may provide a timely signal to markets that a turning point is imminent. This may be so for several reasons. Changes in production costs, as represented in this analysis, are very gradual until resources are nearly totally depleted. The availability of a close substitute in the form of unconventional oil also tends to moderate price increases. Technological progress may further dampen any tendency for prices to increase. Finally, although this analysis has nothing to say about this issue, short-term fluctuations in oil prices could very well obscure the long-term signal. It could be that markets will not see potentially disruptive turning points coming. These turning points could require 
extremely rapid increases in the production of alternative energy sources or major reductions in demand. In the long run, markets will sort this out. However, the short-run disruptions could be very expensive.

Areas for Future Research

There are many opportunities to improve this analysis in future research.

1. Adding a realistic representation of the difficulty of increasing production rates while petroleum resource occurrences are approaching depletion could lead to more accurate regional production schedules.

2. Estimates of regional oil production costs and costs of unconventional production costs are needed.

3. Better, more complete estimates of world unconventional oil resources are needed.

4. Fossil and renewable energy resource alternatives to oil sands, heavy oil and shale oil should be added to permit a more complete analysis of energy transitions.

5. A more flexible representation of Middle East oil supply, perhaps allowing alternative behavioral assumptions should be incorporated.

6. Important linkages to other energy sectors, especially natural gas production and use should be added.

7. World oil supply and demand could be made endogenous and linked to economic growth.

Despite these shortcomings, it is hoped that this analysis has made a contribution to understanding the role of oil resources in future energy transitions. 



\section{REFERENCES}

Adelman, M.A. 2003. "Comment on: R.W. Bentley, 'Global Oil \& Gas Depletion,"” Energy Policy, vol. 31, no. 4, pp. 389-390.

Adelman, M.A. and M.C. Lynch. 1997. "Fixed View of Resource Limits Creates Undue Pessimism," Oil and Gas Journal, April 7, pp. 56-59.

Alazard, N. 1996. "Technical Scientific Progress in Petroleum Exploration and ProductionImpact on Reserves and Costs," Energy Exploration and Exploitation, vol. 8, no. 6, pp. 380-392.

(ARC) Alberta Chamber of Resources. 2003. "Oil Sands Technology Roadmap,” Workshop Draft, www.ptac.org/cho/dl/OSTRM.pdf, June 10.

Attanasi, E.D. and D.H. Root. 1993. Statistics of Petroleum Exploration in the Caribbean, Latin America, Western Europe, the Middle East, Africa, non-Communist Asia and the Southwest Pacific," U.S. Geological Survey Circular 1096.

Bakhtiari, A.M.S. 2003. "Middle East oil Production to Peak Within Next Decade," Oil \& Gas Journal, July 7.

Bentley, R.W. 2002. “Global Oil and Gas Depletion: An Overview,” Energy Policy, vol. 30, pp. 189-205.

Bentley, R.W., R.H. Booth, J.D. Burton, M.L. Coleman, B.W. Sellwood, G.R. Whitfield. 2000. "Perspectives on the Future of Oil," Energy Exploration and Exploitation, vol. 18, nos. 2 \& 3, pp. 147-206.

Bower, D. 2002. "More Where That Came From," Petroleum Economist, March, pp. 20-21.

Campbell, C.J. 2003. Newsletter No. 30, Association for the Study of Peak Oil and Gas, Staball Hill, Ballydehob, Co. Cork, Ireland, aspoone@eircom.net.

Campbell, C.J. 2000. Table 1, year-end 1999, revision date 4/29/2000, http://www.hubbertpeak.com/campbell/update2002.htm .

Campbell, C.J. 1997. "Better Understanding Urged for Rapidly Depleting Reserves," Oil and Gas Journal, special issue, April 7, pp. 51-53.

Campbell, C.J. and J. Laherrere. 1998. "The End of Cheap Oil," Scientific American, vol. 278, no. 3, pp. 78-83.

Cavallo, A.J. 2002. "Predicting the Peak in World Oil Production," forthcoming, Natural Resources Research, vol. 11, no. 3, pp. 187-195.

Cliffe, K. 2002. “Oil Sands Working Paper,” Petroleum Resources Division, Natural Resources Canada, unpublished manuscript, May 14.

Davies, P. and P. Weston. 2000. "Oil Resources: A Balanced Assessment," vol. 6-15, The Journal of the Center for Energy Petroleum and Mineral Law and Policy, http://www.dundee.ac.uk/cepmlp/journal/html/article6-15.html .

Duncan, R.C. 2003. "Three World Oil Forecasts Predict Peak Oil Production," Oil \& Gas Journal, vol. 101.21, pp. 18-21, May 26.

Duncan, R.C. and W. Youngquist. 1999. "Encircling the Peak of World Oil Production," Natural Resources Research, vol. 8, no. 3, available on the web at http://www.mnforusutain.org/duncan and youngquist encircling oil.htm .

Dyni, J.R. 2000. "Oil Shale," paper by the Oil Shale Committee Chairman, US Geological Survey, Denver, Colorado, 2/27/00 version, http://www.emdaapg.org/Oil\%20Shale.htm .

Economist. 2003. “There's Oil in Them Thar Sands!" The Economist, June 28 ${ }^{\text {th }}$, pp. 75-76. 
Edwards, J.D. 1997. "Crude Oil and Alternative Energy Production Forecasts for the TwentyFirst Century: The End of the Hydrocarbon Era," AAPG Bulletin, vol. 81, no. 8, pp. 12921305.

(EEA) Energy and Environmental Analysis, Inc. 1999. "Canadian Highway Sector Greenhouse Gas Accounting Model (Champagne): Description and Documentation," prepared for Transportation Energy Use Division, Natural Resources Canada, Ottawa, Ontario, Canada, March.

Gately, D. 2002. "The Payoffs to Faster or Slower Output Growth for OPEC," Economics Department, New York University, NY, NY.

Grubb, M. 2001. "Who's Afraid of Atmospheric Stabilisation? Making the Link Between Energy Resources and Climate Change," Energy Policy, vol. 29, pp. 837-845.

Hubbert, M.K. 1962. Energy Resources, A Report to the Committee on Natural Resources: National Academy of Sciences, National Research Council, Publication 1000-D, Washington, DC.

(IEA) International Energy Agency. 2002. "Background Paper on IEA Conference on Prospects for Non-Conventional Oil", Calgary Canada, November 25-26, 2002, IEA Paris.

Laherrere, J. 2001. "Estimates of Oil Reserves," presented at the EMF/IEA/IIASA meeting, Laxenburg, Austria, June 19, available on the Internet at http://www.oilcrisis.com/laherrere/.

Martin, J.-M. 1999. "Concerning the End of Cheap Oil," Energy Policy, vol. 27, pp. 69-72.

Masters, C., E. Attanasi and D. Root. 1994. "World Petroleum Assessment and Analysis," U.S. Geological Survey, National Center, Reston, Virginia, Proceedings of the $14^{\text {th }}$ World Petroleum Congress, Stavanger, Norway, published by John Wiley \& sons, New York.

Nakićenović, N., Editor. 1993. "Long-Term Strategies for Mitigating Global Warming," Energy, vol. 18, no. 5, pp, 401-609.

Nakićenović, N., A. Grübler and A. McDonald. 1998. Global Energy Perspectives, published for the International Institute of Applied Systems Analysis and the World Energy Council by Cambridge University Press, Cambridge, UK.

(NEPDG) National Energy Policy Development Group. 2001. National Energy Policy, U.S. Government Printing Office, Washington, DC (bookstore.gpo.gov).

(NRCan) Natural Resources Canada. 2002a. "The Canadian Highway Sector Greenhouse Gas Accounting Model (CHAMPAGNE)," Transportation Energy Use Division, Office of Energy Efficiency, Ottawa.

(NRCan) Natural Resources Canada. 2002b. "North American Future Transportation Study: Long-term Scenarios to 2050," Transportation Energy Use Division, Office of Energy Efficiency, Ottawa.

(NRCan) Natural Resources Canada. 2002c. “Oil Sands Working Paper," Office of Energy Technologies Futures and Oil Division, Petroleum Resources Branch, Ottawa.

Odell, P.R. 1999. "Dynamics of Energy Technologies and Global Change," Energy Policy, vol. 27, pp. 737-742.

Odell, P.R. 1998. "Oil and Gas Reserves: Retrospect and Prospect," Energy Exploration and Exploitation, vol. 16, no. 2, pp. 117-124.

(OTA) Office of Technology Assessment. 1980. "An Assessment of Oil Shale Technologies," Congress of the United States, U.S. Government Printing Office, Washington, DC.

Pallisade Corporation. 2002. @RISK: Risk Analysis and Simulation Add-In for Microsoft® Excel, Newfield, NY.

Porter, E. 1995. “Are We Running Out of Oil?” Discussion Paper \#081, American Petroleum Institute, Washington, DC, December. 
Reynolds, D.B. 2002. Scarcity and Growth Considering Oil and Energy, The Edwin Mellen Press, Lewiston, New York.

Roberts, J. 2002. "What is the Potential of Canada's Oil Sands?" Energy Economist Briefings, Energy Economist, April.

Rogner, H.H. 1997. "An Assessment of World Hydrocarbon Resources," Annual Review of Energy and Environment, vol. 22, pp. 217-262.

Schmoker, J.W. and T.R. Klett. 2000. "Estimating Potential Reserve Growth of Known (Discovered) Fields: A Component of the USGS World Petroleum Assessment 2000," Chapter RG, USGS World Petroleum Assessment 2000, USGS Digital Data Series 60.

Stauffer, T.R. 1994. "Trends in Oil Production Costs in the Middle East, Elsewhere," Oil and Gas Journal, March 21, 1994, pp. 105-107.

(U.S. DOE/EIA) U.S. Department of Energy, Energy Information Administration. 2002. International Energy Outlook, DOE/EIA-0484(2002), Washington, DC.

(U.S. DOE/EIA) U.S. Department of Energy, Energy Information Administration. 1996. Oil Production Capacity Expansion Costs for the Persian Gulf, DOE/EIA-TR/0606, Washington, D.C., February.

(USGS) U.S. Geological Survey. 2000. World Petroleum Assessment 2000 - Description and Results, U.S. Geological Survey Digital Data Series - DDS-60, U.S. Department of the Interior, Reston, Virginia, available on the internet at http://greenwood.cr.usgs.gov/WorldEnergy/DDS-60.

(WEC) World Energy Council. 2001. "2001 Survey of Energy Resources," $19^{\text {th }}$ Edition, CDROM, London.

(WEC) World Energy Council. 1992. Survey of Energy Resources, $16^{\text {th }}$ Ed., WEC, London.

Williams, Bob. 2003. "Debate Over Peak-Oil Issue Boiling Over, With Major Implications for Industry, Society," Oil \& Gas Journal, July 14.

Wood, J., G. Long and D. Morehouse. 2000. "Long Term World Oil Supply (A Resource Base/Production Path Analysis)," (7/28/2000) presentation available on the Internet at www.eia.doe.gov. 



\section{APPENDIX A}

\section{DESCRIPTION OF WESM MODEL}





\section{APPENDIX A: DESCRIPTION OF WESM MODEL}

\section{A1. OVERVIEW}

\section{A1.1 PURPOSE}

The World Energy Scenarios Model (WESM) is a tool for using global energy scenarios to 2050 to explore the depletion and expansion of world oil supplies and the transition from conventional to unconventional oil resources, such as heavy oil, tar sands and oil shale.

\section{A1.2 FUNCTION}

The WESM model is designed to carry out four key functions:

1. Manipulation and modification of global energy Scenarios

2. Reconciliation of Scenarios with Cases of N.A. transportation energy use

3. Simulation of the global oil market dynamics of transitions to unconventional oil resources, and

4. Accounting for the depletion of oil reserves and resources, by category and region.

While all energy types are represented in the global energy scenarios, WESM's focus is on world oil markets and oil resources.

Reserve and resource accounting is the key function of the WESM model. Both conventional and unconventional oil resources are considered, including discovered and estimates of undiscovered resources. Also recognized is the potential for expansion of existing and future resources due to enhanced recovery on other factors, enabled by technological advances. Both stocks and flows of resources of six different categories are tracked.

\section{A1.3 STRUCTURE}

For twelve world regions, WESM tracks energy production, primary energy use and final energy use, by energy type. Beginning with integrated world energy scenario databases (Table A1) created by the IIASA and the WEC (Nakićenović, 1998), broad patterns of energy production and use may be customized by the user. Factors that can be manipulated include, (1) rates of improvement in the energy intensities of overall primary and final energy use per dollar of GDP, (2) calibration to U.S. Department of Energy International Energy Outlook (IEO) forecasts to 2020, and (3) calibrations to Champagne model (EEA, Inc., 2002) scenarios of North American transportation use. The ability to modify the IIASA-WEC scenarios is mechanistic. It is not based on energy market and macroeconomic interactions, but rather on the application of userspecified rates of change or calibration to an alternative world energy forecast. 
Table A1. WEC-IIASA Scenarios

\begin{tabular}{ll}
\hline B & Middle Course \\
A1 & High growth, Ample oil and gas \\
A2 & High growth, Return to coal \\
A3 & High growth, Fossil phaseout \\
C1 & Ecologically driven, New renewables with nuclear phaseout \\
C2 & Ecology driven, Renewables and new nuclear \\
\hline
\end{tabular}

Table A2. World Regions and Abbreviations

\begin{tabular}{ll}
\hline USA & United States of America \\
CAN & Canada \\
WEU & Western Europe \\
PAO & Pacific OECD (Japan, Australia, New Zealand) \\
FSU & Newly independent states of the former Soviet Union \\
EEU & Central and Eastern Europe \\
LAM & Latin America and the Caribbean \\
MEA & Middle East and North Africa \\
AFR & Sub-Saharan Africa \\
CPA & Centrally Planned Asia and China \\
PAS & Other Pacific Asia \\
SAS & South Asia \\
IND & Industrialized countries (NAM, WEU, PAO) \\
REF & Reforming economy countries (EEU, FSU) \\
DEV & Developing countries (LAM, MEA, AFR,CPA, PAS, SAS) \\
TRD & International trade \\
WOR & World total \\
\hline
\end{tabular}

Table A3. Energy Types

\begin{tabular}{ll}
\hline Primary Energy Carriers & Final Energy Carriers \\
\hline Coal & Coal \\
Oil products & Oil products \\
Natural gas & Methanol \\
Nuclear energy & Natural gas \\
Hydropower & Hydrogen \\
Biomass commercial & Electricity \\
Biomass noncommercial & District heat \\
Solar energy & Biomass commercial \\
Other renewables (wind, geothermal, wastes) & Biomass noncommercial \\
Total & Total \\
& Solar thermal energy \\
\hline
\end{tabular}

The WESM model is comprised of six ExcelTM ${ }^{\mathrm{TM}}$ workbooks (Figure A1). The IIASA-WEC global energy scenarios data is stored in several worksheets in the Scenario Generator. This 
database includes not only energy use, but also key drivers and indicators such as population, GDP, and energy intensities. The sheet also contains graphs of these variables to facilitate the comparison of scenarios and to aid in choosing a scenario for subsequent model runs.

The Scenario Generator allows the user to select a scenario from the input database and to modify that scenario by specifying alternative rates of change in the energy intensities for primary and final energy use, and by calibrating the scenario to base year 2000 energy use or to an IEO 2002 forecast.

Champagne Model Outputs for Canada and the United States must be stored in the North American/Conversion Module spreadsheets by the user. A Base Case, plus up to three alternative cases can be handled at one time. The North American/Conversion Module calibrates the modified global scenario to a Champagne Case, and converts an IEO forecast from quads to Gtoe for calibrating an IIASA/WEC scenario.

A modified and calibrated scenario is passed from the Scenario Generator to the Resource Accounting Module. Resource accounting is done twice. On the first pass the calibrated scenario numbers are used to produce initial estimates of resource depletion, as well as conventional and unconventional oil supply by region. Long-run production cost estimates based on each region's depletion status are also calculated in the Resource Accounting Model. The initial estimates of conventional and unconventional oil supply and production costs by region are used by the Oil Market Model to calibrate regional oil supply and demand curves, by year.

Oil primary energy use, production and long-run costs from a calibrated Scenario-Case are passed to the Oil Market Model. The Oil Market Model calibrates supply and demand curves and solves for a new oil market equilibrium price at which regional supplies and demands of both conventional and unconventional oil equilibrate. The model solves demand for all twelve regions and supply for eleven regions. Production from the MEA (Middle East and North Africa) region is used to represent OPEC, and is treated as exogenous. The results of the Oil Market Model equilibration are then passed back to the Resource Accounting Model, where oil resource depletion and expansion are calculated.

Finally, results from the Oil Market and Resource Accounting Models are collected in the Output Report Generator. In addition to collecting results from Scenario-Case runs, the Output Report Generator also controls the execution of model runs. Key assumptions are also input here to facilitate constructing and documenting model runs. From the Output workbook printable tables and graphs illustrating results can be sent to the Results workbook. 
Figure A1. World Energy Scenarios Model Structure

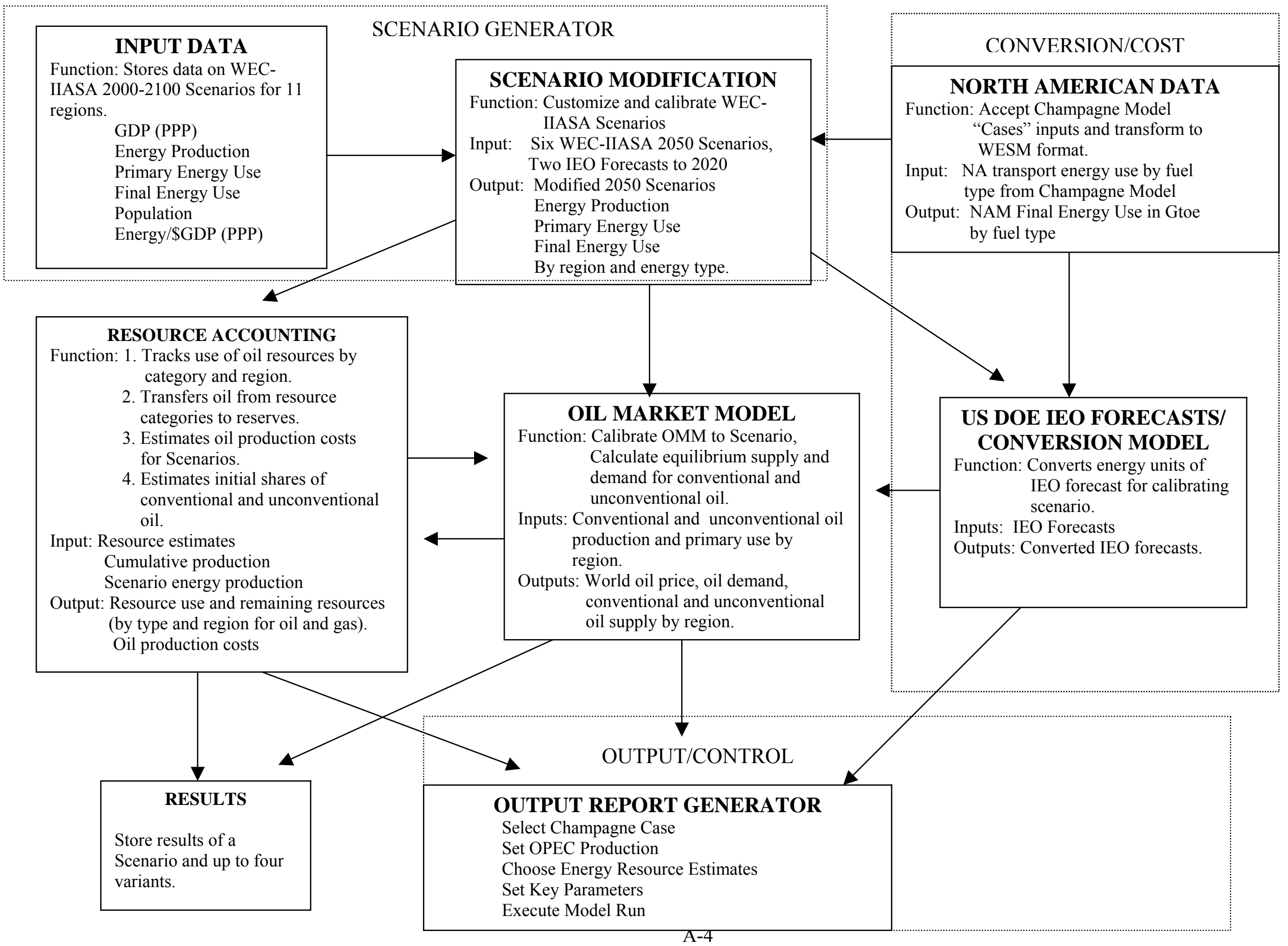




\section{A1.4 IMPLEMENTATION}

The model has been implemented as a set of six, linked Excel ${ }^{\mathrm{TM}}$ Workbooks. For risk analysis simulations the workbooks are accessed by means of @ Risk ${ }^{\mathrm{TM}}$ software (Pallisade Corp., 2002).

Running the model requires (1) creating a scenario with the Scenario Generator, (2) modifying the scenario to make it consistent with a selected Champagne Model, (3) defining a path of MEA oil production, (4) entering parameter assumptions, and (5) copying results to the Results workbook to be saved or printed.

\section{A2. SCENARIO GENERATOR}

The scenario generator contains data from the six IIASA/WEC (Nakićenović, Grübler and McDonald, 1999) Scenarios, and permits modification of these scenarios to create an initial WESM Scenario. The six IIASA/WEC Scenarios were driven by assumptions about population and economic growth, choices among primary energy sources, and the rate of technical efficiency improvement. The scenario generator allows for changes to the rate of technical efficiency improvement.

All six IIASA/WEC Scenarios assume major improvements in energy efficiency, as measured by energy use per dollar of GDP. ${ }^{14}$ In the C Scenarios, energy use per dollar declines by a factor of five over the next century (Figure A2). By 2050, energy use per dollar is more than halved in the $\mathrm{C}$ Scenarios, and reduced by about 60 percent in the $\mathrm{B}$ and A Scenarios. While declining energy use per dollar of GDP has been a relatively consistent trend during the latter half of the $20^{\text {th }}$ Century, it has not always been the case. It is therefore reasonable to allow examination of future scenarios with less dramatic reductions in energy intensity.

From the patterns in Figure A1, it is evident that energy intensities decline approximately exponentially in all IIASA/WEC Scenarios. The average rates of decline in final energy use range from $-0.7 \% / y r$. in the B Scenario to $-1.3 \% / y r$. in the $\mathrm{C}$ Scenarios. Primary energy intensity declines even more rapidly, reflecting gains in the efficiencies of energy conversion technologies (Figure A3).

The Scenario Generation spreadsheet allows the user to specify a new rate of change in energy intensity, in order to modify or override the rate implied by a IIASA-WEC Scenario. The rate of change in energy intensity may be increased or decreased by multiplying by the user-specified factor, $(1+r)$.

\footnotetext{
${ }^{14}$ The IIASA-WEC Scenarios provide GDP measured either in US dollars or adjusted for regional purchasing power parity (PPP). The WESM default is to use PPP-adjusted GDP.
} 


$$
\left(\frac{E}{G D P}\right)_{t}^{N E W}=\left(\frac{E}{G D P}\right)_{t}(1+r)^{t}
$$

Equation 1

Figure A2.

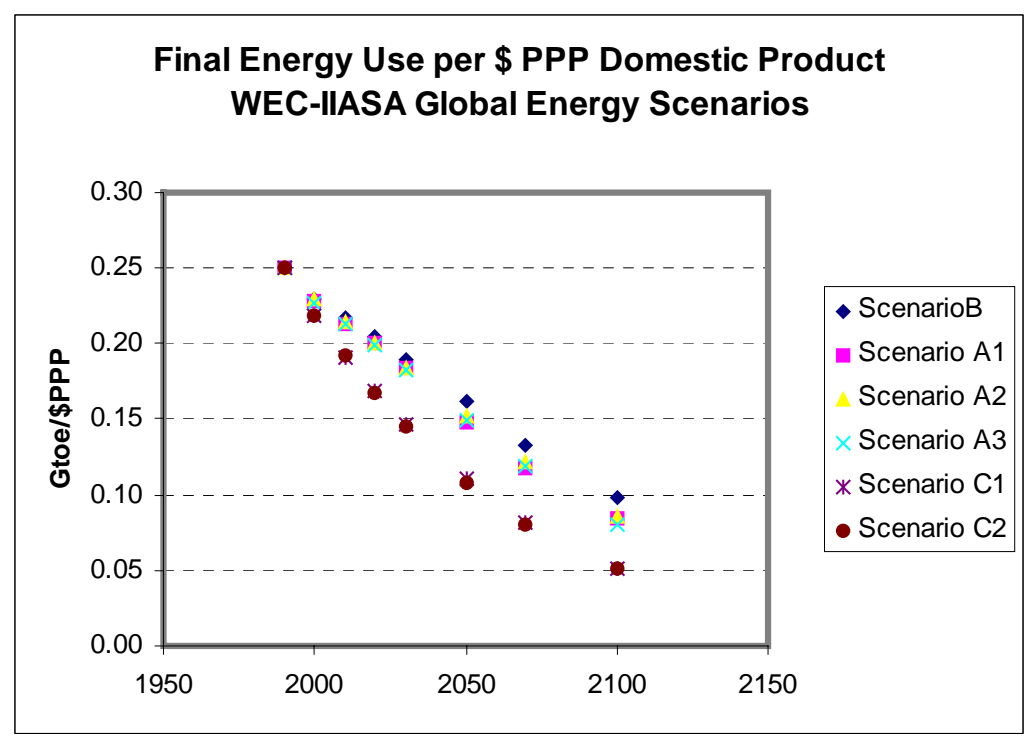

Figure A3.

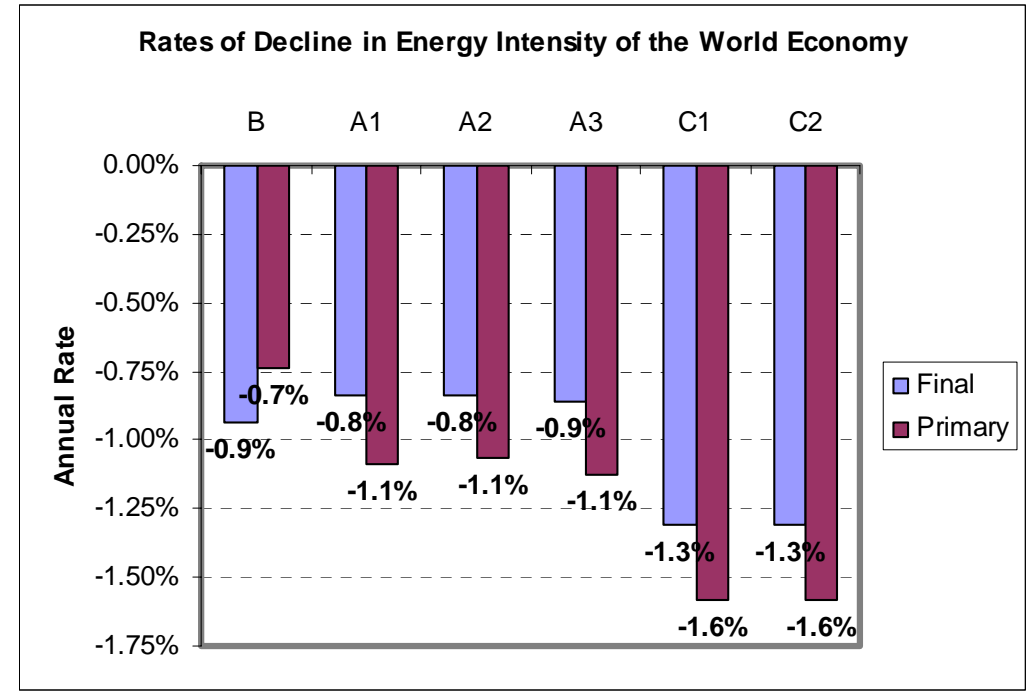

For example, the rate of change in the energy intensity of final energy use in Scenario B is $-0.9 \% / y r$., which implies a ratio of 0.991 between succeeding years. By choosing $r=$ 0.0091 , the decrease in final energy intensity in the B Scenario would be effectively nullified $(0.991 \times 1.0091=1.00002)$. Final energy intensity would remain essentially constant. The Scenario generator allows different rate adjustment factors for final and primary energy intensity, but does not allow different factors for different fuel types. 
Scenarios may be calibrated either to base year 2000 data or to one of three International Energy Outlook 2002 forecasts to 2020 (U.S. DOE/EIA, 2002): (1) Reference Case, (2) High Economic Growth, and (3) Low Economic Growth. Calibration to base year 2000 simply factors the scenario projections up or down so that they pass through year 2000 actual energy supply and demand by region and fuel type. Calibration to an IEO 2002 forecast replaces the IIASA/WEC scenario energy production and primary energy use with the IEO forecast through 2020. Final energy use is not specified by the IEO forecast. The IIASA-WEC scenario's final energy use is factored up or down in proportion to the IEO forecast's primary energy use. This procedure would leave a discontinuity between years 2020 and 2021. A weighted average splining method is used to smooth the transition from the IEO 2020 forecast back to the uncalibrated scenario.

\section{A3. RESOURCE ACCOUNTING}

The Resource Accounting Module tracks stocks (reserves and resources) and flows (production and transfers) by region, energy type and year from 1996 to 2050. Beginning with initial estimates of world energy resources by energy type and resource category, this module performs the critical function of accounting for the use of oil and natural gas resources over time. It also estimates long-term trends in the costs of oil production by region as a function of the percent of ultimate resources that have already been produced. All the calculations are carried out at the regional level.

The accounting begins with an initial inventory of oil and gas resources by six categories, following Rogner (1997). The six categories describe the world's oil and gas resources according to the likely cost of development and the degree of certainty about their existence and extent. To this, a seventh category, resources already produced, is added. The inventory is updated to 2000 based on production of crude oil and NGLs. For each future year, production of oil by region, as specified in a Scenario, is subtracted from proved reserves (Category I). Two types of proved reserves are tracked, conventional and unconventional. Other resource categories are transferred to proved reserves over time depending on the rate of production and user-specified, exogenous assumptions. Thus, there are continuous flows of oil out of proved reserves to production, and into proved reserves from other resource categories. The definitions of reserve categories are essential to understanding the logic of these resource flows.

\section{A3.1 RESOURCE CATEGORIES}

Accounting for resources begins with base year inventories of fossil energy resources. Three sources have been used for estimates of oil, gas and coal energy by resource category: (1) Rogner, 1997, (2) USGS, 2000, and (3) Campbell, 2001 and 2003. Cumulative production to 1996 based on USGS (2000) is used for all three sets of resource estimates. 
Rogner (1997) distinguishes eight resource categories for oil and gas occurrences and ten for coal (Table A4). Only six categories are accounted for in WESM. Additional occurrences of unconventional resources (categories VII and VIII) are comprised of very low-grade resources and resources unrecoverable (left in situ) after enhanced recovery. They are assumed not to be used before 2050. Definitions of the six categories are as follows:

Category I: Known, measured reserves that are either known or believed to be economically recoverable. This includes both proved and probable reserves.

Category II: Undiscovered occurrences that are believed to exist and have a reasonable probability of being discovered and of being economically developable. Presumably, exploration and development efforts will replenish Category 1 reserves with Category 2 resources. Roughly intended to correspond to Masters' et al. (1994) "mode or 50 percent probability of being discovered," or to the WEC definition of "estimated additional reserves."

Category III: More speculative resources, roughly corresponding to the difference between Masters' et al. (1994) 50 percent and 5 percent probability estimates of undiscovered oil and gas. Using this definition, the most likely estimate of the size of these reserves would be close to zero.

By definition, Category I-III resources are believed to be developable with the application of existing recovery technology. What distinguishes them is the certainty with which they are believed to exist.

Category IV reflects the potential for technological advances to enhance oil recovery and thereby increase the fraction of in situ oil recoverable from existing and future fields. According to Rogner's definition this category does not represent additional undiscovered oil, but technological advances permitting greater production from Categories I-III. In the past, 34 percent of oil and 70 percent of in situ gas has been recoverable. Rogner (1997) assumes that for Categories I-III, 40 percent of oil and 80 percent of gas will be recoverable. In the United States, the average recovery rate for fields in the lower 48 states increased from 1967 to 1979 at an average annual rate of 0.2 percent (Porter, 1995), and further increases are likely in the future. However, when USGS source estimates are used we use the USGS 2000 category of "reserve growth" as Category IV oil. There is considerable controversy about this estimate, as explained in Part I of the main body of the report. The USGS apparently intends it to represent the effects of both technology and initial underestimation of field sizes. 
Table A4. Estimates of Oil Occurrences, 1995, in Gtoe

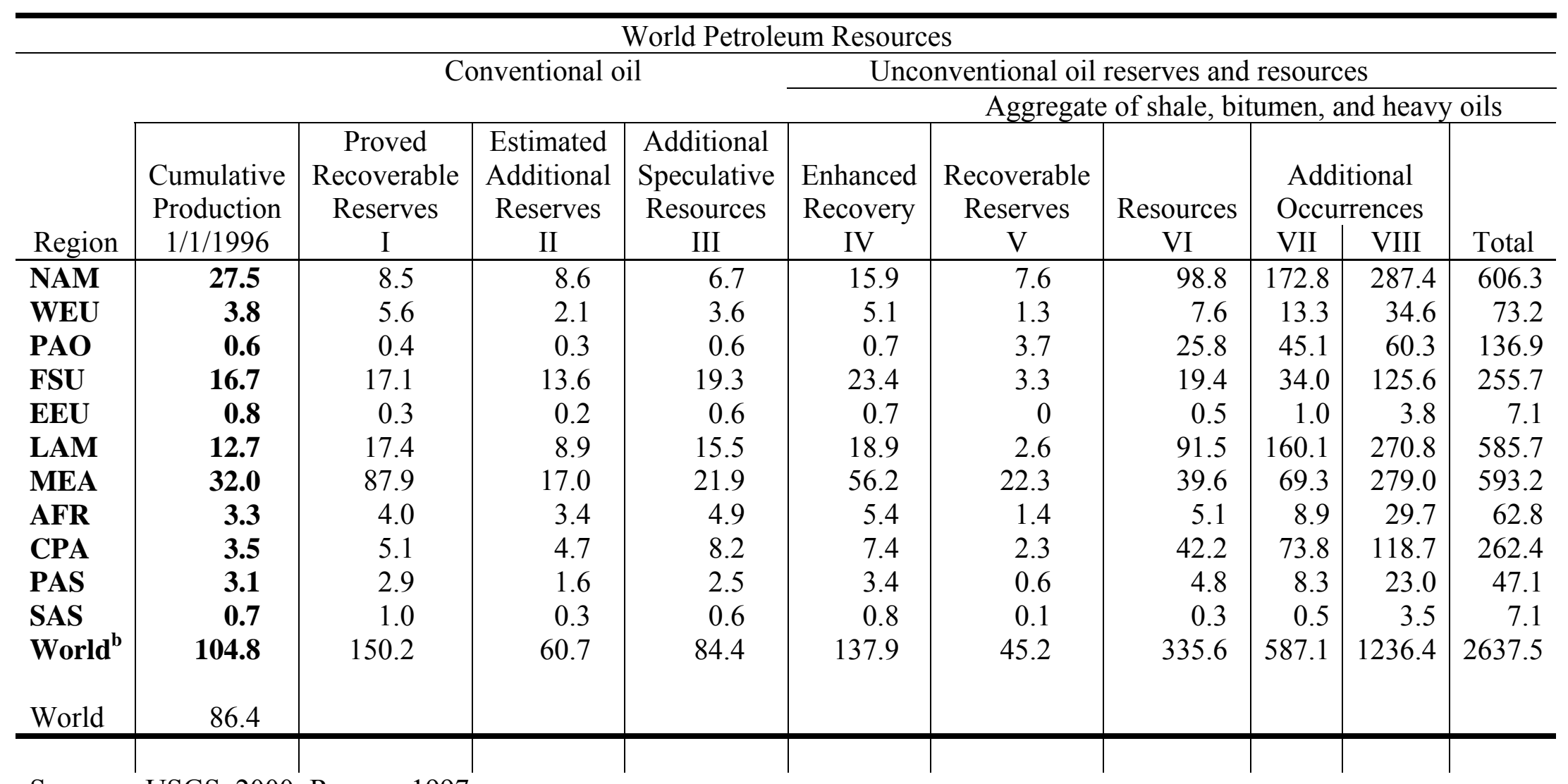

Sources: USGS, 2000; Rogner, 1997

${ }^{\text {a }}$ Compiled from Tables 2 and 3

${ }^{\mathrm{b}}$ Totals may not add up owing to rounding. 
Categories V-VIII represent unconventional sources of oil and gas. Unconventional oil resources include extra heavy oils, oil and tar sands, deep-sea oils, bitumen, and shale oil. Unconventional natural gas includes gas in Devonian shales, tight sandstone formations, geopressured aquifers, coal bed methane, and methane hydrates. In some cases, synthetic crude oils are already being produced from these sources (e.g., Canadian Athabasca Oil Sands and Venezuelan extra heavy oil). In others, such as the 85 percent of oil shales that contain less than 0.08 percent oil by weight or deep sea methane hydrates, serious questions exist about whether these resources will ever be produced economically.

Category V comprises the identified reserves of unconventional oil and gas. For Rogner (1997) it is the sum of WEC (1992) estimated shale reserves, BGR (1995) tar sands reserves and Meyers et al. (1988) estimated heavy oil reserves. These are the reserves that can be produced economically at current market prices.

Rogner allocated all remaining occurrences between categories VI, VII and VIII according to a 20:35:45 ratio. In addition, all the oil remaining in the ground after conventional and enhanced recovery is allocated to Category VIII. Categories VII and VIII have been excluded from production by 2050 WESM.

\section{A3.2 RESOURCE STOCKS AND FLOWS}

\section{Category I, Proved Reserves}

Regional Proved Reserves (I) and Unconventional Recoverable Reserves (V) are the sole sources for regional oil production. All other categories of conventional oil resources may flow into proved reserves, but production can be taken only from proved reserves. Similarly, unconventional resources (VI) may flow into unconventional recoverable reserves (V), but production may come out only from unconventional recoverable reserves. In the equations below, regional subscripts have been omitted for simplicity, although all calculations are carried out at the regional level.

The equation for the stock of proved reserves at the beginning of year $t, X_{\mathrm{Pt}}$, consists of last year's proved reserves $\mathrm{X}_{\mathrm{Pt}-1}$ (at the beginning of the year), minus last year's production, $\mathrm{V}_{\mathrm{Pt}-1}$, plus reserve expansion at the rate of $\delta \times 100$ percent per year, plus the inflow from estimated additional reserves, $\mathrm{V}_{\mathrm{At}-1}$, plus the inflow from speculative reserves, $\mathrm{V}_{\mathrm{St}-1}$. The rate of reserve expansion is a user-specified parameter. Once the total quantity of category IV (EOR/Reserve Growth) estimated to be available has been exhausted, reserve expansion ceases.

$$
X_{P t}=X_{P t-1}-V_{P t-1}+\delta X_{P 1995}+V_{A t-1}+V_{S t-1}
$$

Equation 2

The flow from proved reserves, $\mathrm{V}_{\mathrm{Pt}}$, is equal to the quantity of production required by the scenario, $\mathrm{Q}_{\mathrm{t}}$, provided that the reserve to production ratio, $(\mathrm{R} / \mathrm{P})=\left(\mathrm{X}_{\mathrm{Pt}} / \mathrm{Q}_{\mathrm{t}}\right) \geq \rho$, a target $\mathrm{R} / \mathrm{P}$ ratio. Otherwise, only a fraction of production is taken from proved reserves. The 
fraction is a weighted average of the previous year's production-to-reserves ratio and the target production-to-reserves ratio $\left(\frac{1}{\rho}\right)$.

$$
V_{P t}=Q_{t} \quad \text { if } \quad \frac{X_{P t}}{Q_{t}} \geq \rho
$$

Otherwise,

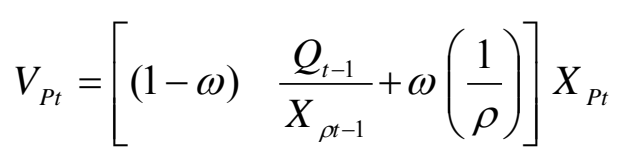

Equation 3

Where $\omega$ is a user-specified adjustment rate ( 0.2 by default). This function creates a smooth transition between the past year's production level and that implied by the target $R / P$ ratio. The model user must specify the target $R / P$ ratio.

The transfer from estimated additional reserves to proved reserves is set equal to the current year's outflow from proved reserves, if the available stocks of estimated additional reserves divided by the outflow from proved reserves exceeds a desired $\mathrm{R} / \mathrm{P}$ ratio $\left(\rho^{*}\right)$. The desired $\mathrm{R} / \mathrm{P}$ ratio is the minimum of the target $\mathrm{R} / \mathrm{P}$ ratio and the region's actual R/P ratio in 1995. If a region's stock of estimated additional reserves is inadequate, an amount equal to the actual stock divided by the desired $\mathrm{R} / \mathrm{P}$ ratio is transferred.

$$
V_{A t}=V_{p t} \quad \text { if } \quad \frac{X_{A t}}{V_{p t}} \geq \rho^{*}
$$

Otherwise,

$$
V_{A t}=\frac{X_{A t}}{\rho^{*}}
$$

Equation 4

\section{Category III, Additional Speculative Resources}

Rogner (1997) defines Category III resources as the difference between Masters et al.'s (1994) 50 percent probability estimate of recoverable conventional oil resources and their 5 percent estimate. Thus, according to Masters et al., the most probable amount of oil that will be found in this category, as it is defined by Rogner, is close to zero. By definition, speculative resources have yet to be discovered. Therefore, the representation of their production in WESM should begin close to zero, increase and then, ultimately, decline. One such model is the logistic curve, which can be derived from a few simple assumptions. The adequacy of the logistic curve as a representation of the complete cycle of oil development, however, is highly controversial. It is used here simply to provide a means of converting speculative to proved resources at user-specified rates. 
The most basic premise of the logistic model is that production of an oil region will pass through four stages: (1) production increasing at an increasing rate, (2) production increasing at a decreasing rate, (3) production decreasing at an increasing rate, and (4) production decreasing at a decreasing rate. The simplest model of this process can be derived as follows. ${ }^{15}$

Let $X^{*}$ be the ultimately recoverable quantity of speculative resources for region $r$ (the subscripts $r$ and $s$ are omitted for simplicity). Let $X_{t}$ be the quantity remaining at time $t$. (Since, in WESM, speculative resources must be converted into proved reserves before being produced, $X_{t}$ is more precisely the quantity not yet converted to proved reserves at time t.) It is assumed that the rate of production (conversion), $\mathrm{dX}_{t} / \mathrm{dt}$, is proportional to: (1) the state of knowledge about the resource, and (2) the amount of the resource that remains to be produced $\left(X_{t}\right)$. As more of the resource is produced, more is learned about the location and condition of the remaining resource and so the state of knowledge is assumed to be proportional to the amount of the resource already produced (i.e., $X^{*}-X_{t}$ ). These assertions correspond to the following non-linear differential equation.

$$
\begin{aligned}
& \frac{d X_{t}}{d t}=k X_{t}\left(X^{*}-X_{t}\right) \\
& \frac{d\left(X_{t} / X^{*}\right)}{d t}=\frac{d \delta_{t}}{d t}=k \delta_{t}\left(1-\delta_{t}\right)
\end{aligned}
$$

Equation 5

Its solution is the following logistic equation, in which $\mathrm{C}_{0}$ is a constant of integration that depends on, $\mathrm{X}_{\mathrm{o}}$, the quantity already produced at time $\mathrm{t}=0$ (or, equivalently, on $\delta_{\mathrm{o}}$ ).

$$
\delta_{t}=\frac{1}{1+e^{-k t+C_{o}}}
$$

Equation 6

The parameter $\mathrm{k}$ describes both the rate of learning and the rate of production from the remaining resource.

Calibration of the speculative resource development model requires the model user to specify three parameters: (1) the fraction of speculative resources assumed to exist $\alpha$, (2) the fraction that has already been converted to proved reserves in the base year $\left(\delta_{0}\right.$, in general, a small number), and (3) the year, $\tau$, in which half of the available speculative resources will have been transformed to proved reserves.

The constant $\mathrm{C}_{\mathrm{o}}$ is directly calculated from $\delta_{0}$.

\footnotetext{
${ }^{15}$ The derivation given here is similar to Reynolds' (2002, ch. 1) derivation of the Hubbert model.
} 


$$
C_{o}=-\ln \left(\frac{1}{\delta_{o}}-1\right)
$$

Equation 7

The rate of conversion will reach a maximum when $X=X^{*} / 2$, i.e., when half of the speculative resources have been converted. The value of $\mathrm{k}$ can be readily computed from an assumed peak production time, $\tau$.

$$
k=\frac{C_{o}}{\tau}
$$

Equation 8

The flow of speculative resources is their discovery and conversion into proved reserves. A year's flow is the difference between cumulative discovery at the end of the year and at the beginning.

$$
V_{s t}=X_{s t}-X_{s t-1}
$$

Equation 9

The stock of speculative resources may expand due to enhanced recovery.

$$
X_{S t}=X_{S t-1}+\alpha \delta X_{S 1996}-V_{S t-1}
$$

Equation 10

This equation allows reserve expansion only for the fraction of speculative reserves believed to exist $(\alpha)$.

\section{Category IV, Enhanced Recovery/Reserves Growth}

Category IV resources represent the potential for technological advances, learning, and perhaps higher oil prices, to permit the economic recovery of a greater percentage of in situ oil. Historically, only about 35 percent to 40 percent of the oil in situ could be economically recovered, but recovery rates have been improving over time. Porter (1995, pp. 36-37), for example, cites an expansion rate of $0.2 \% / y e a r$ for reserves in the lower 48 between 1966 and 1979. There is substantial controversy about the amount that enhanced oil recovery will contribute to the world's proved reserves over the next 50 years. Reserve growth is also a controversial subject that has been discussed in the main body of the report.

Since "flows" from enhanced recovery, as seen in the equations above, are calculated as a percentage of the total base year resource quantity, it is only necessary to keep track of the stock, $X_{E t}$. 


$$
X_{E t}=X_{E t-1}-\delta\left(X_{P 1996}+X_{A 1996}+\gamma X_{S 1996}\right)
$$

Equation 11

When the remaining stock of $X_{E t}$ falls below a user-specified minimum level, e.g., 0.01 Gtoe, reserve growth/enhanced recovery expansion stops.

\section{Categories V and VI, Unconventional Recoverable Reserves and Resources}

A key issue is how to determine when unconventional oil will penetrate the world oil market and what its share will be. The Resource Accounting and Oil Market Modules handle this in two steps. First, unconventional recoverable reserves are treated as a global backstop for proved conventional reserves. They may be produced whenever the call on production from a region, $\mathrm{Q}_{t}$, cannot be satisfied from the region's proved reserves (Category I). Whenever this occurs a deficit, $D_{\mathrm{rt}}$, for region $\mathrm{r}$ in year $\mathrm{t}$ is created. The sum of deficits over all regions is an initial estimate of the total amount of unconventional oil to be produced.

$$
V_{U t}=\sum_{r} D_{r t}=\sum_{r}\left(Q_{r t}-V_{\mathrm{Pr} t}\right)
$$

Equation 12

The total initial call on unconventional proved reserves is allocated to regions in proportion to their shares of world unconventional proved reserves.

$$
V_{U r t}=V_{U t} \cdot\left(X_{U r t} / X_{U t}\right)
$$

Equation 13

$\mathrm{V}_{\mathrm{Ut}}$ will be greater than zero when any region's $\mathrm{R} / \mathrm{P}$ ratio falls below the user-specified critical level.

The initial regional "backstop" estimates of unconventional oil production are passed to the Oil Market Module where they are used to calibrate unconventional oil supply curves and a market equilibrium of demand and supply for conventional and unconventional oil. If the cost of producing unconventional oil from a given region is high relative to the cost of conventional oil from other regions, the market equilibration will shift production away from unconventional and towards conventional oil.

The Oil Market Model thereby produces a second-round estimate of unconventional oil production that is passed back to the Resource Accounting model, where a second, final accounting of resource depletion is carried out. If the quantity of unconventional oil required in the second-round exceeds available reserves of unconventional oil, the deficit is simply recorded as a deviation from the scenario. This prevents unconventional stocks from becoming negative. 
The stock of unconventional recoverable reserves receives an inflow, $V_{R}$, from unconventional resources (Category VI) as these resources are discovered and as technology advances to permit their economical recovery.

$$
X_{U t}=X_{U t-1}-V_{U t-1}+V_{R t-1}
$$

Equation 14

The fraction of unconventional resources transferred, $f_{t}$, is a logistic function of the region's actual ratio of production to reserves $\left(\mathrm{V}_{\mathrm{pt}} / \mathrm{X}_{\mathrm{pt}}\right)$ and an ideal production-toreserves ratio $(\mathrm{P} / \mathrm{R})$. A different $\mathrm{P} / \mathrm{R}$ ratio can be specified for each region. The function is initially calibrated so that the transfer from unconventional resources equals current production. It is also calibrated so that a $1 \%$ deviation from the desired $\mathrm{P} / \mathrm{R}$ ratio will cause a $1 \%$ increase in the flow from unconventional resources to reserves.

$$
V_{R t}=X_{R t} f_{t}=\frac{X_{R t}}{1+e^{A+\alpha\left(\frac{V_{U t}}{X_{U t}}-\frac{P}{R}\right)}}
$$

Equation 15

Assumptions for calibrating equation 15 insure that in the first year, the flow from unconventional resources to reserves exactly equals production from unconventional reserves.

$$
A=\ln \left(\frac{X_{R 0}}{V_{U 0}}-1\right)-\alpha\left(\frac{V_{U 0}}{X_{U 0}}-\frac{P}{R}\right)
$$

Equation 16

If the difference between the actual and ideal production-to-reserves ratio is about -0.01 (as it would if the ideal $\mathrm{R} / \mathrm{P}=15$ and the actual were 18), then $\alpha$ should be about -100 for the elasticity of $(\beta)$ the flow from proved reserves with respect to the deviation from the ideal $\mathrm{P} / \mathrm{R}$ ratio to be about 1.0 . This would imply that a $1 \%$ change in the deviation from the ideal $\mathrm{R} / \mathrm{P}$ ratio would produce a $1 \%$ change in the flow from estimated additional reserves to proved reserves.

$$
\beta=\alpha\left(\frac{V_{U 0}}{X_{U 0}}-\frac{P}{R}\right)\left(1-f_{t}\right) \approx-100(0.011) 0.95 \approx 1
$$




\section{A3.3 DEPLETION-BASED PRODUCTION COST ESTIMATION}

The Reserve and Resource Accounting Module produces an initial estimate of the longrun cost of producing oil for each region a function of the state of depletion of the region's ultimate resources (as opposed to reserves). Following an approach outlined by Rogner (1997), production costs, $C_{\mathrm{rt}}$, are assumed to rise as a logistic function of the state of depletion, $\Phi_{\mathrm{rt}}$, of total ultimate resources. State of depletion is defined as the fraction of total resources that have been consumed at time t. For conventional oil, total resources are defined as the sum of cumulative production, proved reserves, estimated additional reserves, plus the fraction of additional speculative reserves assumed to exist, plus the eventual reserve expansion due to enhanced recovery over the period 1995 to 2050. For unconventional oil, total resources are defined as reserves plus resources. The price rise with state of depletion depends on parameters defining the slope, $\beta$, and intercept, $\alpha_{\mathrm{r}}$, of the logistic curve. Intercepts are allowed to vary across regions. ${ }^{16}$

$$
P_{r t}=\left(\ln \left[\frac{1}{\phi_{r t}}-1\right]-\alpha_{r}\right) / \beta
$$

Equation 18

An illustrative curve is shown in Figure A4.

Figure A4.

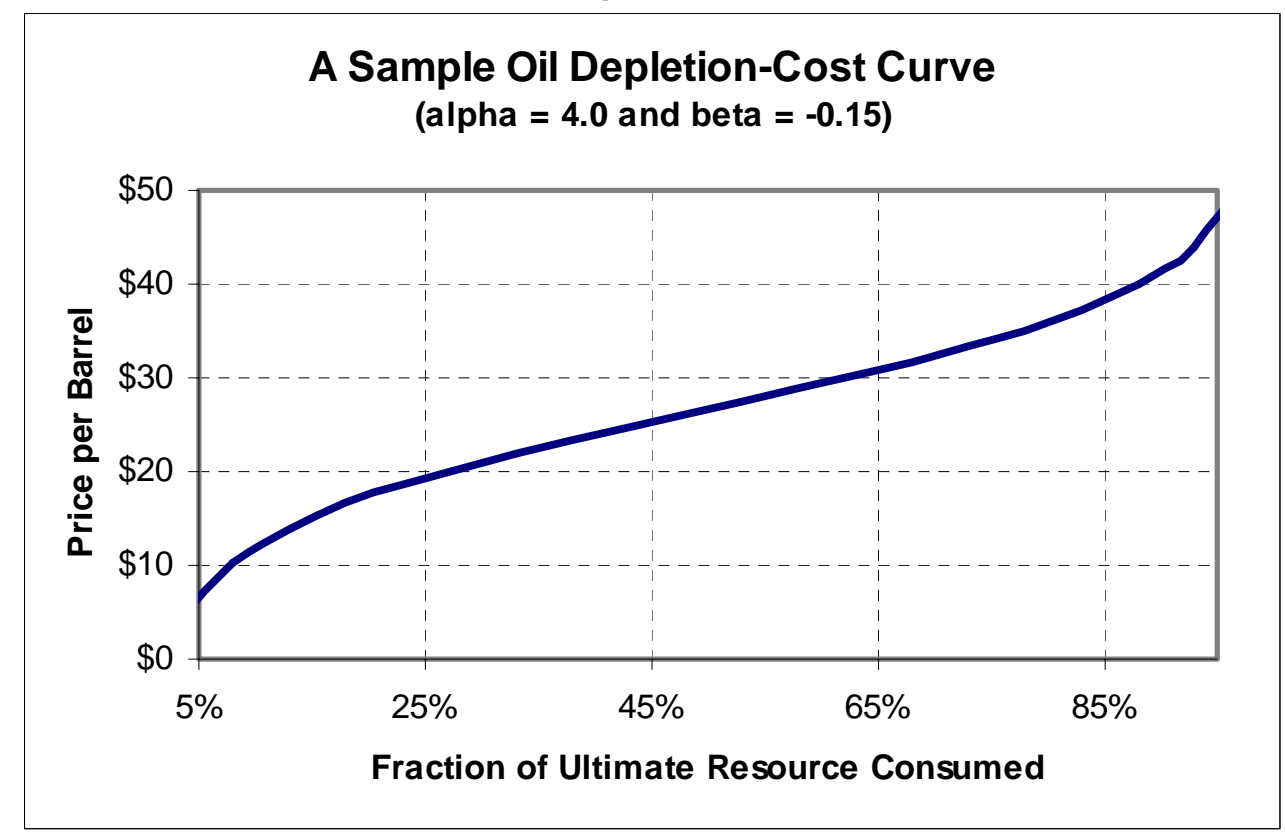

${ }^{16}$ Because $P_{r t}$ would otherwise approach infinity as the state of depletion approached 1.0, an upper bound is set on $\Phi_{\mathrm{rt}}$. This upper bound, in effect, defines a backstop price for liquid fuels from other energy sources. In the analyses described in this report, and upper bound on depletion of $95 \%$ was assumed. 


\section{Long-Run Costs of Producing Conventional and Unconventional Oil}

Calibration of the depletion cost curves requires an estimate of the current long-run cost of oil production in each region. Unfortunately, information on regional production costs is not readily available even for conventional oil. The interconnectedness of the world oil market notwithstanding, there is evidence that production costs vary substantially from region to region (e.g., Porter, 1995, and Stauffer 1994). Setting aside the Middle East where producers clearly act non-competitively, it is reasonable to ask why production cost estimates should vary so much (Figure A5). First, not all factors that determine the total cost of bringing oil to the market are included in the available regional estimates. The estimates by Stauffer (1994) include all exploration and development outlays, including a $15 \%$ real rate of return, but exclude taxes (or subsidies) and operating costs, which can be substantial and vary from region to region. The cost estimates also make no attempt to account for risk, which in some regions is a significant component of the cost of doing business. Nor do they address institutional issues such as the performance and reliability of local infrastructure. Second, even in a region where average costs are low, marginal costs may be similar to other regions and it is the marginal cost that defines the regional supply curve. Still, it is not clear whether these factors are able to explain regional differences in production cost estimates.

For conventional oil, it is assumed that all regions other than MEA behave as competitive producers. The world oil market has been in operation for many decades. Economic theory suggests that the full marginal cost of producing a barrel of oil from each region should tend to be the same for all competitive regions. ${ }^{17}$ This marginal cost will not necessarily equal any given year's market price of oil, since prices fluctuate widely and supply adjusts slowly. In theory, there is a long-run price which depends on past prices and to which the market has adjusted at any particular time. For the year 2000, the longrun price is assumed to be $\$ 20 / \mathrm{barrel}$. This long run price, plus the state of depletion of each region is assumed to be a point on the region's depletion cost curve. The complete regional curve is then defined by assuming a price slope.

Information about the costs of unconventional oil production outside of Canada and Venezuela is scarce, and estimates of shale oil production costs in the United States date primarily from the 1970s and 1980s. Current supply cost estimates cited by the IEA (2002) range from $\$ 5$ to $\$ 20$ per barrel for Canadian oil sands, and around $\$ 8 / \mathrm{bbl}$ for Venezuelan extra-heavy oil. Shale oil production cost estimates range from $\$ 60 / \mathrm{bbl}$ upwards (OTA, 1980). Future supply costs could be lower or higher, depending on the rate of technological progress, the ease of production from remaining occurrences, the costs of environmental remediation, and of inputs to the production process. Thus, the results of simulating oil market dynamics will be dependent on assumptions based on scant information.

${ }^{17}$ It is recognized that in reality this assumption will not generally be satisfied, for a variety of reasons, ranging from government ownership of national oil companies to market disequilibrium, and so on. It is argued that the assumption is still useful because it imposes logical consistency on the model and because equating the marginal cost of producing oil will be a strong tendency in the market, even if it is not strictly satisfied at any time. 
Figure A5. Regional Costs of Oil Production (after Stauffer, 1994)

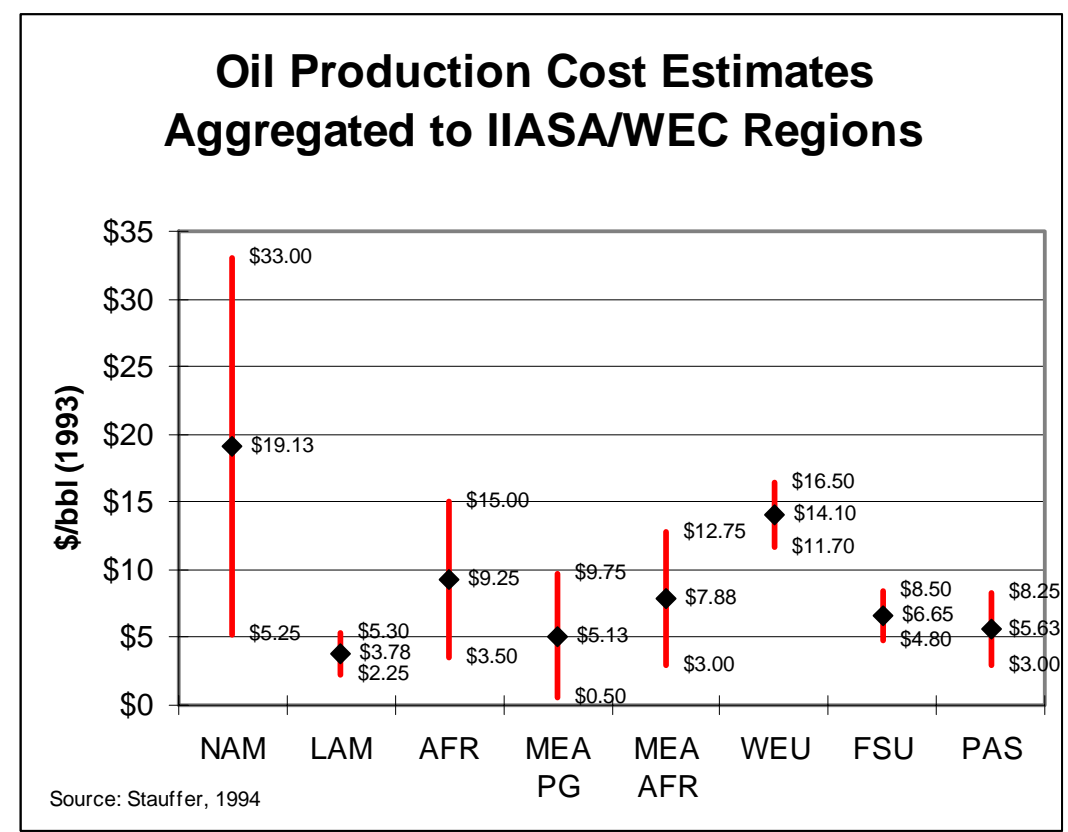

Substantial information on the costs of producing Canadian oil sands is available (Cliffe, et al., 2002). Supply cost estimates, covering exploration, development and production, including capital costs, operating costs, taxes, royalties and a $10 \%$ rate of return on investment range from \$US5 to \$US22 per barrel. Costs vary depending on resource quality, recovery method, project size and the price of natural gas for fuel and gas condensate for diluting syncrude for shipment by pipeline (Table A5). In general, in situ operations are less costly than strip mining and are appropriate for the larger share of Canadian oil sands resources.

Other sources report that several Canadian oil sands projects have widely fluctuating costs for current operations (Roberts, 2002). Syncrude corporation was reported to have produced 81 million barrels of synthetic crude in 1999 at a cost of \$Can12.64, of which \$Can11.44 were direct operating costs. ${ }^{18}$ However, a variety of problems caused costs to jump to $\$$ Can18.47 in 2001. Suncor reported production costs of \$Can12.50 (\$US8.40) in 2001 , and noted that production costs had fallen by $25 \%$ over the past ten years. Cost overruns for development projects have apparently been seen, and the lack of availability of labor has been cited as a chief cause.

Several factors could cause oil sands supply costs to increase in the future, while continued technological progress might produce further declines. Some have questioned whether the rate development of Canada's oil sands may not be limited primarily by the difficulties caused by labor requirements. Large settlements must be rapidly developed in remote, ecologically sensitive regions. Availability of adequate water supplies for

18 This seems like an extremely small non-operating cost component, raising questions about the definitions used to calculate these cost estimates. 
expanding operations is also a concern (Economist, 2003). Expanding production to very high levels (5-15 MMBD) could produce unacceptably high social costs in the form of enormous boom and bust settlements. Bitumen from mining is generally upgraded by means of coking or hydrocracking and desulphurization to synthetic crude oil with similar characteristics to light sweet crude. Crude from in situ operations is currently made transportable by mixing with $33 \%$ to $40 \%$ pentanes plus (a byproduct of natural gas production). Expanding in situ operations several fold would require huge capital investments for on-site upgrading since pentanes plus supplies are limited. In short, while current production costs are reasonably well understood, the costs of greatly expanded production (ten times, or more) are highly uncertain.

Table A5. Supply Cost Estimates for Canadian Oil Sands (1997 US\$)

\begin{tabular}{ccc}
\hline \multicolumn{1}{c}{ Resource Type } & Operating Cost & Supply Cost \\
\hline Oil Sands - In Situ (Cliffe, et al., 2002) & & \\
Primary Recovery - Wabasca & $\$ 3-6$ & $\$ 7-10$ \\
Primary Recovery - Cold Lake & $\$ 6-9$ & $\$ 10-13$ \\
$\quad$ Cyclic Steam Stimulation & $\$ 6-10$ & $\$ 10-16$ \\
$\quad$ Steam Assisted Gravity Drainage & $\$ 5-9$ & $\$ 8-14$ \\
Oil Sands - Mining (Cliffe, et al., 2002) & & $\$ 15-18$ \\
$\quad$ Integrated Mining \& Upgrading & $\$ 10-12$ & $\$ 18-22$ \\
$\quad$ Stand-Alone Upgraders & $\$ 10-12$ & $\$ 10-13$ \\
Mining - No Upgrading & $\$ 5-8$ & \\
In Situ (Raw Bitumen Production) (IEA, 2002) & & $\$ 5-10$ \\
$\quad$ Primary Recovery & $\$ 2-7$ & $\$ 8-12$ \\
$\quad$ Cyclic Steam Stimulation & $\$ 5-8$ & $\$ 6-11$ \\
$\quad$ Steam Assisted Gravity Drainage & $\$ 4-7$ & \\
Integrated Mining and Upgrading (IEA, 2002) & & $\$ 11-16$ \\
$\quad$ Expansion of Existing Plants & $\$ 6-10$ & $\$ 15-20$ \\
$\quad$ Greenfield Plants & $\$ 6-10$ & \\
\hline
\end{tabular}

Source: Cliffe, 2002; IEA, 2002.

Costs of producing Venezuelan heavy oil have been put at \$7-10 (IEA, 2002). More than half of the roughly $\$ 8 /$ barrel cost of Venezuelan heavy oil is due to upgrading; extraction costs are only about $\$ 3 /$ barrel.

The cost of producing oil from oil shale is also highly uncertain, however, it will clearly be much higher than the cost of producing oil sands. It has been estimated that profitable production of shale oil from the Naval Oil Shale Reserve in Colorado would require prices for conventional oil in excess of $\$ 100$ per barrel. In 1978, one estimate asserted that producing 15 million barrels per day of shale oil from western U.S. resources could be profitable when world oil prices exceeded $\$ 15$ per barrel in 1975 dollars (Ericsson and Morgan, 1978); inflated to current dollars this would be something in excess of $\$ 40$ per barrel. In its assessment, the U.S. Office of Technology Assessment (OTA) calculated a breakeven price of $\$ 48$ per barrel (presumably 1980 dollars), which would be approximately $\$ 90$ per barrel in current dollars. ${ }^{19}$ The cost of shale oil production is also likely to vary with the overall cost of energy.

${ }^{19}$ The implicit price deflator of US Gross Domestic Product, 1996 chained dollars, fourth quarter, was used to inflate past dollars to 2002 dollars. 
For the reasons explained above, depletion cost curves are calibrated differently for conventional oil and unconventional oil. For conventional oil, it is assumed that all regions except the Middle East (MEA) act as competitive producers in the world oil market. This implies that each region would expand production until the marginal cost of producing oil is equal to the market price. The market price, however, has fluctuated considerably over recent history. The state of depletion of a region will therefore depend on past, as well as current prices. The remaining resources of a region, $X_{R}$, equal the total resources, $\mathrm{X}$, minus the sum of each year's production, $\mathrm{Q}_{\mathrm{s}}$, to date. Assuming a linear lagged adjustment model for supply, each year's production depends on the price in that year, $\mathrm{p}_{\mathrm{s}}$, and the previous year's production.

$$
X_{R}=X-\sum_{s=0}^{t} Q_{s}\left(p_{s}\right)=X-\sum_{s=0}^{t}\left(a+b p_{s}+c Q_{s-1}\right)
$$

Equation 19

Repeatedly substituting for lagged supply $\left(\mathrm{Q}_{\mathrm{s}-1}, \mathrm{Q}_{\mathrm{s}-2}, \mathrm{Q}_{\mathrm{s}-3}, \ldots \mathrm{Q}_{0}\right)$ in equation 15 leads to an expression for $\mathrm{X}_{\mathrm{R}}$ in terms of lagged prices.

$$
X_{R}=X-a t-b\left[p_{t}+(1+c) p_{t-1}+\left(1+c+c^{2}\right) p_{t-2}+\ldots+p_{0} \sum_{s=0}^{t} c^{s}\right]
$$

Equation 20

Equation 17 shows that the measure of price that determines the current level of depletion is a weighted sum of past prices, where the weights are polynomials in the lagged adjustment parameter. Rather than diminishing as one goes back in time, these weights increase, but not without limit since $0<\mathrm{c}<1$. If one uses this formulation, together with a lagged adjustment parameter of 0.9 to calculate a weighted average price back to 1970 , an average price of approximately $\mathrm{p}^{*}=\$ 25$ per barrel is obtained (year 2000 chained dollars). Extending the calculation further back in time would reduce the price. For calibration purposes, it is assumed that each region's (except MEA) current state of depletion corresponds to a long-run price of $\$ 20$ per barrel. Given the state of depletion and the corresponding price, only the price slope is needed to complete the calibration of each region's depletion cost curve. Assuming a price slope of $\beta=-0.15$ for all regions, regional intercepts $(\alpha)$ can be calculated using equation 18. The same slope value is used for all regions due to the absence of information about this parameter. The value of -0.15 can also be inferred from data presented in Rogner (1997). Even with the same depletion curve price slope, regions will have very different price-quantity relationships because of the very large differences in the states of depletion of regional resource endowments (Table A6). 


$$
\alpha_{r}=\ln \left(\frac{1}{\phi_{r}}-1\right)-\beta p^{*}
$$

Equation 21

The MEA region's intercept was assumed to be 2.0 which, combined with a resource depletion level of $16 \%$ in 2000, implies a year 2000 production cost of about $\$ 2.33$ per barrel. This is generally consistent with Persian Gulf region production cost estimates found in U.S. DOE/EIA (1996).

The parameter $\alpha$ is an indicator of the quality (ease of discovery and development) of resources in a region, while $\beta$ describes the sensitivity of price to the state of depletion. By substituting $\phi=0.5$ (50\% depletion) in equation 2, the equation simplifies to $P=-\alpha / \beta$. Thus, the price at the midpoint of depletion is the negative of the ratio of the two parameters. By differentiating price with respect to $\phi$, an expression relating the change in price to a change in percent depletion can be derived.

$$
\frac{d P}{d \phi}=\frac{d}{d \phi}\left(\ln \left[\frac{1}{\phi_{r t}}-1\right]-\alpha_{r}\right) / \beta=\left(\frac{1}{\beta}\right) \frac{1}{\left(\frac{1}{\phi}-1\right)}\left(\frac{-1}{\phi^{2}}\right)=\frac{-1}{\beta \phi(1-\phi)}
$$

Equation 22

\begin{tabular}{|c|c|c|c|c|c|c|c|}
\hline & $\begin{array}{c}\text { Slope } \\
\text { Parameter } \\
\text { Beta } \\
-\mathbf{0 . 1 5}\end{array}$ & \multicolumn{2}{|c|}{$\begin{array}{l}\text { Price Increase per } \\
10 \% \\
\text { Depletion at } 50 \% \\
\text { Depleted }=\mathbf{\$ 2 . 6 7}\end{array}$} & & & & \\
\hline Region & $\begin{array}{c}2000 \\
\text { Production } \\
\text { (Gtoe) }\end{array}$ & $\begin{array}{c}2000 \\
\text { Reserves } \\
\text { (Gtoe) }\end{array}$ & $\mathrm{R} / \mathrm{P}$ & $\begin{array}{c}\text { In } 2000 \\
\% \text { Depleted }\end{array}$ & $\begin{array}{l}\text { Intercept } \\
\text { Parameter } \\
\text { Alpha } \\
\end{array}$ & $\begin{array}{l}\text { Regional } \\
\text { Midpoint } \\
\text { Price } \\
\end{array}$ & $\begin{array}{c}\text { Price at \% } \\
\text { Depleted } \\
\text { In } 2000 \\
\end{array}$ \\
\hline USA & 0.41 & 4.5 & 11.0 & $56 \%$ & 2.76 & $\$ 18$ & \\
\hline Canada & 0.09 & 1.2 & 12.9 & $43 \%$ & 3.26 & $\$ 22$ & $\$ 20$ \\
\hline WEU & 0.35 & 5.2 & 15.0 & $17 \%$ & 4.60 & $\$ 31$ & $\$ 20$ \\
\hline PAO & 0.04 & 0.7 & 19.8 & $19 \%$ & 4.48 & $\$ 30$ & $\$ 20$ \\
\hline FSU & 0.43 & 26.7 & 61.8 & $18 \%$ & 4.49 & $\$ 30$ & $\$ 20$ \\
\hline EEU & 0.01 & 0.4 & 40.0 & $46 \%$ & 3.16 & $\$ 21$ & $\$ 20$ \\
\hline LAM & 0.57 & 12.0 & 20.9 & $22 \%$ & 4.27 & $\$ 28$ & $\$ 20$ \\
\hline MEA & 1.37 & 83.1 & 60.7 & $17 \%$ & 2.00 & $\$ 3$ & $\$ 2.90$ \\
\hline AFR & 0.24 & 4.5 & 19.0 & $15 \%$ & 4.73 & $\$ 32$ & $\$ 20$ \\
\hline CPA & 0.17 & 3.4 & 19.9 & $34 \%$ & 3.68 & $\$ 25$ & $\$ 20$ \\
\hline PAS & 0.18 & 2.8 & 15.7 & $32 \%$ & 3.76 & $\$ 25$ & $\$ 20$ \\
\hline SAS & 0.05 & 1.2 & 21.7 & $24 \%$ & 4.17 & $\$ 28$ & $\$ 20$ \\
\hline
\end{tabular}

Table A6. Long-Run Depletion Cost Curve Parameters for Conventional Oil 
This expression shows that the slope of the depletion-price curve depends on the state of depletion, and that it will be at a minimum when $\phi=0.5$. These two equations provide an expression for the median price and the slope at the median price. Note that the slope at the median price depends on $\beta$ alone. If $\beta=-0.15$, then the slope at $\phi=0.5$ is 26.67 . This implies that a unit change in $\phi$ would produce a price change of $\$ 26.67$ per barrel. Since $0<\phi<1$, a change in $\phi$ of 1.0 corresponds to using up all of the region's resources. In the vicinity of 0.5 , a change in $\phi$ of 0.01 , would change price by about $\$ 0.27$, or a change of 0.1 (a 10 percent increase in depletion) would increase price by about $\$ 2.67$ per barrel. Since the depletion price curve is nearly linear over a wide range near $\phi=0.5$, the slope given by equation 3 is a useful indicator of the price sensitivity implied by any particular choice of $\beta$.

Finally, advances in the technology of discovery and extraction will cause production costs for both conventional and unconventional oil, at all levels of depletion, to decline over time. Technological change parameters, $-1<\theta_{\mathrm{i}}<0$, $\mathrm{i}=$ conventional, oil sands/bitumen, shale oil) can be specified in terms of a fractional change in costs per year. The parameters are applied to the cost curve intercept term, $\alpha$, to shift the curve downward over time according to the equation 22.

$$
\alpha_{i t}=\left(1+\theta_{i}\right) \alpha_{i t-1}
$$

Equation 23

Depletion price curves for unconventional oil are not calibrated to oil market prices because most of the world's unconventional resources have not yet been developed. Using the data on oil sands, heavy oil and oil shale resources shown in Figure 2 in the main body of the report, the twelve regions were divided into two sets: (1) oil sands/heavy oil dominant, and (2) oil shale dominant. Each region was then assigned one of the two curves shown in Figure A6. The curves parameters are: (1) heavy oil/oil sands, $\alpha=7.66, \beta=-0.15$, and (2) shale oil, $\alpha=14.41, \beta=-0.15$. To be sure, assigning all oil sands and heavy oil regions the same depletion cost curve, and all oil shale regions another is a great simplification of reality. Nonetheless, the available evidence indicates that the cost of producing oil from oil sands or heavy oil is far less than the cost of producing synthetic crude from oil shale. The dichotomous division of regions is intended to reflect this important difference while overlooking hopefully smaller differences among regions within a resource type. 
Figure A6.

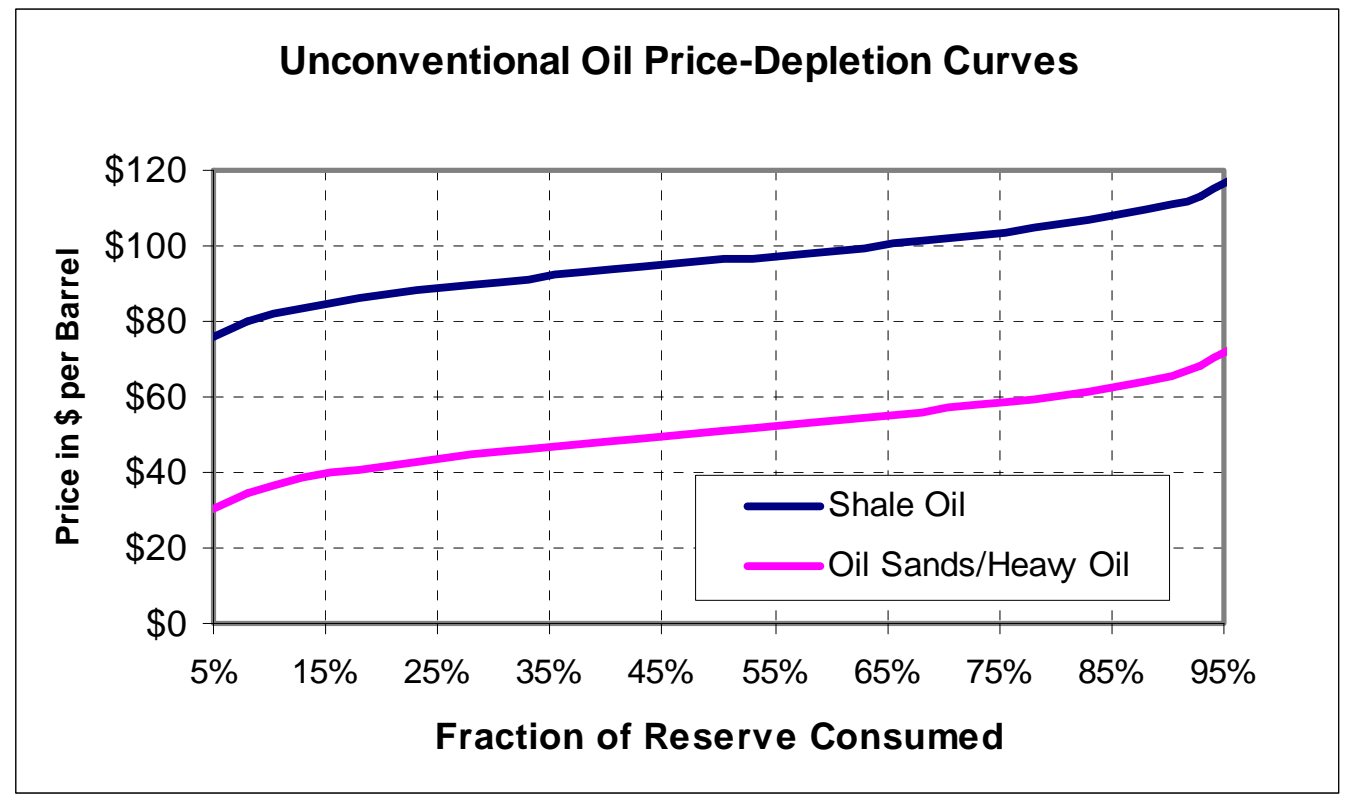

\section{A4. OIL MARKET MODULE}

\section{Simulating a Transition to Unconventional Oil}

The Oil Market Module simulates a market equilibrium transition to unconventional oil. It is a highly simplified representation of the world oil market. In it, regional oil supply and demand equations are calibrated to fit the primary energy oil use and oil production of a Scenario produced by the first pass through the Resource Accounting Module and the depletion costs associated with that scenario produced by the previous year's second pass through the Resource Accounting Module. Supply curves are calibrated for both conventional and unconventional oil, by region. There are twenty-three supply curves and twelve demand curves for each year. These curves form a recursive system of simultaneous linear equations that can be solved in the Excel ${ }^{\circledR}$ workbooks in closed form. Production of conventional oil by MEA is exogenous, reflecting the assumption that OPEC producers are not price takers, but select output levels in order to influence market prices. While MEA conventional oil supply is given, MEA unconventional supply is modeled according to the same methods used for all other regions.

The scenario oil production for each region is first sent to the Resource Accounting model to determine whether the region has sufficient conventional oil reserves to produce the amount of oil required. If so, all of the production required from the region by the scenario is assigned to the region's conventional oil production and sent to the Oil Market model for calibration. If not, then the maximum amount possible is assigned to the region's conventional oil production, and the remainder is assigned to a world pool to be allocated to unconventional oil production. The sum of unconventional oil requirements across all regions is then distributed to the regions according to their share of unconventional oil reserves. This is not the final determination of how much 
unconventional oil will be produced, however, since unconventional oil must compete with conventional oil supply from other regions in the equilibrium solved for in the Oil Market Model.

All supply and demand equations are assumed to have the linear lagged adjustment form.

$$
\text { Supply: } Q_{r t}=A_{r t}+B_{r t} P_{t}+\Lambda Q_{r t-1}
$$

Equation 24

Demand : $q_{r t}=a_{r t}+b_{r t} P_{t}+\lambda Q_{r t-1}$

Equation 25

The lagged adjustment coefficients, $\Lambda$ and $\lambda$, control the rates at which markets respond to changes in prices and quantities.

The calibration of supply and demand equations begins with the assumption that the initial estimate of production (from the first pass through the Resource Accounting Model), together with the long-run cost predicted by the region's depletion-price curve at its current depletion status, is a point on its supply curve. Given a point on the linear supply curve, two additional pieces of information must be supplied to calibrate a linear, lagged adjustment supply function: (1) the price elasticity of oil supply, and (2) the rate of adjustment of supply to price changes. These must be supplied by the model user in the Output workbook. In the current version of WESM, elasticities may be different for North America and the ROW. Both the lagged adjustment coefficients and the elasticities are assumed to remain constant over time.

Given the assumed elasticities and lagged adjustment rates, the coefficients of linear supply equations are calculated to precisely fit the first pass estimates of conventional and unconventional supply, by region. Regional price slopes $\left(\mathrm{B}_{\mathrm{rt}}\right.$ and $\left.\mathrm{b}_{\mathrm{rt}}\right)$ are calculated using the assumed price elasticity of oil supply, $\left(\beta_{\mathrm{r}}\right)$ regional production as specified by the scenario after a first pass through the resource accounting model $\left(\mathrm{Q}_{\mathrm{rt}}\right)$, and the regional depletion price $\left(\mathrm{P}_{\mathrm{rt}}\right)$.

$$
B_{r t}=\beta_{r} \frac{Q_{r t}}{P_{r t}}
$$

Equation 26

Given price slopes for the supply equations, intercepts can be calculated using the relevant prices and quantities.

$$
A_{r t}=Q_{r t}-B_{r t} P_{r t}-\Lambda Q_{r t-1}
$$


Conventional and unconventional supply curves are calibrated in the same way (subscripts have been omitted for convenience).

Regional demand curves are similarly calibrated using the scenario's primary energy demand for oil, assumed price elasticities and lagged adjustment rates, and a world oil price calculated using the regional supply curves for conventional and unconventional oil. Because the world oil market is well integrated, it would not be appropriate to use regional prices to calibrate regional demand curves.

A single world oil price is calculated for each year through 2050, as follows. Given the total world petroleum demand for each year, as specified by the scenario, find the single world oil price, $\mathrm{P}_{\mathrm{t}}$, that causes the sum of the just-calibrated regional supply curves to supply exactly the quantity of oil demanded.

$q_{t}=\sum_{r=1}^{R} q_{r t}=\sum_{r=1}^{R}\left(Q_{c r t}+Q_{u r t}\right)=Q_{c M E A t}+Q_{u M E A t}+\sum_{r=1}^{R}\left[\left(A_{c r t}+B_{c r t} P_{t}+\Lambda_{c} Q_{c r t-1}\right)+\left(A_{u r t}+B_{u r t} P_{t}+\Lambda_{u} Q_{u r t-1}\right)\right]$

Equation 28

Equation 28 can be readily solved to find the world oil price at which the total supply of conventional and unconventional oil equals total world demand.

$$
P_{t}=\frac{q_{t}-Q_{c M E A t}-Q_{u M E A t}-\sum_{r=1}^{R}\left[\left(A_{c r t}+\Lambda_{c} Q_{c r t-1}\right)+\left(A_{u r t t}+\Lambda_{u} Q_{u r t-1}\right)\right]}{\sum_{r=1}^{R}\left[B_{c r t}+B_{u r t}\right]}
$$

Equation 29

Using this world oil price, demand equations are then be calibrated. Price coefficients depend on the assumed price elasticities $\left(\eta_{r}\right)$, the quantity demanded in the scenario $\left(\mathrm{q}_{\mathrm{rt}}\right)$, and the just calculated world oil price $\left(\mathrm{P}_{\mathrm{t}}\right)$.

$$
b_{r t}=\eta_{r} \frac{q_{r t}}{P_{t}}
$$

Equation 30

Intercepts can then be computed using the assumed lagged adjustment rates.

$$
a_{r t}=q_{r t}-b_{r t} P_{t}-\lambda q_{r t-1}
$$

Equation 31

These calibrated coefficients specify individual oil supply and demand equations for each region and year, given the regional elasticities and lagged adjustment rates specified. No 
supply coefficients are estimated for the Middle East North Africa region, since its supply decisions are assumed to be exogenous.

A new oil market equilibrium is found by simultaneously solving the system of world oil supply-demand equations. Because all supply and demand equations are linear, and dependent variables depend only on current price and lagged dependent variables, the system of supply and demand equations can be solved for all years recursively, in closed form. This produces a single world price for each year that equates the sum of oil supplies across regions to the sum of demands.

$$
\sum_{r \neq O P E C}\left[A_{r t}+B_{r t} P_{t}+\Lambda Q_{r t-1}\right]+Q_{O P E C}=\sum_{r=1}^{11}\left[a_{r t}+b_{r t} P_{t}+\lambda q_{r t-1}\right]
$$

Equation 32

The resulting forecast of supplies, of conventional and unconventional oil, by region, is sent to the Resource Accounting model where final resource depletion calculations are made.

\section{A5. NORTH AMERICAN /CONVERSION MODULE}

The North American/Conversion Module accepts Champagne Model Outputs for Canada and the United States and summarizes and reformats the outputs for use in the Energy Conversion/Cost Module. A Base Case and up to six alternative cases can be accepted at one time. This module is contained within the same spreadsheet as the Conversion/Cost Module, entitled ConversionCost.xls.

\section{A5.1 RECONCILING WORLD ENERGY SCENARIO TO CHAMPAGNE MODEL RESULTS}

The Champagne Models for Canada and the United States cover transportation energy use only. While this will represent the majority of petroleum use in North America, it will not represent the entire amount of any final energy carrier. On the other hand, the World Energy Scenarios do not break out final energy use by transportation, or any other sector. This means that is it not possible to simply replace IIASA/WEC transportation energy estimates with Champagne results, nor to factor them up or down by multiplying by fuel-specific factors. A different approach based on the relationship of the two forecasts has been adopted.

The logic of the reconciliation approach is based on which projection of final energy use is greater in 2000 and in 2050. Normally, one would expect the IIASA/WEC estimate of any particular type of final energy carrier to exceed that of the Champagne Model, since the Champagne Model covers the transportation sector only. If the Champagne model forecast for a particular final energy carrier in 2000 exceeds the IIASA/WEC forecast, then the two are in conflict. The same applies for the year 2050. The logic of the 
reconciliation approach is to adopt the Champagne Model forecast when it exceeds the WES forecast for a final energy carrier. When the IIASA/WEC forecast is greater, it is assumed that the difference will remain constant for all Champagne Model Cases.

The reconciliation process calculates a matrix of deltas, or differences between a modified scenario and a Base Case Champagne Model run. The deltas are then added to alternative Champagne Cases to produce a complete picture of energy use by the North American economy. A key feature of this method is that the differences in energy use between Champagne Cases are preserved in the final WESM Model Scenario-Cases. The detailed logic follows.

Let $\mathrm{E}_{\mathrm{N}, \mathrm{f}, \mathrm{t}}$ represent WES North American use of final energy carrier $\mathrm{f}$, in year $\mathrm{t}$. Let $\mathrm{e}_{\mathrm{N}, \mathrm{f}, \mathrm{t}}$ represent the Champagne Model's estimate of transportation energy use.

1. If $\mathrm{E}_{\mathrm{N}, \mathrm{f}, 2000}>\mathrm{e}_{\mathrm{N}, \mathrm{f}, 2000}$, then,

a. If $\mathrm{E}_{\mathrm{N}, \mathrm{f}, 2050} \leq \mathrm{e}_{\mathrm{N}, \mathrm{f}, 2050}$, let the initial difference $\Delta_{\mathrm{f}, 2000}$ decrease linearly to zero by 2050. In effect, it is assumed that the other sectors' use of oil is decreasing from $\triangle_{\mathrm{f}, 2000}$ to zero by 2050 .

b. If $\mathrm{E}_{\mathrm{N}, \mathrm{f}, 2050}>\mathrm{e}_{\mathrm{N}, \mathrm{f}, 2050}$, (the WES forecast is always greater) let $\Delta_{\mathrm{f}, \mathrm{t}}=\mathrm{E}_{\mathrm{N}, \mathrm{f}, \mathrm{t}}$ $\mathrm{e}_{\mathrm{N}, \mathrm{f}, \mathrm{t}}$.

2. If $\mathrm{E}_{\mathrm{N}, \mathrm{f}, 2000}=\mathrm{e}_{\mathrm{N}, \mathrm{f}, 2000}$, then,

a. If $\mathrm{E}_{\mathrm{N}, \mathrm{f}, 2050} \leq \mathrm{e}_{\mathrm{N}, \mathrm{f}, 2050}$, then use $\mathrm{e}_{\mathrm{N}, \mathrm{f}, \mathrm{t}}$ for all $\mathrm{t}$.

b. If $\mathrm{E}_{\mathrm{N}, \mathrm{f}, 2050}>\mathrm{e}_{\mathrm{N}, \mathrm{f}, 2050}$, then calculate $\Delta_{\mathrm{f}, \mathrm{t}}=\mathrm{E}_{\mathrm{N}, \mathrm{f}, \mathrm{t}}-\mathrm{e}_{\mathrm{N}, \mathrm{f}, \mathrm{t}}$.

3. If $\mathrm{E}_{\mathrm{N}, \mathrm{f}, 2000}<\mathrm{e}_{\mathrm{N}, \mathrm{f}, 2000}$, then,

a. If $\mathrm{E}_{\mathrm{N}, \mathrm{f}, 2050} \leq \mathrm{e}_{\mathrm{N}, \mathrm{f}, 2050}$, then use $\mathrm{e}_{\mathrm{N}, \mathrm{f}, \mathrm{t}}$ for all $\mathrm{t}$.

b. If $\mathrm{E}_{\mathrm{N}, \mathrm{f}, 2050}>\mathrm{e}_{\mathrm{N}, \mathrm{f}, 2050}$, then calculate $\in_{\mathrm{N}, \mathrm{f}, \mathrm{t}}=\left(\mathrm{e}_{\mathrm{N}, \mathrm{f}, 2000} / \mathrm{E}_{\mathrm{N}, \mathrm{f}, 2000}\right) \mathrm{E}_{\mathrm{N}, \mathrm{f}, \mathrm{t}}$, and let $\Delta_{\mathrm{f}, \mathrm{t}}=\epsilon_{\mathrm{N}, \mathrm{f}, \mathrm{t}}-\mathrm{e}_{\mathrm{N}, \mathrm{f}, \mathrm{t}}$.

\section{A5.2 INTERNATIONAL ENERGY OUTLOOK - WESM CALIBRATION}

There are three basic steps in the calibration of the IIASA/WEC data to an International Energy Outlook projection:

1. Matching regions and fuel types

2. Inferring Final Energy and Production data from the Primary Energy data

3. Splining the IEO forecasts to the IIASA data.

\section{A5.2.1 Matching Regions and Energy Types}

To establish a correspondence between the IEO data and the IIASA/WEC data it is necessary to adjust the regions and fuel types of the IEO data to match the regions and fuel types of the IIASA/WEC data.

Since, the IEO does not provide country level data for all regions, it is not always possible to precisely reallocate countries into IIASA/WEC regions. For example, IEO combines all countries of developing Asia into a single region whereas this region is subdivided into Centrally Planned Asia, South Asia and Other Pacific Asia in the 
IIASA/WEC data. Using IIASA/WEC's shares of for these regions we subdivided the IEO data into separate forecasts for Centrally Planned Asia, South Asia and Other Pacific Asia.

Hydroelectric energy and renewable energy are combined in a single consumption table in the IEO data. The IIASA/WEC data provides separate forecasts of primary energy for hydroelectric energy, commercial biomass, non-commercial biomass, solar and other energy. Using IIASA/WEC's shares of different energy types we subdivided the IEO data into separate forecasts for hydroelectric energy, commercial biomass, noncommercial biomass, solar and other. All of the other IEO energy consumption tables match the categories used in the IIASA data.

\section{A5.2.2 Inferring Final Energy and Production data from Primary Energy}

The IEO projections do not provide estimates of final energy use. IEO Final Energy use is estimated as follows:

1. For oil, natural gas, coal, biomass, and solar, the IEO Final Energy is estimated from the IEO Primary Energy (i.e., EIA's consumption tables) using the IIASA/WEC ratio of Final to Primary Energy by energy type and region.

2. Electricity Final Energy is from EIA's Table A-9 World Net Electricity Consumption.

3. For Methanol, Hydrogen and Distributed Heat the IIASA-WEC estimates for Final Energy are used.

The IEO provides production estimates for oil for the reference case only. The oil production for the high and low growth cases were estimated using the reference case production and the high and low growth oil consumption tables.

Coal and natural gas production were estimated using the IEO consumption data and IIASA/WEC's production shares. Production for all other fuel types (nuclear, hydroelectric energy, commercial biomass, non-commercial biomass, solar and other energy) is assumed to be equal to consumption.

\section{A5.2.3 Splined Forecasts}

The IIASA/WEC data available for public download include the years 2000, 2010, 2020, 2030 and 2050 only. Intervening years must be interpolated. The International Energy Outlook forecasts are for five-year intervals from 2000 to 2020. Beyond 2020, the data from a modified IIASA/WEC Scenario are used. This can result in a discontinuity between 2020 and 2030. Splining is used to make a smooth transition from the IEO to IIASA/WEC scenarios. The splining method used recognizes that the IEO forecast may have a different trend from the IIASA/WEC forecast. The spline should therefore attempt to reconcile, (1) continuing the IEO trend, and (2) moving toward the IIASA/WEC forecast. 
An IEO trend estimate for 2030 is created by linear extrapolation of the IEO 2010 to 2020 trend. A weighted average of this trend forecast and the 2030 IIASA/WEC forecast becomes the splined forecast. The energy for 2030 is calculated as follows:

$$
\operatorname{Energy}_{\mathrm{Y} 2030}=\operatorname{alpha}\left(\left(\mathrm{IEO}_{\mathrm{Y} 2020}-\mathrm{IEO}_{\mathrm{Y} 2010}\right)+\mathrm{IEO}_{\mathrm{Y} 2020}\right)+(1-\mathrm{alpha}) * \mathrm{IIASA}_{\mathrm{Y} 2030}
$$

Alpha is a weighting factor between 0 and 1.

For 2050 there is no reasonable basis for projecting the IEO forecast. Instead, the splined forecast is a weighted average of the IIASA/WEC 2050 Scenario and a linear extrapolation from the 2030 splined forecast, based on the 2030 to 2050 trend of the IIASA/WEC Scenario. The formula for the 2050 splined forecast is as follows:

$$
\text { Energy }_{\mathrm{Y} 2050}=\operatorname{alpha}\left(\left(\operatorname{IIASA}_{\mathrm{Y} 2050}-\operatorname{IIASA}_{\mathrm{Y} 2030}\right)+\text { Energy }_{\mathrm{Y} 2030}\right)+(1-\text { alpha }) * \operatorname{IIASA}_{\mathrm{Y} 2050}
$$

The default value for alpha is 0.7 , but it can be set to any value the model user chooses.

\section{A6. PROCEDURE FOR EXECUTING A MODEL RUN}

All of the WESM spreadsheet files should be copied to the same directory.

6 workbooks are required:

Scenarios.xls (allows you to select a IIASA-WEC Scenario)

ConversionCost.xls

OilMarketModel.xls

Output.xls

ResourceAccounting.xls

Results.xls (temporary results file)

If a risk analysis simulation is to be carried out, the @RISK software must be run and the worksheets opened from within the @RISK program.

Executing a model run requires ten steps:

1. Open all the workbooks except Results.xls which must remain closed.

2. Scenarios.xls. (Graphs comparing the scenarios are available on the comparisons page.) Set the annual rate of change in energy intensity (values highlighted in yellow). There are two options for calibrating a scenario:

a. Use IIASA-WEC Scenarios calibrated to Y2000 (select any of the scenarios)

b. Use IEO-EIA forecast data to 2020 splined to IIASA-WEC data.

i. Select the IIASA-WEC case

ii. Select the IEO Case (Reference, High Growth, Low Growth)

iii. Select Use IEO forecast

3. The model is run from the "Parameters and Controls" page in the Output Workbook. Select a Champagne Model scenario for Canada and United States or 
select "Do Not Use Champagne". If you are starting a new set of cases you should run the ClearResults macro from the "Parameters and Controls" page to clear the results file of old data. Be sure you have saved the "old results" to a file with a new name.

4. Select the resource data to be used (USGS, 2000; Rogner, 1997; Campbell, 2003).

5. Specify MEA oil production, either by choosing the IIASA-WEC production estimates, entering estimates by hand, or entering a rate of annual increase in MEA production.

6. Edit the parameters in the "Parameters and Controls" area.

7. Once the parameters are set, click on "Run Base Case". This sets the base case in the ConversionCost workbook. Results can be viewed in other spreadsheets in the Output Workbook.

8. Having run the Base Case you can save it by right clicking on the button "Copy Current Case to Results.xls". This places the results in a worksheet labeled Base Case in the Results.xls workbook.

9. You may run up to three additional cases by changing any of the options available in the Parameters Control \& Work Area worksheet (e.g., Champagne Scenario, resource data, MEA production and other parameters). Once you have defined a new case, run it by right-clicking on the button "Run Case n" and then save it by clicking on "Copy Current Case to Results.xls."

10. Once you have finished with a group of related cases you can save them either by manually saving Results.xls or by clicking on the button "Save Results.xls as...", which will prompt you for a new name for the Results file.

11. If you want to start a new set of runs click on "Clear Results" to clear the old data. (Be sure you've saved the old results first!)

\section{A6.1 SELECTING A WEC-IIASA SCENARIO}

The IIASA study, Global Energy Perspectives (Nakićenović et al., 1998) produced six alternative, integrated global energy scenarios for the period 1990 to 2100 . Key drivers for the scenarios were population, economic growth, and the energy intensiveness of economic output. The six scenarios were built around three general paths: Case A: High Growth, Case B: Middle Course and Case C: Ecologically Driven.

The A scenarios foresee a future of ambitiously high economic growth and technological progress, reflecting the belief that there are "no limits" to human ingenuity. Rates of annual growth in purchasing-power-adjusted gross domestic product run at about 2 percent for OECD countries and twice that for the developing economies. By 2100, global average GDP per capita exceeds that of even the richest nations today. Three variations on the A assumptions portray different evolutions of energy supply. Scenario A1 foresees abundant oil and natural gas resources. In contrast, in scenario A2 oil and gas are scarce, resulting in a return to reliance on coal. In A3 progress in renewable and nuclear energy allows the near elimination of fossil energy sources by 2100 .

There is but one B scenario, representing more moderate economic growth and technological progress. Reliance on fossil fuels is greatest in this scenario. However, lacking the technological progress of the A scenarios, dramatic changes in energy sources 
are necessary to cope with the depletion of fossil resources after 2020. Oil and gas are able to maintain a significant share of energy markets through 2070 by tapping increasingly into unconventional oil and gas resources.

The two $\mathrm{C}$ scenarios are optimistic about technology and additionally assume enormous progress in addressing global environmental problems requiring a high degree of international cooperation. Environmental policies play major roles in shaping the future of energy use in the $\mathrm{C}$ scenarios. By 2100 , global carbon emissions are reduced to onethird of the base year level. In scenario C1, nuclear power disappears entirely by 2100 . In $\mathrm{C} 2$, advanced, small-scale, inherently safe nuclear reactors are assumed to play a major role in electricity production.

Tables and graphs illustrating the six scenarios are contained in the Scenario Generator Module. These enable the WESM user to compare the alternatives and to choose one that most closely approximates the scenario desired. Once a WEC-IIASA scenario has been chosen, it can be modified and calibrated.

\section{A6.2 MODIFYING A SCENARIO}

In principle, five types of modifications to scenarios could be made by changing:

1. economic growth rates,

2. population growth rates,

3. rates of energy intensity changes,

4. patterns of energy use by energy source, and

5. calibration to a base year or reference projection.

In WESM, only the rates of change in energy intensity can be modified, and scenarios can be calibrated to year 2000 or to one of three IEO forecasts.

Once a Scenario has been generated, the linked Resource Accounting Module automatically calculates resource depletion and initial long-run oil prices. These are linked to the Oil Market Module that calculates market equilibrium supplies and demands. These return to the Resource Accounting Module that carries out the final resource depletion calculations. All the above calculations are performed automatically by the Excel ${ }^{\circ}$ software.

\section{A6.3 INPUTTING CHAMPAGNE MODEL CASES}

A Base Case and up to three Alternative Cases of Champagne Model runs for Canada and the United States can be stored in the Conversion/Cost Workbook. The transportation total energy use from the Champagne model's Spreadsheet B2-Outputs, Part E. Summary of Energy Use and GHG Emissions, must be pasted into the North American/Conversion worksheets. Each scenario for the United States or Canada is contained in a separate spreadsheet in the Conversion/Cost Workbook. 


\section{A6.4 CALIBRATING A SCENARIO TO CREATE A CASE}

The user must select one of the four possible Champagne Model data sets from the Parameters and Control and Work Area Spreadsheet of the Output Workbook. Customized IIASA/WEC Scenarios are calibrated to the North American Champagne Cases by then selecting the "Run Case" option in the Output Module. The result is a set of Cases that, for North America, force the Scenario primary and final oil use to be consistent with the Champagne model results.

\section{A6.5 GENERATING AN OUTPUT REPORT}

The results of a scenario-case can be saved in the Results Workbook. For the first case of a scenario, the Results Workbook must first be cleared, and then the results saved. Up to three additional cases may also be saved to the Results Workbook. When all the desired cases have been saved, the Results Workbook can be renamed and saved. These actions are executed by means of macros linked to buttons in the Output workbook.

\section{A7. CONCLUSIONS}

The WESM provides the capability to analyze the depletion of conventional oil resources and the transition to unconventional resources under a variety of global energy scenarios and a variety of assumptions about resource availability and utilization. With this version of the model it is possible to analyze how various factors will affect the timing of the peaking of conventional fossil fuel use, and the rate of transition to unconventional petroleum. 


\section{APPENDIX B}

\section{OIL RESOURCE ESTIMATES BASED ON CAMBELL}





\section{APPENDIX B. OIL RESOURCE ESTIMATES BASED ON CAMPBELL}

C.J. Campbell's resource estimates for year end 2002, published in his Newsletter No. 30 - June 2003 were used as control totals and allocated to the twelve regions based on country level data published by Campbell for year end 1999 (The revision date of the 1999 data is 4/29/2000). Campbell (2003) puts ultimate resources of "regular oil" at 1,900 billion barrels. We interpret regular oil to be conventional oil, but to not include certain categories of oil that we have included as conventional oil in this analysis. Campbell's regular oil estimates for year-end 2002 are broken down as follows:

Known oil $=1767$ billion barrels is comprised of:

Past (Cumulative Production $)=896$ billion barrels

Future (Reserves) $=871$ billion barrels

New Fields $=133$ billion barrels

Campbell's 1999 data indicate cumulative production of 822 billion barrels as of year end. The 1767 billion barrels of known oil were allocated to our categories of cumulative production and categories I and II oil as follows:

$($ Reserves $=$ Known Oil $(1767$ Gb $)-$ Cumulative Production $1999(822 \mathrm{~Gb})=$ Reserves 1999 (Category I) $=945 \mathrm{~Gb}$

"Yet to Find" 1999 (Category II) = 133 Gb

This gives the three categories of conventional oil for year-end 1999.

\section{B1. REGULAR OIL RESERVES (CATEGORY I)}

The estimated 945 billion barrels of Category I reserves existing at year end 1999 were allocated to countries based on Campbell's country-specific estimates for 1999.

Reserves for Country " $\mathrm{X}$ " =

(1999 Reserves for Country X / 1999 Total Reserves)*(945 Gb)

These estimates were summed over the countries in each IIASA/WEC region to obtain regional estimates for year-end 1999. 
Table B1.

(billions of barrels)

\begin{tabular}{lr}
\hline & Category I \\
\hline US-48 & 20.78 \\
CANADA & 8.27 \\
WEU & 36.19 \\
PAO & 3.90 \\
FSU & 90.70 \\
EEU & 1.85 \\
LAM & 74.36 \\
MEA & 622.57 \\
AFR & 31.80 \\
CPA & 31.00 \\
PAS & 17.26 \\
SAS & 6.31 \\
World & 945 \\
\hline
\end{tabular}

To produce start-of-year 1995 estimates consistent with Rogner's (1997) data and as required by the Resource Allocation Model, regional production data for 1995 through 1999 were subtracted from the regional cumulative production totals and added to each region's Category I proved reserves.

\section{B2. REGULAR OIL "YET TO FIND/NEW FIELDS" AND NON-REGULAR OIL(CATEGORY II)}

The total "New Fields" of regular oil $(133 \mathrm{~Gb})$ were also allocated to countries using Campbell's 1999 "Yet-to-find" country shares.

"Yet to Find" for Country "X" = (1999 "Yet to Find" for Country X / 1999 Total "Yet to Find")*(133Gb)

The resulting estimates are summarized by IIASA region below: 
Table B2.

(billions of barrels)

\begin{tabular}{lr}
\hline & Category II \\
\hline US-48 & 6.50 \\
CANADA & 1.15 \\
WEU & 2.59 \\
PAO & 0.57 \\
FSU & 42.07 \\
EEU & 0.75 \\
LAM & 17.29 \\
MEA & 53.15 \\
AFR & 3.05 \\
CPA & 2.87 \\
PAS & 2.10 \\
SAS & 0.91 \\
World & 133 \\
\hline
\end{tabular}

\section{B3. “NON-REGULAR" OIL}

Campbell (2003) defines four categories of "non-regular" oil. We classify all but "Heavy" oil as conventional oil and assign it to category II.

Polar 30 billion barrels

Deepwater 60 billion barrels

NGL 400 billion barrels

Heavy, etc 300 billion barrels

We include polar with conventional oil, and allocated the 30 billion barrels as follows

Cumulative Production (end 1999) $=14 \mathrm{~Gb}$

Reserves (end 1999) (Category I) $=6 \mathrm{~Gb}$

Category II (Estimated Additional) $10 \mathrm{~Gb}=$

Total $(30 \mathrm{~Gb})-($ Cumulative Production $(14 \mathrm{~Gb})+$ Reserves $(6 \mathrm{~Gb}))$

All polar oil was assigned to the US (i.e., Alaska).

Campbell (2003) breaks down the deepwater oil estimates by country. The oil was therefore assigned to the country's region. The rest-of-world (ROW) estimate was divided evenly between the following regions: PAO, WEU, FSU, LAM, PAS, CPA, SAS, AFR. 
Table B3.

(billions of barrels)

\begin{tabular}{lcc}
\hline & Current Fields & New Fields \\
\hline Angola & 5.6 & 7.5 \\
Brazil & 8.2 & 4.0 \\
Nigeria & 3.1 & 3.0 \\
U.S. & 5.5 & 5.0 \\
Mexico & & 5.0 \\
ROW & 2.9 & 10 \\
\hline
\end{tabular}

Table B4.

(billions of barrels)

\begin{tabular}{lcc}
\hline Deepwater & Category I & Category II \\
\hline US-48 & 5.50 & 5.00 \\
CANADA & 0.00 & 0.00 \\
WEU & 0.36 & 1.25 \\
PAO & 0.36 & 1.25 \\
FSU & 0.36 & 1.25 \\
EEU & 0.00 & 0.00 \\
LAM & 8.56 & 10.25 \\
MEA & 0.00 & 0.00 \\
AFR & 9.06 & 11.75 \\
CPA & 0.36 & 1.25 \\
PAS & 0.36 & 1.25 \\
SAS & 0.36 & 1.25 \\
World & 25.30 & 34.50 \\
\hline
\end{tabular}

Campbell (2003) reports 400 billion barrels of ultimate resources of natural gas liquids (NGL). From this we subtract his 1999 estimates of cumulative production of NGLs $(50 \mathrm{~Gb})$ and reserves $(160 \mathrm{~Gb})$ to obtain an estimated 190 billion barrels of Category II, estimated additional reserves.

Cumulative Production (end 1999) $=50 \mathrm{~Gb}$

Reserves (end 1999) $=160 \mathrm{~Gb}$

Category II (Estimated Additional) $190 \mathrm{~Gb}=$

Total (400 Gb) - (Cumulative Production (50 Gb) + Reserves (160 Gb))

These NGL estimates were shared to regions using the USGS (2000) resource estimates for lease condensate plus the natural gas plant liquid resource estimates from Masters et al. (1994). 
USGS data:

Table B5. Lease Condensate (USGS World Assessment 2000)

+ NGPL (Masters et al., 1994)

(millions of barrels)

\begin{tabular}{lcc}
\hline & Category I (Reserves) & Category II (Estimated Additional) \\
\hline US & 7823.0 & 7200.0 \\
CANADA & 4317.0 & 7078.3 \\
WEU & 10688.0 & 17811.5 \\
PAO & 3176.0 & 5797.8 \\
FSU & 38032.0 & 73429.6 \\
EEU & 508.0 & 709.4 \\
LAM & 10461.0 & 27241.4 \\
MEA & 64103.0 & 89672.3 \\
AFR & 5132.0 & 13718.4 \\
CPA & 882.0 & 6607.5 \\
PAS & 6109.0 & 7383.6 \\
SAS & 1405.0 & 2918.8 \\
World & 152636.0 & 259568.6 \\
\hline
\end{tabular}

Reserves of NGL for Country "X" =

(USGS Reserves for Country X / USGS Total Reserves)*(160 Gb)

Estimated Additional of NGL for Country "X" =

(USGS Estimated Additional NGL for Country X /USGS Total Estimated Additional NGL)*(190 Gb)

Table B6.

(billions of barrels)

\begin{tabular}{lcc}
\hline $\begin{array}{l}\text { Share Campbell's NGL data } \\
\text { using USGS shares }\end{array}$ & $\begin{array}{c}\text { Reserves } \\
\text { (Category I) }\end{array}$ & $\begin{array}{c}\text { Yet to Find } \\
\text { ( Category II) }\end{array}$ \\
\hline US-48+Polar & 8.20 & 5.27 \\
CANADA & 4.53 & 5.18 \\
WEU & 11.20 & 13.04 \\
PAO & 3.33 & 4.24 \\
FSU & 39.87 & 53.75 \\
EEU & 0.53 & 0.52 \\
LAM & 10.97 & 19.94 \\
MEA & 67.20 & 65.64 \\
AFR & 5.38 & 10.04 \\
CPA & 0.92 & 4.84 \\
PAS & 6.40 & 5.40 \\
SAS & 1.47 & 2.14 \\
World & 160.00 & 190.00 \\
\hline
\end{tabular}




\section{B4. HEAVY OIL (CATEGORIES V \& VI)}

In his 1999 report, Campbell divided ultimate heavy oil resources into three categories. We assigned these to Categories V and VI, as follows.

Cumulative Production (end 1999) $=16 \mathrm{~Gb}$

Unconventional Reserves (end 1999) (Category V) $=44 \mathrm{~Gb}$

Unconventional Resources (Category VI) $-240 \mathrm{~Gb}=$

Total $(300 \mathrm{~Gb})-($ Cumulative Production $(16 \mathrm{~Gb})+$ Reserves $(44 \mathrm{~Gb}))$

Campbell's heavy oil was then shared to regions based on the USGS/WEC/IEA unconventional resource estimates derived in this study.

Table B7. USGS/WEC/IEA Unconventional Oil (billions of barrels)

\begin{tabular}{lrr}
\hline & $\begin{array}{c}\text { Recoverable } \\
\text { reserves }\end{array}$ & Resources \\
\hline Region & \multicolumn{1}{c}{$\mathrm{V}$} & \multicolumn{1}{c}{ VI } \\
US & 0 & 159 \\
CANADA & 28.3 & 18.1 \\
WEU & 0.069 & 6.831 \\
PAO & 0.37 & 36.63 \\
FSU & 0.46 & 45.54 \\
EEU & 0 & 0.1 \\
LAM & 4.870396 & 44.2296 \\
MEA & 0.328 & 32.472 \\
AFR & 0.079 & 7.821 \\
CPA & 0.012 & 1.188 \\
PAS & 0.008 & 0.792 \\
SAS & 0.001 & 0.099 \\
World & 34.4974 & 352.8026 \\
\hline
\end{tabular}

Reserves of Heavy Oil for Country "X" (Category V)= (USGS/WEC/IEA Category V for Country X / USGS/WEC/IEA unconventional Total Reserves)*(44 Gb)

Unconventional Resources for Country "X" = (USGS/WEC/IEA Unconventional Resources for Country X/ USGS/WEC/IEA Total Unconventional Resources $) *(240 \mathrm{~Gb})$ 
Table B8.

(billions of barrels)

\begin{tabular}{lrr}
\hline & Category V & Category VI \\
\hline US & 0.000 & 108.162 \\
CANADA & 36.095 & 12.313 \\
WEU & 0.088 & 4.647 \\
PAO & 0.472 & 24.918 \\
FSU & 0.587 & 30.979 \\
EEU & 0.000 & 0.068 \\
LAM & 6.212 & 30.088 \\
MEA & 0.418 & 22.090 \\
AFR & 0.101 & 5.320 \\
CPA & 0.015 & 0.808 \\
PAS & 0.010 & 0.539 \\
SAS & 0.001 & 0.067 \\
World & 44.000 & 240.000 \\
\hline
\end{tabular}

\section{B5. CONVERSION FACTORS}

The following factors were used to convert from barrels of oil and NGL to Gtoe.

$1 \mathrm{MMBO}$ Oil $=1.36 \mathrm{E}-04 \mathrm{GTOE}$

$1 \mathrm{MMBNGPL}=1.15 \mathrm{E}-04 \mathrm{MTOE}$ 



\title{
APPENDIX C
}

\begin{abstract}
ALLOCATION OF USGS BASED UNCONVENTIONAL RESOURCE ESTIMATES TO CATEGORIES V AND VI
\end{abstract}





\section{APPENDIX C. ALLOCATION OF USGS BASED UNCONVENTIONAL RESOURCE ESTIMATES TO CATEGORIES V AND VI}

The estimates of world resources of oil sands and shale oil presented in Table 3 of the main body of the report were divided into Category V and Category VI as follows. The World Energy Council (2001) Survey of Energy Resources provides estimates of proved unconventional oil reserves for Canada and Venezuela. These were converted to Gtoe to obtain 28.3 Gtoe of Category V reserves for Canada and 4.9 Gtoe for Venezuela (LAM). The remainder of the unconventional resources in these two regions was assigned to Category VI. For all other regions, $1 \%$ of total unconventional resources were assigned to Category $\mathrm{V}$ and the remaining $99 \%$ to Category VI. The resulting estimates are shown in the table below.

Table C1. Oil Sands and Oil Shale Resources Based on IEA, WEC, USGS (Gtoe)

\begin{tabular}{lccc}
\hline \multicolumn{1}{c}{ Region } & $\begin{array}{c}\text { Total } \\
\text { Unconventional }\end{array}$ & $\begin{array}{c}\text { Proven } \\
\text { Reserves } \\
\text { (Category V) }\end{array}$ & $\begin{array}{c}\text { Resources } \\
\text { (Category VI) }\end{array}$ \\
\hline US & 159 & 0.0 & 159.0 \\
CANADA & 46.4 & 28.3 & 18.1 \\
WEU & 6.9 & 0.1 & 6.8 \\
PAO & 37 & 0.4 & 36.6 \\
FSU & 46 & 0.5 & 45.5 \\
EEU & 0 & 0.0 & 0.1 \\
LAM & 49.1 & 4.9 & 44.2 \\
MEA & 32.8 & 0.3 & 32.5 \\
AFR & 7.9 & 0.1 & 7.8 \\
CPA & 1.2 & 0.0 & 1.2 \\
PAS & 0.8 & 0.0 & 0.8 \\
SAS & 0.1 & 0.0 & 0.1 \\
World & 387.2 & 34.5 & 352.7 \\
\hline
\end{tabular}

